
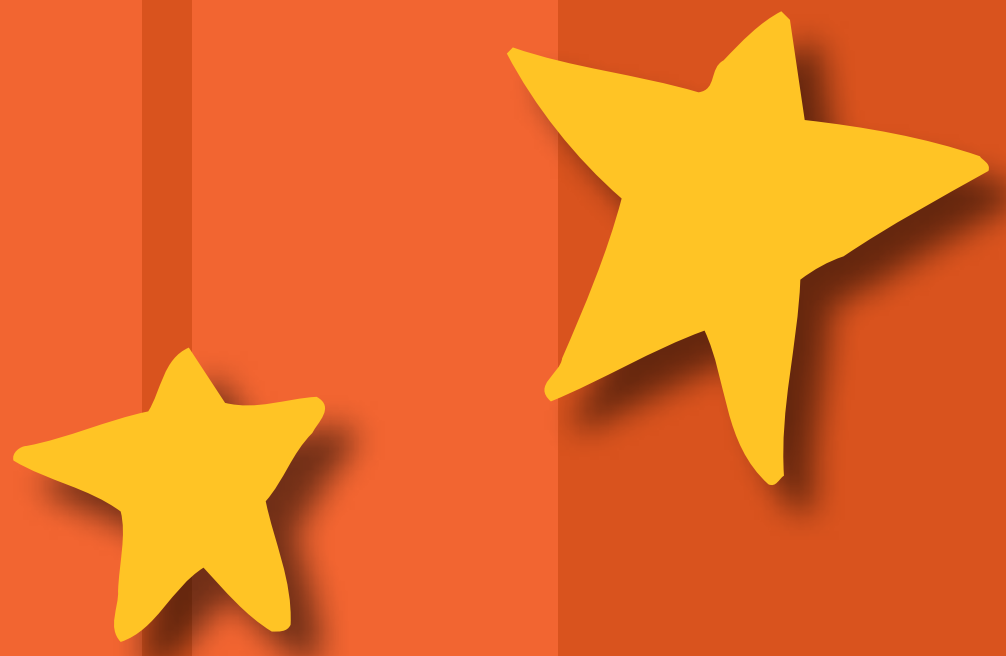

Young People's Homeless and Housing Pathways:

Key findings from a 6-year qualitative longitudinal study

The National Children's Strategy Research Series 



\section{Young People's Homeless and Housing Pathways: Key findings from a 6-year qualitative longitudinal study}




\section{The authors of this report are}

Paula Mayock of the School of Social Work and Social Policy and Children's Research Centre, Trinity College, Dublin, and Mary-Louise Corr of the School of Life, Sport and Social Sciences, Edinburgh Napier University.

Copyright $\odot$ Minister for Children and Youth Affairs, 2013

Department of Children and Youth Affairs

43-49 Mespil Road

Dublin 4

Tel: $+353(0) 16473000$

Fax: +353(0)1667 0826

E-mail: dcyaresearch@dcya.gov.ie

Web: www.dcya.ie

Published by Government Publications, Dublin

ISBN $978-1-4064-2774-5$

The views expressed in this report are those of the authors and not necessarily those of the Department of Children and Youth Affairs.

All rights reserved. No part of this publication may be reproduced, stored in a retrieval system, or transmitted, in any form or by any means, electronic, mechanical, photocopying, recording or otherwise, without the prior permission in writing of the copyright holder.

For rights of translation or reproduction, applications should be made to the Head of Communications, Department of Children and Youth Affairs, 43-49 Mespil Road, Dublin 4, Ireland. 


\section{CONTENTS}

Acknowledgements

Introduction $\quad 1$

1. Understanding and researching youth homelessness 3

Defining and measuring youth homelessness

Legislative and policy framework governing responses to youth homelessness

in Ireland

The extent of homelessness among young people in Dublin $\quad 8$

Background to the current study $\quad 11$

A pathways approach to youth homelessness $\quad 13$

$\begin{array}{ll}\text { Summary } & 13\end{array}$

2. Research methodology 15

\begin{tabular}{ll} 
Study design & 16 \\
\hline
\end{tabular}

Data management and analysis $\quad 19$

$\begin{array}{ll}\text { Ethical considerations } & 19\end{array}$

$\begin{array}{ll}\text { Summary } & 19 \\ & 20\end{array}$

3. Young people's homeless pathways $\quad 21$

The study's young people at Phase 1

The process of becoming homeless $\quad 23$

Phase 2 Pathways: Homeless exits and continued homelessness $\quad 24$

Phase 3 Pathways: Sustained exits and prolonged homelessness $\quad 25$

$\begin{array}{ll}\text { Summary } & 26\end{array}$

4. The process of exiting homelessness $\quad 29$

$\begin{array}{ll}\text { Young people's exiting 'journeys' } & 30\end{array}$

The process of exiting homelessness $\quad 35$

$\begin{array}{ll}\text { The meaning of home } & 41\end{array}$

Summary $\quad 42$

5. The process of remaining homeless 45

From youth to adult homelessness $\quad 46$

The process of remaining homeless $\quad 48$

Acculturation or institutionalisation? $\quad 53$

Summary $\quad 55$

6. Conclusions and key messages $\quad 57$

The importance of speedy exits from homelessness $\quad 58$

The transition from the child welfare system to adult services

Exiting homelessness: An incremental process $\quad 59$

The 'institutional circuit' and the process of remaining homeless 62

Facilitators and barriers to housing stability $\quad 63$

Key messages for policy $\quad 65$

Concluding remarks $\quad 67$

$\begin{array}{ll}\text { References } & 69\end{array}$

Appendix: ETHOS Typology on Homelessness and Housing Exclusion 76 


\section{Acknowledgements}

We want to express very special thanks to the young people who have participated in this study over a 6-year period and to others who were interviewed during earlier phases of the study. We recognise that taking part in this research has been personally demanding and we greatly appreciate the time and effort invested by all of our participants. It has been a great privilege to have had the opportunity to maintain contact with so many young people since the study was initiated in 2004. This research has been an inspiring journey for us as researchers and we owe all of what we have learned to the young people who shared their experiences with us over several years.

The study would not have been possible without the cooperation and commitment of a large number of professionals who helped us to recruit and track young people. We want to extend sincere thanks to staff members in several statutory and non-statutory services who assisted us over the course of the research.

We want to thank the Department of Children and Youth Affairs (DCYA) (formerly the Office of the Minister for Children and Youth Affairs) and the Dublin Region Homeless Executive (DRHE) (formerly the Homeless Agency) for jointly funding this research. Special thanks to Bairbre Meaney, Anne-Marie Books and Michele Clarke at the DCYA and to Dr. Bernie 0'Donoghue-Hynes, Cathal Morgan and Daithí Downey at the DRHE. We also want to thank Dr. Sinéad Hanafin, former Head of Research at the DCYA, for her commitment to this research and for her advice and support over many years.

Finally, we would like to thank our colleagues and friends at the Children's Research Centre and School of Social Work and Social Policy, Trinity College, Dublin, for their support. Special thanks to Sarah Parker, who assisted with the preparation of this report, and to Dr. Eoin O'Sullivan, who has contributed to several publications arising from this research. 


\section{Introduction}

This report documents key findings from a qualitative longitudinal study of homeless young people in Dublin city. The study was initiated in 2004 and has involved three waves of data collection over a 6 -year period.

The first phase of the research was funded by the Office of the Minister for Children (OMC) - now the Department of Children and Youth Affairs (DCYA) - under the National Children's Research Programme. At baseline, biographical interviews were conducted with 40 homeless young people during late 2004 and early 2005. Summary findings of this phase of the research were published in December 2006 by the Office of the Minister for Children (Mayock and Vekić, 2006) and the full findings were subsequently published in a book entitled Lives in Crisis: Homeless Young People in Dublin (Mayock and 0'Sullivan, 2007).

In 2006, the Homeless Agency and Health Service Executive granted funding to embark on a second phase of research that involved tracking and re-interviewing the young people who enlisted in the study at baseline. This work was undertaken during 2005-2006 and the findings were published in 2008 by the Homeless Agency as Young People's Homeless Pathways (Mayock et al, 2008).

A third phase was initiated following a period of approximately 3 years, during 2009-2010, and this wave of data collection was jointly funded by the DCYA and the Homeless Agency - now the Dublin Region Homeless Executive (DRHE).

The following chapters introduce the background and methodological approach to the study and document findings related to the homeless and housing pathways of the study's young people over the 6 -year period of the study. Much attention is given to the 'routes' taken by young people into, through and out of homelessness. It is important to note that this report does not document all aspects of the study's findings and does not claim to present a complete account of the lives and experiences of the study's young people.

The report is structured as follows:

Chapter 1 provides an overview of the background and rationale for the study and outlines its conceptual framework.

Chapter 2 outlines the research methodology, describing the study's recruitment and tracking strategies, as well as the data analysis procedures. The value of qualitative longitudinal research is also discussed.

Chapters 3, 4 and 5 present key findings under the following headings: young people's homeless pathways, the process of exiting homelessness and the process of remaining homeless.

Chapter 6 concludes the report by discussing five issues that are central to understanding the dynamics of the homeless and housing pathways of young people: the importance of speedy exits from homelessness; the transition from the child welfare system to adult services; the incremental process of exiting homelessness; the 'institutional circuit' and the process of remaining homeless; and facilitators and barriers to housing stability. Finally, the chapter outlines several key messages for policy arising from the study's findings.

The report ends with a list of References that informed the research and an Appendix summarises the ETHOS Typology of Homelessness and Housing Exclusion by FEANTSA (European Federation of National Associations Working with the Homeless). 


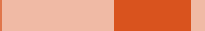




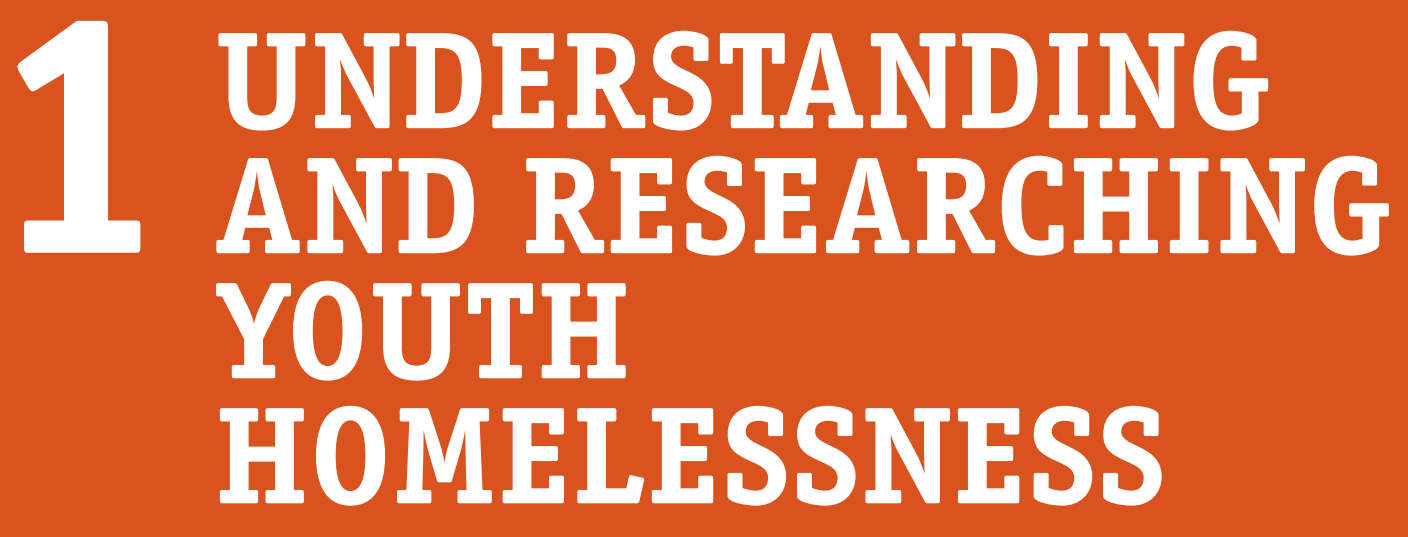


This chapter starts by discussing the challenges of defining and measuring youth homelessness. An overview of the legislative and policy frameworks governing responses to youth homelessness in Ireland is provided and available data on the extent of homelessness among children and young people are presented. The background to this longitudinal study of homeless young people in Dublin is then described, with particular attention to recent developments in the international research literature. The chapter concludes with a discussion of the merits of a pathways approach to youth homelessness - the conceptual driver of the current study.

\section{Defining and measuring youth homelessness}

There is no single, universally accepted definition of homelessness (Jacobs et al, 1999) and researchers have instead employed a spectrum of definitions depending on the scope, nature and purpose of the study (Anderson and Christian, 2003; Third, 2000). As Quilgars et al (2011, p. 13) put it, homelessness is 'a relative term and one that is defined differently in statute as well as in common parlance'. Irrespective of age, those who lack a secure home frequently enter a cycle of moving between temporary or insecure accommodation types, making it difficult to delineate their diverse and changeable living situations. This transience, and the episodic nature of much homelessness, exacerbates the problem of providing a single, all-encompassing definition.

The most obvious definition of homelessness, and one that dominates public perception, is 'street homelessness' or 'rooflessness', terms used to refer to those who are without shelter of any kind. This also constitutes the narrowest definition of homelessness (Fitzpatrick et al, 2000) and includes rough sleepers and others who face the prospect of, or are currently, living on the street. At the other end of the spectrum, and taking a wider view, is a definition that includes all those people who are in 'inadequate accommodation' and those who are 'at risk' of homelessness. In between the two extremities of highly visible and relatively concealed or 'hidden' homelessness are people living in emergency and temporary accommodation, such as night shelters, hostels and refuges, as well as people who have insecure or impermanent tenure (e.g. staying with friends or relatives, squatting).

In recent years, researchers have tended to use definitions of homelessness that are more directly linked to the housing situations of individuals, irrespective of their age. Possibly the most systematic and detailed definition is ETHOS (the European Typology of Homelessness and Housing Exclusion), developed under the auspices of FEANTSA, the European Federation of National Associations Working with the Homeless (Fédération Européenne d'Associations Nationales Travaillant avec les Sans-Abri). ETHOS adopts a conceptual classification or definition of homelessness that includes four distinct housing situations: rooflessness, houselessness, living in insecure accommodation and living in inadequate accommodation (see Appendix). The first two categories (rooflessness and houselessness) are more likely to be described as 'homeless', while the second two (insecure and inadequate accommodation) are more likely to be described as 'housing exclusion'. The idea of a continuum of homelessness, ranging from people at risk of homelessness to people who are temporarily or episodically without shelter, to individuals who are persistently homeless, is strongly reflected in this fourfold typology. As a further elaboration, operational definitions are provided for each of the four housing situations to ensure that each of the categories is mutually exclusive and unambiguous. The use of these operational definitions should, it is argued, enable the measurement of different elements of homelessness in any jurisdiction (Busch-Geertsema, 2010).

While ETHOS provides a strong basis for discussing the range of potential housing difficulties that a young person may face, it has been suggested that it may be useful to develop an ETHOS specifically for young people (Quilgars, 2010). For example, Quilgars et al (2011) point out that ETHOS classifies homeless hostels and transitional supported accommodation under the category 'houseless', although these services tend to offer very different types of accommodation services and supports to young people. 
Definitions of homelessness determine, in large part, those who are counted as homeless and consequently influence estimates of its prevalence. ${ }^{1}$ The problems associated with measuring homelessness have been widely discussed in the literature (Avramov, 2002; Busch-Geertsema, 2010; Edgar, 2009; Edgar et al, 2007). Debates about data collection and measurement are likely to continue due to the complex conceptual, operational and methodological challenges associated with prevalence estimation. Youth, a phase of the life course that marks a period of transition from childhood to adulthood, is also defined variously ${ }^{2}$ and the age range associated with youth homelessness 'has implications for measuring it and what situations may be counted as "homeless" '(Quilgars et al, 2011, p. 13). In the Irish context, available data on the extent of youth homelessness are limited, a situation which arguably exemplifies the many challenges associated with counting those young people who are homeless or at risk of homelessness (see section below on 'Limitations of current information systems on youth homelessness').

\section{Legislative and policy framework governing responses to youth homelessness in Ireland}

A detailed account of the emergence of youth homelessness as a social problem in Ireland is provided elsewhere (Mayock and 0'Sullivan, 2007; 0'Sullivan and Mayock, 2008). In brief, a serious problem of homelessness among young people became apparent from the 1970s, particularly in Dublin, and the following two decades produced mounting evidence of a significant problem of homelessness among the young (Carlson, 1990; Harvey and Menton, 1989; HOPE, 1979; National Youth Policy Committee, 1984; National Campaign for the Homeless, 1985). However, it was only in the early 1990s that youth homelessness became an officially recognised legal construct with the implementation of Section 5 of the Child Care Act 1991. Under the terms of Section 5 of the Act, health boards are statutorily responsible for the provision of suitable accommodation for young people up to the age of 18 who are homeless or in need of care. Section 5 of the Act states:

'Where it appears to a health board that a child in its area is homeless, the board shall enquire into the child's circumstances, and if the board is satisfied that there is no accommodation available to him which he can reasonably occupy, then, unless the child is received into the care of the board under the provisions of this Act, the board shall take such steps as are reasonable to make available suitable accommodation.'

Section 45 of the Child Care Act 1991 empowers former health boards (renamed Health Service Executive (HSE) areas in 2005) to provide aftercare support for children in their care, stating that a health board may assist a person leaving its care up to the age of 21 years or until he or she has completed their education or training. This provision in the legislation has been described as enabling rather than obligatory, thereby providing a weak legislative basis for leaving care provision (Kelleher et al, 2000). Furthermore, in the absence of a mandatory requirement to provide aftercare, the type, nature and quality of aftercare provision are effectively left to the discretion of each HSE area (Doyle et al, 2012, p. 208). The publication in 2012 of Leaving and Aftercare Services: National Policy and Procedure by the HSE signals a strong commitment to 'delivering and implementing a leaving and aftercare service for young people which is responsive and relevant to each young person's circumstance' (HSE, 2012, p. 3) and will go some way towards ensuring standardised aftercare provision and practice nationally. ${ }^{3}$ There is evidence, nation-wide, of a substantial rise in the number of young

\footnotetext{
1 The issue of the quantitative extent of homelessness is a controversial one at local and national levels. According to Busch-Geertsema (2010, p. 28), 'There is a tendency for those responsible for policies and the funding of services to underestimate the extent in order to minimise public responsibilities and to keep the problem they are expected to deal with manageable. On the other hand, pressure groups tend to overestimate the number of homeless people in order to increase their political relevance and the resources made available to them'.

2 The United Nations uses the following definitions: 'adolescents' are individuals between 10-19 years of age, while 'youth' includes those between 15-24 years; 'young people' are defined as including both adolescents and youth (for more in-depth details, see UN General Assembly Resolution 36/215 and 36/28 of 1981). Ireland's Youth Work Act 2001 defines a 'young person' as an individual under the age of 25 years.

3 The Minister for Children and Youth Affairs has also clarified with and issued a Directive to the HSE stating that the Child Care Act 1991 entitles all children approaching the point of leaving care to have an assessment of need carried out.
} 
people accessing aftercare, with an increase of 34\% recorded between 2005 and $2010 . .^{4}$ Noteworthy, however, is that children who are accommodated under Section 5 of the Child Care Act 1991 have no entitlement to statutory aftercare provision since they are not legally in the care of the State.

The statutory provision of services for homeless young people under the age of 18 currently operates within a child welfare framework. Within this framework, the Crisis Intervention Service, commonly referred to as the Out-of-Hours Service (OHS), is the initial point of contact for many young people who experience homelessness. This service was established in Dublin in 1992 following mounting concern about a visible increase in street homelessness among the young (0'Sullivan and Mayock, 2008). It is a social work service rather than a specific accommodation service, but much of its remit relates to 'out-of-home' young people. In order to access a service, a young person must report to a Garda station and declare him or herself as homeless, at which point the Gardaí contact the out-ofhours social work service. A social worker then attends and determines whether it is possible for the young person to return home. In cases where this is not possible, the young person is placed in $\mathrm{OHS}$ emergency (hostel) accommodation. These settings are designed to serve the immediate or short-term needs of 'out-of-home' young people, with the aim of finding a stable placement or living situation for the young person at the earliest possible juncture. Since 1999, children and young people known to the OHS who need emergency accommodation can access a Reception Service at Lefroy House (in Dublin city centre) between $5 \mathrm{pm}$ and $11 \mathrm{pm}$ without first presenting at a Garda station.

The Youth Homelessness Strategy, published by the Department of Health and Children in 2001, provided a framework for tackling youth homelessness on a national level for the first time. The strategy's stated goal was 'to reduce and if possible eliminate youth homelessness through preventative strategies and where a child becomes homeless to ensure that he/she benefits from a comprehensive range of services aimed at re-integrating him/her into his/her community as quickly as possible'.

Homeless young people were defined in the following terms: 'Those who are sleeping on the streets or in other places not intended for night-time accommodation or not providing safe protection from the elements or those whose usual night-time residence is a public or private shelter, emergency lodging, $B \& B$ or such, providing protection from the elements but lacking the other characteristics of a home and/or intended only for a short stay'.

Included in this definition are 'young people who look for accommodation from the Eastern Health Board Out-of-Hours Service' and 'those in insecure accommodation with relatives or friends regarded as inappropriate, that is to say where the young person is placed at risk or where he or she is not in a position to remain'.

The Youth Homelessness Strategy set out 12 specific objectives, placing particular emphasis on the prevention of youth homelessness through the provision of support to schools, communities and families. The importance of tackling the problem of children at risk of homelessness in local areas through locally based services was also highlighted. Where youth homelessness occurs, it stressed the need for prompt, responsive, child-focused services aimed at re-integrating the young person into his or her community as quickly as possible. The strategy recognised the link between leaving care and the risk of homelessness, stating that 'Aftercare is an integral part of the care process, it is not an optional extra' (ibid, p. 27). It also set out an aftercare protocol requiring that each health board, in collaboration with the local authorities and other relevant statutory and non-statutory agencies, devise a comprehensive strategy for effective aftercare as part of its 2-year plan to address youth homelessness.

Given the importance of distinguishing between youth and child homelessness (Quilgars, 2010; Tyler and Johnson, 2006), with the latter usually defined as affecting people under the age of 18 years (FEANTSA, 2007), it is noteworthy that the Youth Homelessness Strategy did not provide a clear definition of 'youth'. In practice, a large number of the objectives and related actions set out in the strategy are concerned with preventing and responding to homelessness among

4 Personal communication, Department of Children and Youth Affairs. 
children and young people under the age of 18 . This contrasts with the situation in the UK, where 'reflecting a raft of legislative and common understandings as to when a young person can potentially live independently from their parents', most commentators engaged in discussions of 'youth homelessness' focus on housing need as affecting those aged between 16 and 24 years (Quilgars et al, 2011, p. 13). More broadly, in terms of any consideration of an upper age limit for 'youth' who experience homelessness or housing instability, there is general consensus that youth transitions are becoming more extended (Arnett, 2004; Bynner et al, 2002; Jones, 2002) . $^{5}$ The bureaucratic distinction that exists in Ireland between young people under and over the age of 18 is not consistent with the notion of extended youth to adulthood transitions. Indeed, the current organisation of homeless services in Ireland - which necessitates an abrupt transfer from child welfare to adult services at the age of 18 - has been argued to perpetuate housing instability among the young and to reduce the likelihood of a speedy exit from homelessness (Mayock et al, 2008; Mayock et al, 2013).

Notwithstanding the conceptual and operational uncertainties arising from the absence of a clear definition of 'youth', the publication of the Youth Homelessness Strategy (Department of Health and Children, 2001) was a significant policy development and signalled a strong commitment to resolving and eliminating the problem of youth homelessness. The strategy acknowledged the vision underlying the National Children's Strategy, 2000-2010 (Department of Health and Children, 2000) and recognised the multidimensional and complex nature of youth homelessness. Homeless young people were explicitly recognised as a heterogeneous group requiring services to 'match individual needs' (Department of Health and Children, 2001, p. 19). The strategy was extremely ambitious in setting out 12 specific objectives unpinned by an emphasis on the prevention of youth homelessness, the need for responsive child-focused services and the importance of coordinated interagency work.

In 2012, the Department of Children and Youth Affairs commissioned a Review of the Implementation of the Youth Homelessness Strategy from the Centre for Effective Services (CES). The purpose of this review by Denyer et al (2013) was:

- to establish the extent to which the strategy has been successful;

- to identify blockages and challenges to the implementation of the strategy;

- to make recommendations for a new implementation framework for the strategy.

The review was based on an examination of key documentation; findings arising from the conduct of semi-structured interviews with stakeholders and service providers; and the administration of an online survey to service providers. Indicators of the demand for youth homelessness services in Dublin and Cork were also examined.

The findings of the review are detailed and include a range of recommendations for action. Overall, the authors conclude that the Youth Homelessness Strategy has made a significant contribution to addressing the problem of youth homelessness. The review notes considerable improvements in accommodation options and services to support children and young people who experience homelessness or who are 'at risk' of homelessness. Investment in child protection and welfare services, fostering, family support, and youth services were deemed to have had a positive impact on the experiences of children and young people who present as homeless. The review concludes that 'The proportion of children needing accommodation and other services solely due to homelessness has diminished substantially since the publication of the strategy in 2001'.

Although the review draws strong attention to several positive developments, it also concludes that an appraisal of the effectiveness of the strategy was 'significantly hampered by a poor definition of youth homelessness in the initial strategy and inadequate information systems for monitoring youth

\footnotetext{
5 Modern-day youth transitions are an important framework within which to understand youth homelessness and young people at greatest risk of homelessness (Quilgars, 2010). There is clearly great diversity in the extended pathways to adulthood that are now well documented in the literature. Nonetheless, some adolescents and young adults are far more vulnerable than others and less well equipped to successfully navigate the journey to adulthood. While all young people face discontinuities and risks, for marginalised youth in particular, the transition to adulthood is even more fractured and complex (MacDonald et al, 2005).
} 
homelessness', both of which also hampered the planning and management of services. It notes deficits in the provision of mental health and disability services for out-of-home children and young people, as well as for specific groups including Travellers, ethnic minorities and LGBT youth. Service responses for young people aged 16-18 years were considered inadequate and in need of attention. Finally, the transition between child and adult services is singled out as a particularly problematic area in need of 'specific attention'. A major conclusion arising from the review is that a new youth homelessness strategy is not currently required, but rather for 'the problem of children being out-of-home or at risk of homelessness to be addressed as part of a wider, integrated and "whole child" response to need'.

Finally, in terms of the broader policy framework governing responses to youth homelessness, it is important to mention the Homeless Preventative Strategy, which was published in early 2002 by the Department of the Environment and Local Government (2002). ${ }^{6}$ The key objective of this strategy was to ensure that 'no one is released or discharged from State care without the appropriate measures in place to ensure that they have a suitable place to live with the necessary supports if needed' (ibid, p. 3). It addressed the prevention of homelessness with specific attention to a number of 'at risk' groups, including adult and young offenders, people leaving mental health residential facilities, people leaving acute hospitals, and young people leaving care. An independent review estimated that just under $30 \%$ of the objectives outlined in this strategy had been fully or significantly progressed (Fitzpatrick and Associates, 2006).

\section{The extent of homelessness among young people in Dublin}

The overview provided here focuses primarily on the identification of salient patterns and trends emerging from existing administrative datasets and homeless counts relevant to children and young people under the age of 18, those aged between 18-25 years and those aged up to 29 years, where relevant. This section will also comment on the limitations of this evidence base.

\section{Homelessness among children and young people under the age of 18}

The following data sources provide information on the number of homeless or 'out-of-home' children and young people under the age of 18 years:

- Child Care Interim Minimum Dataset: From the late 1990s, data were collated by the Department of Health and Children from the regional health boards to provide information on homeless children, as well as the reason for their homelessness. However, information is only available from 1998 to 2004. These figures have been presented in detail elsewhere (Mayock and 0'Sullivan, 2007). In summary, 495 children were identified as homeless ( $43 \%$ of them in the Eastern Regional Health Area) in 2004. This figure was up slightly from the figure of 476 in 2003. A total of 774 children were identified as homeless in 1999 and 588 in 2000, suggesting that, notwithstanding the slight increase in 2004, the trend was towards a decline in the number of children presenting as homeless to the HSE nationally. There were slightly more females (254) than males (241) among the total number recorded as homeless in 2004.

- Referrals to the Crisis Intervention Service: As noted earlier, a dedicated Out-of-Hours Service (OHS) was established in the Dublin region in 1992 and data on the usage of this service provides another source of information on the extent of homelessness among those children and young people under the age of 18 years. The number of referrals to this service rose rapidly during the 1990 s and hit a peak of over 4,500 referrals in 2000. However, the number of referrals had declined to 2,390 by 2006. These referrals include multiple referrals of the same homeless children, which in 2000 translated into just under 1,000 unique individuals presenting to the $\mathrm{OHS}$. By 2006, the number of unique individuals had declined to 363. For the period 2007 to 2010, the data returned were either incomplete or not published and it is therefore not possible to comment on trends during this period.

6 See 0'Sullivan (2008a and 2012) for detailed reviews of recent policy initiatives aimed at preventing and eliminating adult homelessness in Ireland. 
A new monitoring system for youth homelessness was introduced in 2011. This system was designed to collect information on the number of children and young people placed in emergency residential centres. Statistics provided in respect of 2011 (and yet to be published) show that there were 179 referrals to OHS emergency accommodation in that year. During the period January-September 2012, 124 children aged 12-17 were referred to the OHS.

The available data on referrals to the OHS since 2000 are clearly incomplete, making it difficult to draw clear-cut conclusions on patterns and trends. Another significant difficulty with the available data is that the figures do not include young homeless people who do not make contact with services. It nonetheless seems clear, based on the available data, that the number of children and young people entering the OHS has declined significantly over the past decade or more.

- $\quad$ Rough Sleeper Counts: The Dublin Region Homeless Executive (formerly the Homeless Agency) conducts a 'rough sleeper street count' on a bi-annual basis. The counts conducted during 2011 and 2012 indicate that no child or young person under the age of 18 years was recorded as sleeping rough, suggesting that street homelessness among children has declined very significantly and is currently rare.

\section{Homelessness among young people aged 18-29 years}

This section identifies the main trends emerging from available data pertaining to homelessness mainly among young people aged $18-25$ years in the Dublin region, and also among those aged 26-29 years.

- Counted In (2005 and 2008): The Counted In surveys of homelessness, conducted by the Homeless Agency (now the Dublin Region Homeless Executive), provide information on the extent of homelessness among those aged between 18-25 years in the greater Dublin area. These surveys were administered in 2005 and 2008 to every person using homeless services (i.e. emergency accommodation, homeless B\&Bs, domestic violence refuges, long-term supported housing, street outreach teams, food centres), and those accepted as homeless by the relevant local authorities, during the week of the assessments (Homeless Agency, 2005 and 2008). The 2005 figures indicate that 264 young people aged 18-25 were identified as homeless. The total number of young people presenting as homeless in this age cohort increased to 357 in 2008 (15\% of the total homeless population), with young people aged $26-29$ years accounting for a further 277 respondents $(12.4 \%$ of the total homeless population). These two age groups combined (i.e. those aged 18-29 years) represented just over one-quarter $(27.4 \%)$ of all homeless adults surveyed in 2008 . While there were more males $(n=1,598)$ than females $(n=746)$ identified within the total homeless population in 2008 , this gender breakdown varies when disaggregated across the younger age cohorts. For example, there were slightly more young homeless women $(n=185)$ than men $(n=171)$ in the age range 18-25. In 2008, a larger number of 'younger' (under 29 years) compared to 'older' women (over 30 years) were using homeless services.

The 2005 assessment collected data on the type of accommodation utilised by 159 respondents aged 25 years and under. Among this sub-group, the majority of young people were staying in $B \& B s(n=97)$, followed by those sleeping rough $(n=27)$, those staying in hostels $(n=25)$, and those staying with friends and family $(n=8)$. When the findings of the 2005 and 2008 surveys are compared, a decrease is evident in the number of homeless young people aged 25 and under presenting as rough sleepers: from 27 in 2005 to 15 in 2008, accounting for $14.5 \%$ and $4.61 \%$ of the total rough sleeper population, respectively. There was an increase in the number of young people aged 18-25 staying in domestic violence refuges: from 2 in 2005 to 8 in 2008. Other noteworthy findings are that young people aged 18-25 accounted for approximately $22.7 \%(n=50)$ of all households with child dependents in 2005 and that approximately one-quarter of the total homeless population $(n=428,24.7 \%)$ first experienced homelessness between the ages of 18-25 in 2008 . 
- Central Statistics Office (2012): As part of the Census of Population 2011, a comprehensive count of the homeless population in Ireland (i.e. those either sleeping rough or staying in homeless accommodation on the night of the Census) was conducted for the first time (CSO, 2012). Young people aged $15-24$ represented approximately $13.7 \%(n=523)$ of the total homeless population and those aged $25-29$ accounted for a further $9.5 \%(n=363)$. These two age cohorts combined account for almost one-quarter $(n=886,23.2 \%)$ of all respondents surveyed. Slightly more young men $(n=276)$, aged $15-24$, than young women $(n=247)$ were identified as homeless.

- Homelessness and the Housing Needs Assessment Revised Report for Dublin (2012): In accordance with Section 9 of the Housing Act 1988, housing authorities are required to undertake a Housing Needs Assessment (HNA) in their administrative areas on a triennial basis. The HNA 2011 (Housing Agency, 2011) provides a national 'snap shot' of the level of housing need across Ireland based on data from each housing authority in respect of all households approved for social housing at the time of the assessment. Subsequent to the implementation of the Pathway Accommodation Support System (PASS) by the Dublin Region Homeless Executive (DRHE), a client management and support database designed to assess the extent of the known population using funded homeless services, a revised measure of the extent of homelessness in Dublin (using the PASS dataset for September 2011 period) was submitted to the Department of the Environment, Heritage and Local Government. A report published by the DRHE and the Housing and Sustainable Communities Agency (2012) presents revised findings for the HNA 2011 using this approach.

The figures from this 2012 report indicate that 367 young people aged 18-25 were identified as homeless in 2011, accounting for the second largest proportion (19\%) of the total homeless population. Young people aged 26-30 make up a further $17 \%(n=321)$. These two age groups combined account for over one-third $(36 \%)$ of all the homeless adults surveyed. Within the 18-25 age cohort, the proportion of males to females was approximately $60 \%$ $(n=219)$ to $40 \%(n=146)$, while among $26-30$ years-olds, the proportion of males to females was approximately $69 \%(n=221)$ to $31 \%(n=98)$. A further breakdown of age and gender indicates that among the youngest homeless individuals (aged 18-19), young women slightly outnumbered young men.

- Rough sleeper counts: The most recent 'rough sleeper street count' conducted by the DRHE indicates that 29 young people (aged 18-30) were identified as sleeping rough in Dublin in November 2012, representing approximately one-third (33.3\%) of the total rough sleeper population. ${ }^{7}$ This is the first time the number of young people sleeping rough has surpassed 20 since the winter of 2010 count and signals a noteworthy increase from previous counts where the number of young rough sleepers had remained relatively steady throughout 2011 and had, in fact, decreased earlier in 2012.

In summary, the data above suggest that while the level of homelessness among those aged 18-25 years appears to have fluctuated over time, the overall trend points to stability rather than a downward pattern in the number of young people presenting as homeless in recent years. It is important to note that comparisons across the various counts and assessments are precarious at best because of the different methods of enumeration utilised, thus rendering the identification of salient trends and patterns difficult. The picture is clearly incomplete, but based on the available data, the best estimate would suggest that between $15 \%-20 \%$ of the total homeless adult population are in the 18-25 age range. Young people, therefore, account for a significant proportion of the overall population of homeless individuals in the Dublin region.

7 Personal communication, Dublin Region Homeless Executive. See also www.homelessagency.ie 


\section{Limitations of current information systems on youth homelessness}

The absence of reliable data clearly thwarts any attempt to accurately measure the scale of the problem of homelessness among children and young people, and to trace changes over time. It is important to note that the data currently available cover only some aspects of youth homelessness, certainly if ETHOS is accepted as forming a basis from which to enumerate the young homeless (see Appendix). For example, we currently have little or no information on the number of young people living in unfit housing, temporary or non-standard structures, or under the threat of eviction, and practically nothing is known about the number of young people who share accommodation with relatives or friends, a phenomenon commonly referred to as 'hidden' homelessness (BuschGeertsema, 2010). This represents a significant gap in information since a high prevalence rate of 'hidden' homelessness among young people has been confirmed in other jurisdictions (Reeve and Batty, 2011; Quilgars et al, 2008). The phenomenon of 'hidden' homelessness is also relatively well documented in the Irish context (Mayock and 0'Sullivan, 2007; Mayock and Sheridan, 2012).

The problems and limitations associated with current measures of homelessness among children and young people underline the need to develop a more comprehensive youth homelessness information strategy. As in other European countries, targeted research is also needed to improve knowledge and understanding of 'hidden' homelessness among the young.

\section{Background to the current study}

At the time this study was initiated in 2004, there were clear gaps in knowledge and understanding of the phenomenon of youth homelessness. Research undertaken during the previous two decades provided considerable insight into the extent and nature of homelessness among the young and also identified a number of important precursors to young people becoming homeless. These studies highlighted the link between a history of State care and homelessness (Houghton et al, 2001; Kelleher et al, 2000; Perris, 1999) and also demonstrated that young homeless people typically experience disrupted and disadvantaged childhoods, including, in some cases, exposure to domestic violence (Kennedy, 1985). During this period, the measurement of homelessness among children and young people and the identification of risk factors or reasons for their homelessness were the core issues of concern. While the aforementioned studies certainly advanced knowledge of the experiences that push young people out of home prematurely, understanding of the causes of homelessness among the young was far from complete. Moreover, a singular focus on the precursors to young people becoming homeless provided no information or insight into the paths taken by young people subsequent to their first experience of homelessness.

Internationally, explanations for the causes of homelessness have traditionally been divided into two broad categories: structural and individual (Fitzpatrick, 2005; Neale, 1997). Structural explanations locate the reasons for homelessness in social and economic structure and tend to cite poverty, negative labour market forces, cuts and restrictions in welfare payments, and shortfalls in the supply of affordable housing as leading causes of homelessness. Individualistic accounts, on the other hand, focus on the personal characteristics and behaviours of those who are homeless and suggest that homelessness is a consequence of personal problems such as mental ill-health and addiction. The dichotomy apparent in these opposing explanations has been replaced by 'new orthodoxy' (Fitzpatrick et al, 2009) and it is now generally accepted that youth homelessness is a result of a complex interaction between individual characteristics and wider structural factors (Fitzpatrick, 1999 and 2000; Pleace and Quilgars, 1999; Quilgars et al, 2008). A wide range of risk factors for homelessness among the young have been identified, including family disputes and breakdown; a care history; sexual or physical abuse during childhood; exposure to domestic violence; drug or alcohol misuse; mental health problems; debts, particularly rent arrears; offending behaviour and/or experience of prison; and school exclusion (see Mayock and 0'Sullivan (2007) and Quilgars et al (2008) for a summary of research findings). The identification of 'triggers' has also been the focus of research attention, with leaving care or other institutional settings, family 
breakdown and increases in drug or alcohol use featuring as 'crisis points' precipitating first homeless experiences. Although the causal processes related to young people becoming homeless are complex, multifaceted and overlapping, young people from disadvantaged socio-economic backgrounds are disproportionately likely to experience homelessness (Pleace et al, 2008). Perhaps the most obvious manifestation of homeless young people's social exclusion and marginalisation is their inability to access and maintain safe, affordable housing.

In more recent years, research in the UK, Australia and the USA has begun to investigate those factors, mechanisms and experiences that enable young people to exit homelessness, using longitudinal research designs. Longitudinal approaches enable a stronger understanding of the changing relationships and interactions that young people have with homelessness and housing over time (Culhane and Hornburg, 1997; Pickering et al, 2003; 0'Sullivan, 2008b; Robinson, 2003) and of the policies and resources required to enable homeless young people to achieve positive outcomes in adulthood (Robertson and Toro, 1999).

The London-based study by Craig et al (1996) was one of the first to attempt to track a cohort of young homeless people over a specific period. The research initially included a sample of homeless young people as well as a comparative sample of domiciled youth and attempts were made to re-establish contact with both sub-samples following a time lapse of one year. At the time of follow-up, only just over a third of the homeless young people with whom contact was re-established had achieved 'stable' housing (defined as remaining in an independent tenancy, shared accommodation, long-stay hostel or returned to parental home for at least 6 months) or 'fairly stable' housing. Some $28 \%$ had not achieved stable housing and were experiencing continued short stays in various types of accommodation and one-fifth were still sleeping rough and using night shelters. Those young people who had achieved stable housing were more likely to be female, from black/minority ethnic groups, and to have educational qualifications. Those homeless for less than 2 years at first interview were more likely to have achieved stable outcomes than those with longer homelessness histories.

Based on a broader sample of 315 young people, including both homeless youth and those perceived to be 'at risk' of homelessness in the counties of Surrey, Hampshire and the Isle of Wight, Stockley et al (1993) presented a more positive picture of young people's movements based on a follow-up study of 72 of the young people. This research revealed a trend from less adequate to more stable forms of accommodation, concluding that 'some are likely to go through a period of accommodation instability making use of more marginal types of accommodation, before moving into more permanent or more adequate accommodation' (ibid, p. 17).

More recently in the UK, Fitzpatrick's (2000) Glasgow-based qualitative study set out to examine the dynamic ways in which young people experience homelessness. This research identified three factors - remaining in the home community near established networks, receiving competent help from formal agencies, and being female - as facilitating young people's progress out of homeless situations.

In Australia, Mallet et al (2010) examined the pathways followed by young people into and through homelessness over a period of 2 years based on a sub-group of 40 newly homeless young people selected from a larger sample. At the time of follow-up, over half were in the 'going home' pathway, where 'home' was defined as 'accommodation in either private rental, family home or partner's family home' (ibid, p. 38). This study highlighted the benefit to young people of their ongoing relationships with various family members and/or a partner, as well as social service intervention, particularly from an individual service worker, as providing support that was enabling in terms of moving out of homelessness. In a similar vein in the USA, but through a focus on the perspectives of young people on what enabled them to resolve their homelessness, Kurtz et al (2000) found that help from others - particularly from family, friends and professional helpers - was a critical enabler to young people's transition to stable housing. Although most of this study's young people had histories of volatile relationships with their families, their parents and other family members were nonetheless identified as important sources of caring and support. Other US studies have similarly 
found that the help and support of family members and others, including professionals and friends, are often cited by homeless young people as essential elements in facilitating a transition to stable accommodation (MacKnee and Mervyn, 2002; Nebbit et al, 2007; Raleigh-DuRoff, 2004).

The apparent shift within research from an almost exclusive focus on routes or pathways into homelessness towards the investigation of exits out of homelessness reflects broader conceptual developments within homelessness research. As stated above, homelessness is increasingly understood as a complex, multicausal phenomenon and as an interaction between individual and structural factors (Busch-Geertsema et al, 2010; Pleace, 2011). This understanding is associated with what is widely known as a pathways approach, which places a strong emphasis on the identification of facilitators and barriers to exiting homelessness. It is also a conceptualisation that privileges the exploration of processes and meanings associated with people's homeless and housing pathways. This conceptual framework is elaborated upon below, with particular attention to its relevance to understanding homelessness among the young.

\section{A pathways approach to youth homelessness}

Homelessness is increasingly recognised as an experience that is continuously subject to change and as a 'status' that does not necessarily result in a progressive downward spiral toward chronic homelessness. Thus, the episodic nature of many homeless experiences is emphasized (Culhane and Metraux, 2008), as are the multiple paths that people may take into, through and out of homelessness (Anderson and Tulloch, 2000). Research seeking to explore the complex dynamics of homelessness has increasingly drawn on the notion of a homeless or housing pathway.

Theoretically rooted in social constructionism (Clapham, 2002 and 2003), a pathways approach views homelessness as 'an episode or episodes in a person's housing career' (Clapham, 2003, p. 123). Clapham (2003) describes the pathways conceptualisation as a metaphor rather than a theory, which assists in illuminating the changing relationships that people may have with homelessness and housing over the life span. It assumes that homeless and housing pathways are related to other elements of life and lifestyle, 'such as employment, family maturation and so on' (ibid, p. 123). This assumption means that a strong emphasis is placed on the meanings that people attach to 'homelessness' and 'home' (Tomas and Dittmar, 1995; Watson and Austerberry, 1986), thereby illuminating individuals' perspectives on what it is like to be homeless or housed.

Pathways approaches consider the processes at work in relation to the housing careers and life trajectories of individuals who experience homelessness at any (or more than one) point in their lives. This permits an exploration of the key dynamics driving 'careers' in homelessness and the identification of experiences that shape a young person's movement in and out of homelessness over time. The question of how homelessness and housing interact with other processes and experiences is central to the pathways conceptualisation since young people's homeless and housing trajectories are examined alongside other relevant life transitions. This enables a perspective on how family, peers, drug use, criminal activity and so on interact with homelessness and housing over time. This is important since life course approaches are critical to understanding social processes, including homelessness, that are relevant to youth transitions (Edgar, 2009). To date, however, only limited research has examined homelessness 'as a dynamic process concerned with how people do or do not gain access to suitable, affordable housing' (Anderson, 2001, p. 1). This is particularly true of young people who experience homelessness, although a growing body of longitudinal research has gone some way in illuminating the processes and mechanisms that facilitate exits from homelessness in the case of young people (Craig et al, 1996; Fitzpatrick, 2000; Kurtz et al, 2000; MacKnee and Mervyn, 2002; Mallet et al, 2010; Nebbit et al, 2007; Raleigh-DuRoff, 2004; Stockley et al, 1993). Research in the Irish context is only beginning to draw on conceptual and methodological approaches that explicitly seek to generate a more comprehensive understanding of the paths taken by individuals into, through and out of homelessness. 


\section{Summary}

This chapter has discussed several issues that are salient to contextualising this qualitative longitudinal study of homeless young people in Dublin. There are clearly challenges associated with defining and measuring youth homelessness and these are not unique to the Irish context. Although the existing systems of data collection and monitoring are far from complete, the available figures indicate a downturn in the numbers presenting to the Out-of-Hours Service (OHS) in the Dublin region (i.e. children and young people under the age of 18 years) over the past decade or more, a trend which is clearly positive and one which also signals improvements in preventive strategies since the publication of the Youth Homelessness Strategy in 2001. It is important to note, however, that these figures do not provide information on children and young people 'at risk' of homelessness and also that they do not include those in 'hidden' homeless situations, such as living with relatives or friends. For young people aged 18-25 the picture is also partial, but based on the available figures, the best estimate would suggest that between $15 \%$ and $20 \%$ of the total homeless adult population are in this age range. Thus, youth homelessness remains a significant problem in the Dublin region.

This chapter has outlined some key developments within homelessness research internationally over the past decade or more, with particular attention to what is generally termed a pathways approach. This approach does not assume a progressive decline toward prolonged or chronic homelessness; instead, it recognises that young people can transition into and out of homelessness at different stages of their lives. Thus, the notion that individuals can move between being homeless and housed is a key starting point for a complex and dynamic analysis of young people's pathways into, through and out of homelessness.

Chapter 2 outlines the data collection methods and analytic procedures utilised in the conduct of this qualitative longitudinal study of homeless young people in Dublin. 


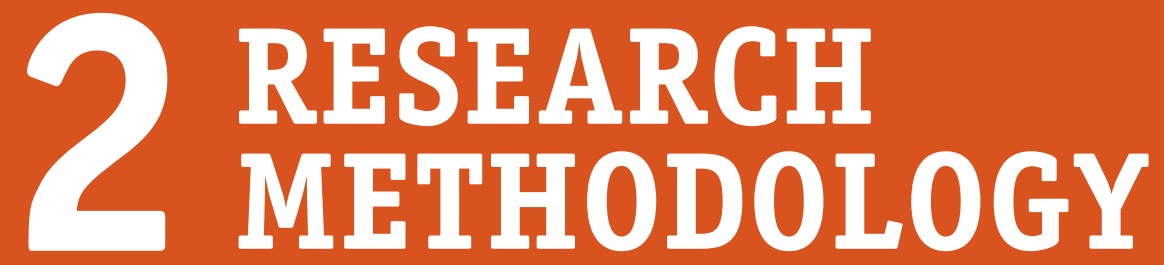


This study set out to conduct an in-depth examination of the lives and experiences of homeless young people in the Dublin region. A core aim was to understand transition and change in their lives with a specific focus on their trajectories into, through and out of homelessness. The term 'homeless' was defined and operationalised to include young people who were 'roofless' or sleeping rough, as well as those living in homeless hostels or other emergency or temporary accommodation types. It also included a small number of young people who had recently experienced homelessness. The study design was underpinned by a pathways approach, a conceptualisation that recognises the fluid and changeable nature of homelessness and the experiences that surround homelessness. Thus, homelessness is not viewed as static or fixed, but rather is an evolving status that is continually subject to change.

This chapter provides an overview of the study design and methods of data collection and analysis, paying particular attention to the merits and challenges associated with the conduct of qualitative longitudinal research with transient and 'hard to track' populations of young people.

\section{Study design}

The task of studying trajectories into, through and out of homelessness is one that ideally demands the investigation of the homeless experience over time. A qualitative longitudinal study was designed and the research was conducted in three waves: the first between September 2004 and January 2005; the second between September 2005 and August 2006; and the third between September 2009 and August 2010. The study's young people were therefore followed over a 6 -year period, which encompassed the transition to young adulthood. This period of contact and engagement provided a unique opportunity to gain insight into the processes that steer young people's 'journeys' into, through and out of homelessness, as well as their perspectives on their homeless and housing situations over time.

At baseline (Phase 1), 40 homeless young people were recruited for participation in the research. To be eligible for participation, young people had to be (1) homeless or living in insecure accommodation during the 6 months prior to interview; (2) aged 12-22 years; and (3) living in the Dublin metropolitan district for the past 6 months. Young people were accessed through hostels and residential centres targeting the under-18s, adult hostels, drop-in centres, and in street-based settings (see Mayock and 0'Sullivan (2007) for a full account of the study's access and recruitment procedures). Contact was re-established with 32 of these respondents during the second phase of the study and information regarding living situations was collected on an additional 5 young people. At Phase 2, therefore, information was available to the research team on 37 of the 40 young people interviewed at baseline and, of these, a total of 30 were re-interviewed. A third wave of data collection was initiated in September 2009 and continued for a 10-month period. During that time, 28 young people were re-interviewed and information gained on the whereabouts of a further 4 participants. Over the course of the study, retention rates were $75 \%$ in Phase 1 and $70 \%$ in Phase 2 , and at least one follow-up interview was conducted with 35 of 40 young people over the 6-year period of the research. These retention rates are satisfactory, particularly in light of the challenges associated with retaining homeless and other 'hard to track' populations in longitudinal studies (Conover et al, 1997; Hobden et al, 2011; Taplin, 2005).

\section{Qualitative longitudinal research}

The importance of time, the temporal dimension of social life, has long been recognised in sociological thinking, but has taken on new significance with the recognition of rapid social change under late modernity. Much of the enthusiasm for qualitative longitudinal or 'tracking' research coincides with the expanding discipline of youth and youth transitions. Over the past decade or more, there has been an increased emphasis on understanding the way in which the transition from youth to adulthood is made and, more specifically, on what makes it possible for some young people to make relatively smooth transitions while, for others, transitions are enormously complex and fraught (see, for example, Furlong and Cartmel, 1996). 
In relation to homelessness, qualitative longitudinal research, because of its characteristic sensitivity to context, can illuminate social processes that impact on young people's living situations, as well as the way they negotiate change as it occurs in their lives. Qualitative longitudinal research also permits the incremental exploration of events and experiences that are personally significant. Thus, as they communicate their experiences and perspectives, past and present, it is possible to acquire a multilayered picture of young people's life experiences. Processes, practices and behaviours can be examined as they develop and evolve, and the meanings they attach to their changing circumstances can be explored. A focus on the meanings placed on experience is important since 'homelessness' is understood differently by homeless youth (Fitzpatrick, 2000; Hutson and Liddiard, 1994). Furthermore, individuals' perceptions of their situations may be subject to change over time.

Qualitative longitudinal research, distinguished by the way in which temporality is built into the research process (Holland, 2011; Saldana, 2003), is relatively new in the context of ongoing methodological developments and innovation within the social sciences, although the relevance of qualitative longitudinal studies to policy-makers is becoming increasingly apparent (Farrall, 2006). Evidence of a growing interest in qualitative longitudinal research within policy arenas is claimed to be associated with 'holistic approaches to policy' and with a commitment to 'understanding the subtle interaction of factors shaping processes such as social exclusion, resilience and risk' (Holland et al, 2004, p. 7). Following people forward over time and collecting data through qualitative approaches 'provides an opportunity to explore how and why people make individual choices that add to particular cumulative trajectories, and more specifically to understand the ways in which people respond to social and welfare services' (Corden and Millar, 2007, p. 529). Qualitative longitudinal research is further argued to have a 'transformative effect' on the way we think about children and young people (Neale and Flowerdew, 2003), a feature which also makes it particularly salient to the policy community.

\section{Tracking and retention}

Sample attrition is a major issue for qualitative longitudinal research, particularly since the smaller sample size (compared to quantitative studies) means that the loss of participants can adversely affect the overall balance of the sample in terms of key baseline sampling criteria. Sample attrition can occur for a range of reasons, such as refusals, changes of residence or, in extreme cases, the death of a respondent (Molloy et al, 2002). Transience is a particular problem in any attempt to follow or track homeless populations over time (Conover et al, 1997), making the design and application of a tracking strategy vital in terms of maximising retention.

During the conduct of baseline interviews for the present study, the research team invited young people to provide details of how and where they might be contacted for a second interview approximately one year later. A 'contact sheet' was designed for this purpose and was used to record a range of possible contact routes (e.g. personal telephone number; the telephone number of a parent(s), other family members or friends; the name and telephone number of a social worker; and, where appropriate, areas or locations where the young person 'hung out'). No young person declined to provide contact information at this juncture, but several were unable to give reliable contact details due to their estrangement from family members and their local communities and/or the transience associated with their unstable living situations. In addition, by Phase 2 of the study, a majority of young people had moved at least once since the time of our initial contact with them, making tracking challenging and, for a considerable number, their places of residence remained temporary (e.g. living in a homeless hostel, bed and breakfast accommodation or sleeping rough). In the case of only a minority did personal mobile telephone numbers yield positive results in terms of re-establishing contact. At Phase 2 of the study, we therefore relied to a considerable extent on the help and support of service providers with whom we had regular contact at the time of recruiting young people to the study. These professionals were often able to provide us with information on the whereabouts of young people and/or assist with access by contacting young people on our behalf and gaining their agreement to be contacted by us directly. 
Predictably perhaps, the tracking process was even more complex and protracted during Phase 3 of data collection and was further complicated by a time lapse of 3-4 years since the conduct of Phase 2 interviews. By this time, practically all of the young people had transitioned out of services targeting the under-18s, making that access route less feasible and reliable. However, some had maintained some level of contact and interaction with these, or related, aftercare services and this situation helped us to re-establish contact with a number of the young people. We used all contact details provided to us at Phase 1, and again at Phase 2, and these proved fruitful in tracking a considerable number. Noteworthy perhaps is that contact with a number of young people's parents (using telephone numbers previously provided by them) yielded positive results in some instances. Parents were similarly found to be a useful source of help in a study which tracked young employment scheme participants' routes into work and other destinations (Molloy et al, 2002).

In most cases, the process of re-establishing contact with young people was an incremental one that involved following-up on all potential contact points or 'leads' over an extended period of time. New information and hunches were always pursued and researcher flexibility in terms of tracking, scheduling and completing interviews was important to reducing attrition (Cotter et al, 2005). Methodical written records of all contact attempts were maintained, including the date, time and outcome of every effort to determine the whereabouts of the study's young people. As time passed, we often received new information from either a professional or family member that enabled us to eventually contact the young person directly. More than anything, the process required persistence (Kleschinsky et al, 2009) and efforts to re-establish contact with the study's young people did not cease until all possible access routes had been exhausted. It is significant that no young person declined to participate in a follow-up interview once contact was re-established with him or her. On the contrary, young people were overwhelmingly positive and very willing to continue their participation in the study. Attrition was therefore associated with tracking and contact challenges rather than with refusals on the part of young people to re-engage with the research.

\section{Biographical interviewing}

The life history interview - which privileges the narration of personal biography (Denzin, 1982) - was the study's core data collection method. Life history interviewing seeks to understand the changing experiences of individuals, what they see as important and how they perceive and interpret their past, present and future (Roberts, 2002). An underlying assumption of the biographical mode of interviewing is that each individual has a unique story to tell and a unique understanding of that experience. The individual is encouraged to tell his or her story in a way that allows this uniqueness to find expression so that the understandings and significance that people give to their lives are illuminated (Chaitin, 2004). Experience is therefore studied and understood from the perspective of the people involved (Denzin, 1970). Participants are encouraged to actively remember and reconstruct their lives through the telling of their stories as the researcher prompts memories and encourages participants' reflections, interpretations and insights (Haglund, 2004). Life history interviewing thus 'gives space to a fuller examination of the complex ways in which people negotiate the opportunities and constraints shaping their access to housing, employment and welfare' (May, 2000, p. 633).

Baseline interviews commenced with an invitation to young people to tell their 'life story'. This approach meant that young people were positioned as active agents in the construction of their stories and yielded rich narrative data on their early life experiences. Throughout the interview, a strong emphasis was placed on the elicitation of narratives of becoming homeless and on establishing a chronology of housing/living situations since homelessness was first experienced. During subsequent waves of data collection, young people were encouraged to update their life stories, including descriptions of change in their housing/homeless situations, social networks and family relationships, substance use, health, and service utilisation practices. They were also encouraged to reflect on events, past and present, and to identify experiences they perceived as 
having specific positive or negative consequences. This process was aided, particularly during Phase 3 interviews, by the use of a 'time line ${ }^{8}$, which included the date (month/year) of earlier interviews as well as details of their living situations during previous phases of the study. Young people responded well to this diagrammatic representation, often spontaneously discussing their situations at the time of previous interviews and highlighting ways in which their circumstances had altered or, alternatively, remained relatively unchanged during the intervening period. This focus on personal experience allowed young people to articulate their views and to discuss transition and change in the telling of their stories over time.

\section{Data management and analysis}

The analysis of longitudinal qualitative data presents unique challenges due in large part to the volume of data produced. The process of coding (Charmaz, 2006; Miles and Huberman, 1994) substantially aided the management of the raw data. A set of coding categories was developed during Phase 1 of the study and this was extended to include new and emerging categories of salient data as the study progressed. A 'case profile' was also prepared for all participants at baseline and this was updated following the conduct of subsequent interviews. These profiles documented important information on young people's pathways into, through and out of homelessness; their family situations; substance use; health; criminal activity and contact with law enforcement agencies; and levels of service utilisation and engagement. 0ther key areas of analytic interest were also documented, including those pertaining to key transitions (housing, education/training, and so on), 'turning points', 'identity' and future plans and aspirations. Case profiles supported cross-sectional analysis by permitting ease of access to data to support typology development, particularly in relation to the identification of young people's pathways into, through and out of homelessness. Cross-sectional analysis was thus undertaken for each round of data collection, while temporal or longitudinal analysis involved a detailed examination of change in young people's situations and experiences over time. This approach has been described elsewhere as combining 'synchronic' (cross-sectional) and 'diachronic' (longitudinal) analyses (Thomson et al, 2004). The question of how change in young people's homelessness and other life experiences inter-relate through time (Saldana, 2003) was central to the analysis of their homeless and housing pathways.

\section{Ethical considerations}

Ethical approval for the conduct of this study was initially attained from the Ethics Committee at the Children's Research Centre, Trinity College, Dublin, and, during subsequent waves, from the Research Ethical Approval Committee, School of Social Work and Social Policy, Trinity College, Dublin. Approval was also sought and attained from the Irish Prison Board Ethics Committee during all three phases of the study in order to access or re-establish contact with young people who were incarcerated.

Importantly, the vulnerability of those young people targeted for participation during all waves of the research was recognised, as was the potential of the life history interview to raise distressing topics for participants. The aims of the research were explained in detail to young people at the outset of the study and voluntary, informed written consent was sought from every participant. These aims were revisited with each young person during later phases of the study and consent was again sought and attained. It was made clear to each participant that they could withdraw from the study at any stage without negative repercussions. The study followed a policy of non-disclosure of information shared and each research participant was given assurances about confidentiality. However, it was also explained to participants on each occasion that if they disclosed that they

\footnotetext{
8 This time line was prepared prior to the conduct of Phase 3 follow-up interviews. Preparation for each wave of follow-up interview was time-consuming and required interviewers to comprehensively review interviews from previous phases of the research. This preparatory work placed a strong emphasis on the identification of issues or topics unique to each young person in the conduct of follow-up interviews.
} 
were at risk of harm or danger, the researcher was obliged to report this to a relevant individual. Anonymity was ensured by removing all identifying information from the data in all written dissemination of the study findings. Each young person was given a unique code which appeared on their interview transcripts and they were also assigned a pseudonym. All participants received a gift voucher to the value of $€ 25$ as a token of appreciation for their time.

Quotations from the narratives of participants are presented throughout Chapters 4 and 5 of this report; in all cases, pseudonyms are used to protect the anonymity of research participants and all potentially identifying information, such as names of places or family members, has been removed, with the words of participants reproduced verbatim to retain the flavour of their narratives.

During a qualitative research endeavour, and perhaps particularly in the context of longitudinal research, a relationship is established between the researcher and participant. However, this relationship is one where a power imbalance may exist in relation to age, gender, education and economic status. While careful not to overstate the benefits, participation in a life history interview can place participants in an empowered position. For example, Miller and Glassner (1997, p. 105) suggest that 'social differences' (and hence 'social distance' between the interviewer and interviewee) can place the interviewee in the position of 'expert' on a topic of interest to the researcher, and therefore addresses the power relationship which otherwise exists in the social structure. In other words, the interviews can provide 'a gratifying opportunity to speak with authority on one of the few subjects about which they could actually do so' (Klockars, 1974).

\section{Summary}

The study, the first of its kind to be conducted in Ireland, set out to generate an in-depth understanding of young people's routes into, through and out of homelessness. Indeed, to our knowledge, no similar study in the European context has attempted to track homeless young people over a 6-year period. Second and third waves of data collection have allowed us to examine the durability and sustainability of the transitions made by young people over time, thus permitting a more robust understanding of their housing and homeless 'careers'.

Chapters 3-5 now draw on the findings from each of the three phases of the study and provide cross-sectional and longitudinal analyses of young people's homeless and housing transitions. 


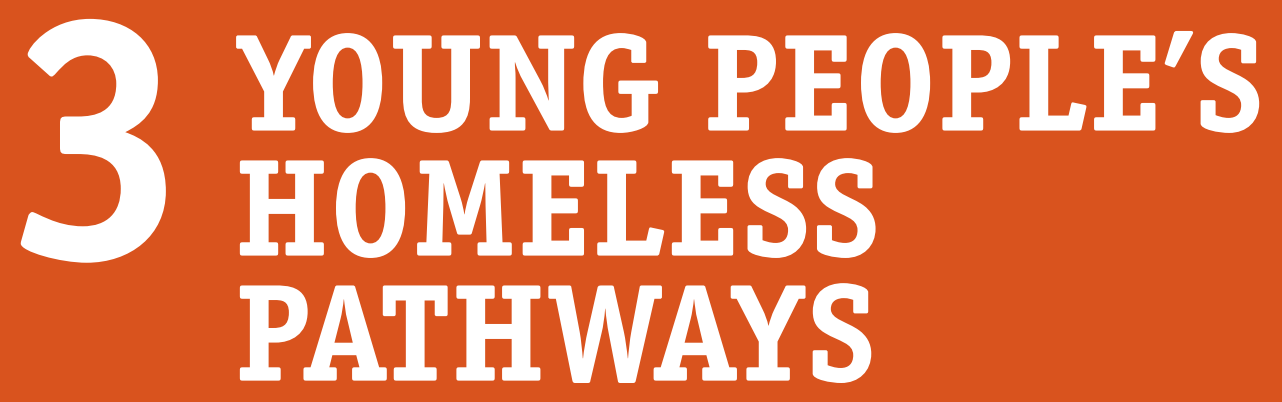


This chapter begins by providing a brief profile of the study's young people at baseline and then discusses the processes associated with young people becoming homeless. The remainder of the chapter is concerned with documenting young people's pathways through and out of homelessness, with a strong focus on their housing and homeless transitions over the course of the three phases of the study.

\section{The study's young people at Phase 1}

In total, 40 young people (23 young men and 17 young women), aged between 14 and 22 years, were interviewed at baseline. All participants had been living in the Dublin metropolitan area for at least 6 months prior to interview.

Practically all of the young people lived in poor neighbourhoods as children and their childhood memories almost always included accounts of hardship linked to poverty, traumatic life events and household instability. Other sources of reported disruption and distress included difficult family dynamics and relationships. Family problems varied in nature and severity, although many reported deteriorating relationships with their parent(s) during their early to mid-teenage years. A majority of the study's young people reported multiple forms of adversity and, as children, most had experienced high levels of stress linked to instabilities, tensions and conflict within their homes. Young people's schooling was also seriously disrupted and many stopped attending at an early age. Eighteen of the 23 young men interviewed left school at or before the age of 15 and only 2 had completed a State examination. Young women reported longer stays in education and, at baseline, 11 of the 17 female participants were attending school.

At Phase 1 of the study, almost two-thirds of the young people $(n=25)$ were residing in under-18s emergency or short-term hostel accommodation, which they had accessed through contact with the Out-of-Hours Service. Most of the remaining participants were residing in a number of other shortor medium-term accommodation types: 2 were living in medium-term hostels; 3 in an adult hostel; 3 were in prison at the time of interview and had been homeless prior to their incarceration; 2 were sleeping rough; 2 were living in supported housing; and 2 had recently returned to the family home having experienced homelessness during the previous 6 months. Finally, one young person was alternating between an emergency hostel and home at the time of her Phase 1 interview.

A considerable number of the young people reported lengthy homeless histories during their Phase 1 interviews, with 11 (just over one-quarter) having been homeless for 2-4 years and a further 8 (onefifth) for 5 years or more. At the outset of the study then, almost half of the young people would be categorised as 'long-term' homeless according to many international definitions. A considerable number of the study's young people - particularly those with longer homeless histories - reported problematic or dependent patterns of drug and/or alcohol use, and only 7 of the 40 young people interviewed had never tried an illegal drug. Across the sample, levels of drug involvement ranged from experimental use to recreational styles of consumption through to heavy and problematic drug use. Half of the study's young people (13 young men and 7 young women) reported lifetime use of heroin and almost all acknowledged that their drug use was problematic to the degree that it had become a dependency. Drug use escalated for practically all young people as their 'careers' in homelessness progressed and this pattern of consumption was especially apparent among those who moved constantly between hostels targeting the under-18s. Accounts of criminal activity also featured strongly in many Phase 1 accounts. Of the 23 young men interviewed, 21 reported 'trouble' with the police at some time and 20 had been charged with at least one criminal offence. Young women were far less likely to report criminal activity and far fewer had contact with law enforcement agencies: 8 had been charged with a criminal offence and a further 2 were enrolled in the juvenile liaison scheme.

The contextual significance of social and situational factors is crucial in explaining the drug use and criminal histories of the study's young people at Phase 1. As stated earlier, a large number had lengthy homeless histories and, to a considerable extent, their accounts demonstrate the interconnectedness of homeless, drug and criminal 'careers'. The homeless experience itself certainly exacerbated the risk of young people becoming more deeply entrenched in drug use and criminal 
behaviour (Mayock and 0'Sullivan, 2007). The relationship between homelessness, drug use and criminal activity is clearly complex. However, few of the young people were heavily involved in drug use and even fewer had records of offending at the time they first left home.

\section{The process of becoming homeless}

For this group of young people, the early to mid-teenage years was the period of greatest risk for homelessness, with almost half of the participants (9 males and 10 females) first experiencing homelessness at the age of 14 or younger and an additional 12 (9 males and 3 females) at the age of 15 . The remaining 5 males and 4 females first experienced homelessness between the ages of 16 and 18.

There was enormous diversity in young people's accounts of becoming homeless and practically all told a unique story of leaving home (see Mayock and 0'Sullivan (2007) for a detailed account of young people's pathways into homelessness). Nonetheless, for a majority, the process of becoming homeless could be traced to early childhood when disruptions of various types began to impact negatively on their lives. For many, the event(s) precipitating homelessness were closely related to other events or home situations, while for others the move out of home was the final stage in a whole sequence of problems. Although the reasons for young people becoming homeless were complex and multifaceted, it was possible to identify three broad pathways or routes 'into' homelessness. These were associated with:

- a history of State care;

- family instability and family conflict;

- problem behaviour and negative peer associations.

Rather than representing discrete routes, there was considerable overlap between these pathways and much of the narrative data points to home and family situations as key contexts for understanding why young people became homeless. Sixteen of the young people $(40 \%)$ had experience of the child care system, predominantly foster care, and a majority of these reported a range of family problems and hardships. Their childhoods were characterised by short or prolonged periods of separation from family, as well as multiple care placements, leading to high levels of instability and disruption. For a considerable number, successive care experiences were dominated by a pattern of rule breaking, accompanied in some cases by deliberate attempts to orchestrate their removal from one or more care setting. A number returned home or lived with relatives between care placements. Young people's accounts of living in care suggest that they held deep feelings of resentment about their separation from their parent(s) and siblings, and did not integrate or settle into the settings where they were placed.

Home-based problems were not restricted to those who had a history of State care, with a majority of the young people recounting a host of family tensions. Parental discord and/or marital breakdown featured strongly in the events leading to first homeless experiences, as did conflict arising from the presence of a step-parent. Parental drug or alcohol use was reported by 16 of the study's young people $(40 \%)$. Reports of physical abuse were also commonplace, with over half of the young people having experienced violence in their homes as children: 18 (45\%) reported physical assault by an adult (father, mother, step-parent or mother's partner) during childhood. For many of these young people, leaving home was a temporary solution to the stress associated with a host of home-based difficulties and, for some, this response became a more enduring break from home.

The final pathway out of home was more strongly related to young people's own behaviour, which led to disagreements with parent(s) during their early and mid-teenage years. For example, a number described staying out late with friends and/or regularly consuming alcohol and drugs. While most openly admitted to being 'rebellious' as teenagers, their accounts also referenced family problems and home-based crises that created vulnerability in them as children. These young people frequently stated that they were 'kicked out' of home and a number reported a period of moving back and forth between home and other sleeping places (most often in their home neighbourhoods) during the initial stages of living out of home. 
At the time young people first experienced homelessness, they had already experienced a series of deprivations and losses regarding housing, caregivers and school. Furthermore, by the time young people found themselves out of home for the first time, their experiences of a number of key institutions (including the family, school or State care) had been overwhelmingly negative. Consequently, at a relatively early age, a large number were living outside, or marginal to, the structures that play a critical role in preparing young people for the transition to adulthood.

\section{Phase 2 Pathways: Homeless exits and continued homelessness}

In total, 30 young people (16 males and 14 females) were successfully tracked and re-interviewed at Phase 2 of the study. Aged between 15 and 24 years at this juncture, their housing situations had changed quite dramatically since Phase 1 of the study. Many reported more than one housing transition since the conduct of baseline interviews 12-18 months earlier and a considerable number had lived in multiple living situations during that time. Notably, all but one had moved on from emergency or short-term hostel accommodation targeting the under-18s. Table 1 presents the young people's homeless pathways at Phase 2, which include exits to (more) stable housing (Pathways 1 and 2) and continued homelessness (Pathway 3).

Table 1: Young people's homeless pathways at Phase $2(n=30)$

\begin{tabular}{|c|c|c|c|}
\hline Homeless pathways & $\begin{array}{l}\text { Young } \\
\text { men }\end{array}$ & $\begin{array}{c}\text { Young } \\
\text { women }\end{array}$ & All \\
\hline $\begin{array}{l}\text { Pathway } 1 \\
\text { Independent exits from homelessness } \\
\text { Family home (6), private rented sector accommodation (1) }\end{array}$ & 2 & 5 & 7 \\
\hline $\begin{array}{l}\text { Pathway } 2 \\
\text { Dependent exits from homelessness } \\
\text { Transitional/supported housing (7), foster or residential } \\
\text { State care (3) }\end{array}$ & 3 & 7 & 10 \\
\hline $\begin{array}{l}\text { Pathway } 3 \\
\text { Continued homelessness } \\
\text { Adult hostels (4), sleeping rough (2), prison (5), other (2) }\end{array}$ & 11 & 2 & 13 \\
\hline
\end{tabular}

As demonstrated in Pathways 1 and 2 above, 17 young people ( 5 males and 12 females) had achieved greater stability of housing by Phase 2 of the study. These young people were living at home, in transitional housing, in a State care setting and in private rented accommodation. Homeless exits were categorised as 'independent' or 'dependent' exits (Mayock et al, 2008 and 2011a). Those who exited in an independent sense were categorised in this way to reflect their relative independence from State-subsidised housing or other non-statutory interventions (although private rented sector occupants may have been receiving rent allowance, a supplementary social welfare payment). This distinguishes them from those who made dependent exits to housing provided by NGOs or to State care where there was ongoing professional social service input and support.

Again as seen in Table 1, 7 young people made an independent exit from homelessness, 6 (1 male and 5 females) to the family home and 1 to private rented accommodation, while 10 reported a dependent exit from homelessness, with 7 (3 males and 4 females) having moved to Statesubsidised transitional housing (agency-managed housing to support young people's move towards independent living) and 3 (all female) to a State care setting. Thus, a far greater number of female participants had exited homelessness by Phase 2 of the study.

As seen in Pathway 3 above, 13 young people (11 males and 2 females) remained homeless at Phase 2 and continued to move between temporary or unstable living situations. Of these, 4 ( 3 males and 1 female) were living in adult hostels, 2 ( 1 male and 1 female) were sleeping rough and 5 (all male) 
were incarcerated. One young man was residing in a residential drug treatment programme, which he had accessed directly from hostel accommodation, and another was living in supported housing but awaiting sentencing at the time of interview.

Thus, by Phase 2, a large number of the young people had moved towards greater stability of housing, a finding which confirms that the experience of homelessness during adolescence need not progress to young adulthood. Young women were far more likely to have exited homelessness than their male counterparts, indicating that gender plays a potentially important role in the exiting process. 13 of the 30 re-interviewed at Phase 2 remained homeless. Although a number of these young people exited homelessness temporarily between Phases 1 and 2 of the study, they did not sustain these housing transitions and all subsequently returned to hostels or other insecure living situations.

\section{Phase 3 Pathways: Sustained exits and prolonged homelessness}

In total, 28 young people (15 males and 13 females) were successfully tracked and re-interviewed at Phase 3 of the study. Aged between 18 and 27 years, all had transitioned out of services targeting children and young people under the age of 18 at this juncture. Of the 28 young people re-interviewed, 15 ( 3 males and 12 females) had exited or maintained a homeless exit and 13 (12 males and 1 female) remained homeless. Consistent with the patterns identified at Phase 2 (see Table 1), far more females than males had exited or sustained an exit from homelessness. Gender therefore remains significant in the exiting patterns of young people: compared to young men, young women were far more likely to have achieved relative stability of housing by Phase 3 of the study. Table 2 presents the living situations of those who had exited homelessness by Phase 3.

\section{Table 2: Young people's homeless exits at Phase $3(n=15)$}

\begin{tabular}{|l|l|}
\hline Living situation & Number of young people \\
\hline Private rental sector & 9 (8 female; 1 male) \\
\hline Local authority housing & 1 (male) \\
\hline Independent flat & 1 (female) \\
\hline Partner's home & 1 (female) \\
\hline Family home & 2 (1 female; 1 male) \\
\hline Residential aftercare setting & 1 (female) \\
\hline
\end{tabular}

Of the 15 classified as having exited homelessness, 9 were living in private rented accommodation, 1 in local authority housing, 1 in an independent flat (provided by a voluntary agency), 1 in the home of her partner, 2 in the family home and 1 in a residential aftercare setting. Therefore, the vast majority who exited were living independently, typically in the private rental sector, by Phase 3 . Significantly, 11 of the 15 young people who were living in stable accommodation at Phase 3 had in fact exited homelessness (either in an independent or dependent sense) by Phase 2 of the study, a finding which indicates that a large number had sustained an exit from homelessness between the two points of follow-up. The remaining 4 young people who had exited at Phase 3 were homeless at Phase 2 but subsequently moved to a stable living situation, most commonly to private rental accommodation.

Compared to young people who sustained an exit from homelessness, the experiences of those who remained homeless signal strong barriers to housing stability, particularly as the duration of their homelessness increased. Of the 13 who remained homeless, 12 had been homeless at the time of their previous contact with the study (whether at Phase 2 or 3 ). The remaining young person was living in private rented accommodation at Phase 2 but subsequently returned to homelessness. 
Figure 1 presents the homeless pathways of the young people over the course of the study.

Figure 1: Homeless pathways - Phases 1, 2 and 3

\begin{tabular}{|c|c|c|}
\hline \multicolumn{3}{|c|}{ PHASE 1} \\
\hline \multicolumn{3}{|c|}{ HOMELESS $=40$} \\
\hline$\downarrow$ & & $\downarrow$ \\
\hline \multicolumn{3}{|c|}{ PHASE 2} \\
\hline \multicolumn{2}{|c|}{ EXIT HOMELESSNESS = 17} & \multirow{2}{*}{ CONTINUED HOMELESS $=13$} \\
\hline Independent exit = 7 & Dependent exit $=10$ & \\
\hline$\downarrow$ & & $\downarrow$ \\
\hline \multicolumn{3}{|c|}{ PHASE 3} \\
\hline \multicolumn{2}{|c|}{ EXIT HOMELESSNESS = 15} & \multirow{2}{*}{ CONTINUED HOMELESS $=13$} \\
\hline Independent exit = 12 & Dependent exit $=3$ & \\
\hline
\end{tabular}

In any reading or interpretation of the homeless and housing transitions presented in Figure 1, it is important to caution that not all Phase 2 participants were retained at Phase 3 and that a number who were not interviewed at Phase 2 re-engaged with the study at Phase 3 . Thus, this diagrammatic representation does not claim to 'follow' precisely the same young people through Phases 2 and 3 of the study. ${ }^{9}$ Nonetheless, despite a time lapse of between 3 and 4 years, the picture remained remarkably similar in terms of the total number who remained or, alternatively, had exited homelessness at Phases 2 and 3 of the study, respectively. In other words, the broad patterns of movement either out of homelessness or towards more chronic homeless states remained relatively stable for the sample over time. These patterns are significant in that they point to early transitions out of homelessness as generally sustained and sustainable, and, conversely, to the absence of early exit routes as prolonging young people's homeless 'careers'.

While Figure 1 details young people's living situations at 3 specific points in time (corresponding to each successive wave of data collection), it does not capture the full range of housing and/or homeless transitions reported by young people over the course of the study. These are documented in detail in Chapters 4 and 5, yielding a far more nuanced account of the processes of exiting and remaining homelessness.

\section{Summary}

This chapter has presented an overview of the study's sample at baseline, including the processes associated with young people becoming homeless, and has documented the young people's housing and homeless transitions over the course of the study. The living situations of the study's young people changed quite significantly during the 6 years subsequent to our first contact with them, with a considerable number having exited homelessness by Phase 3 . It is significant that broad patterns of either exiting or remaining homeless did not alter to any great extent between Phases 2 and 3. On the positive side, this finding highlights young people's ability to exit homelessness with appropriate supports, as well as their capacity to sustain exits from homelessness. It also underlines the significance of timely transitions out of emergency hostel accommodation to stable accommodation. On the other hand, those young people who had not exited by Phase 2 were likely

9 As detailed in Chapter 2, some young people were not retained at Phase 2 of the study but re-engaged at Phase 3. Similarly, it was not possible to 'track' a number of Phase 2 respondents at Phase 3 . However, at least one follow-up interview was conducted with 35 of the 40 young people recruited at baseline. 
to remain homeless by Phase 3, highlighting the risks posed to young people whose homelessness remains unresolved and signalling strong obstacles to housing stability for young men in particular, especially with the passing of time. It appears therefore that the barriers to housing stability intensified the longer young people remained homeless.

While this chapter has provided a useful overview of the young people's housing and homeless transitions over the course of the study, it does not convey the diversity of their homeless 'journeys'. The following chapters privilege the narratives of young people, including their experiences, perspectives and interpretations of their lives and living situations over time. 


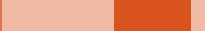




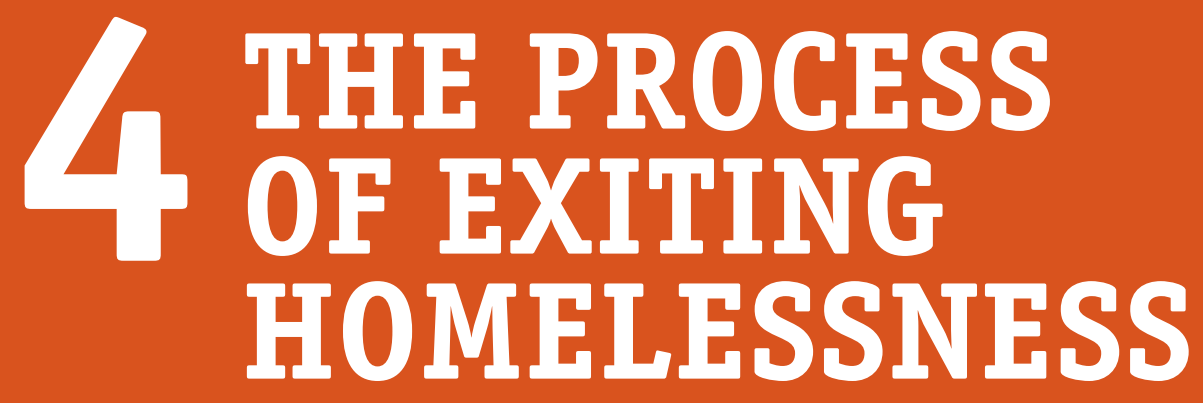


As outlined in Chapter 3, a considerable number of young people had exited homelessness by Phase 2 of the study and had sustained this exit by Phase 3. A smaller number of others ( 4 in total) exited homelessness between Phases 2 and 3. This chapter examines in greater detail the housing transitions of young people who moved to stable accommodation over the course of the study. A key aim is to document their routes out of homelessness, as well as the key processes, events and experiences associated with this transition. The chapter also discusses the meanings young people attached to 'home'.

\section{Young people's exiting 'journeys"}

The journeys taken through and out of homelessness differed for each young person and all told a unique story of exiting homelessness. Those who had exited homelessness by Phase 3 of the study share the experience of having first experienced homelessness during their early or mid-teenage years and most subsequently entered the official network of homeless youth through their contact with the Out-of-Hours Service (OHS). By the time they were interviewed at the third wave of the study, all were living in what they considered to be secure accommodation, even if not all were living independently.

A large number of the 15 young people categorised as having exited homelessness by Phase 3 of the study had, in fact, made this transition out of homelessness by Phase 2. This finding signals the importance of early exits from homelessness since, in the main, those who moved out of homelessness relatively quickly sustained this exit from homelessness. Another relatively consistent characteristic among those who had exited at Phase 2 and sustained this exit by Phase 3 was their low level of movement between short-term, emergency or other unstable living situations following their entry to the official network of homeless youth through their contact with the OHS. While a number lived in medium-term hostel accommodation for a considerable period (sometimes for up to or exceeding 6 months), most did not embark on a cycle of constant movement between emergency under-18s hostels. This pattern contrasts sharply with the experiences of those young people who remained homeless, who almost always reported a succession of placements in hostels targeting the under-18s over an extended period. On reaching the official age of adulthood (i.e. 18 years), they then typically embarked on a cycle of movement through adult hostels, bed and breakfast accommodation (B\&Bs) and other emergency or short-term sleeping places, interrupted by short periods of time spent in more stable housing as well as periods of sleeping rough and squatting (see Chapter 5). Thus, speedy access to secure living situations - whether in the family home, transitional housing, a State care setting or private rented accommodation - was a key enabler to young people exiting homelessness.

As stated in Chapter 3, the routes taken by young people out of homelessness were diverse and their stories reveal marked variation in their exit paths. Their routes to housing stability were patterned in complex ways, revealing both the unpredictability of their journeys through homelessness as well as events and experiences that sometimes altered the course of their exit routes. Although there was no single pattern of movement common to those who exited, it was possible to identify a number of broad housing trajectories followed by them over the course of the study. These trajectories are presented in Table 3. 
Table 3: Young people's exiting trajectories, Phases 1-3

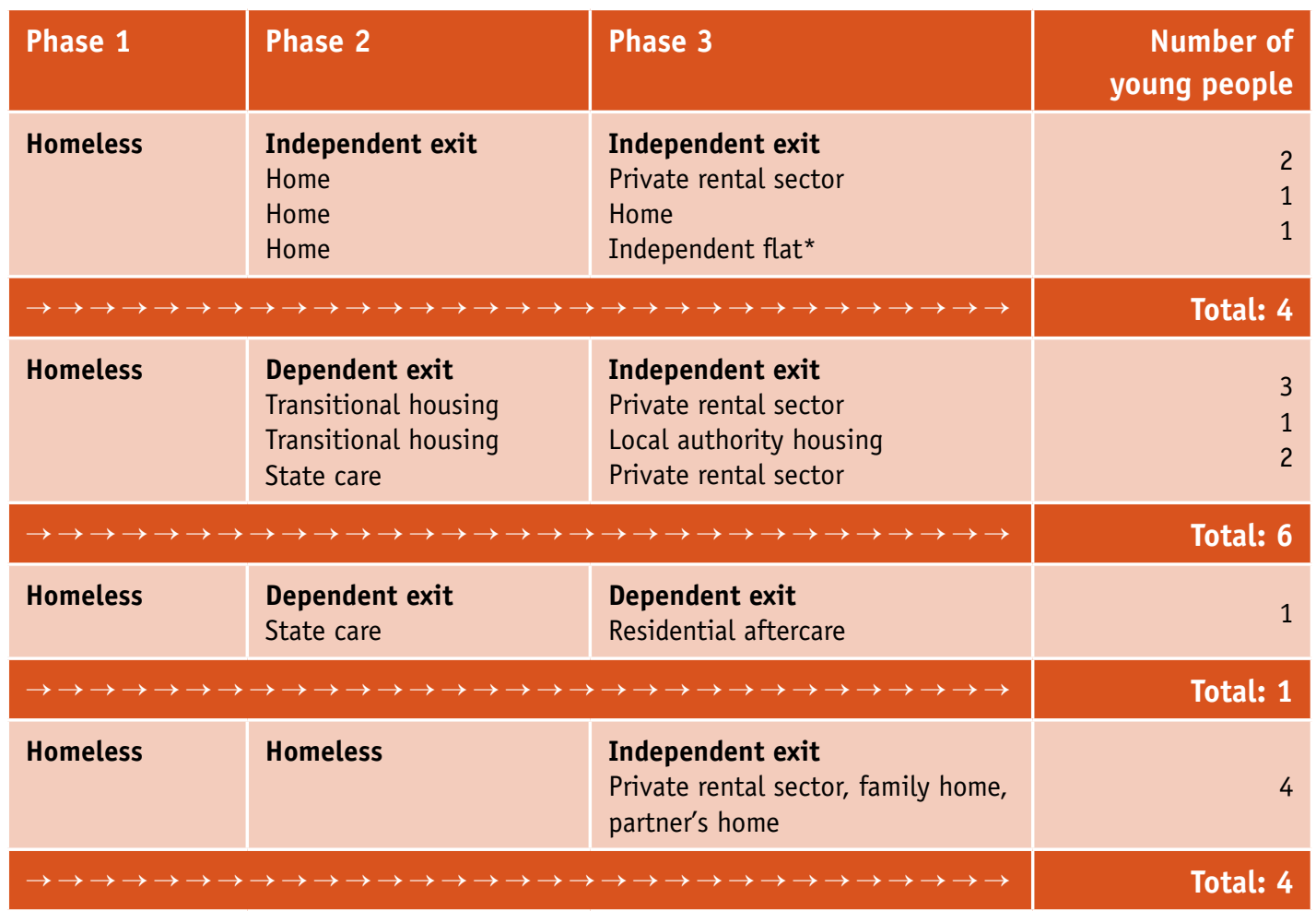

* This accommodation was provided by a voluntary sector agency.

As seen in Table 3, 4 young people maintained an independent exit from homelessness between Phases 2 and 3 of the study and a further 6 transitioned from a dependent exit at Phase 2 (i.e. living in transitional accommodation or State care) to an independent exit by Phase 3 (i.e. living in the private rental sector or in the family home). Dependent exits to transitional housing or State care, whereby young people move to living situations where they are reliant on financial and other forms of assistance and support, therefore appear to act as an enabler to young people in the transition to independent living. The trajectory from dependent to independent exits also points to the incremental nature of the process of exiting homelessness.

One young person moved from a care placement to a residential aftercare programme between Phases 2 and 3 of the study; this young woman expected to move to sheltered accommodation for young adults with learning disabilities during the months subsequent to her Phase 3 interview. Finally, 4 young people who remained homeless at Phase 2 of the study had exited by Phase 3. Most had spent a lengthy period of time commuting between various emergency or temporary living situations prior to exiting homelessness: 2 exited to private rental accommodation, 1 to the family home and 1 to her partner's home.

It is important to caution that Table 3 shows young people's living circumstances at 3 points in time and that it only documents their housing situations at each successive wave of data collection. ${ }^{10} \mathrm{As}$ a consequence, it does not tell the complete 'story' of their paths out of homelessness nor does it capture experiential dimensions of the exiting process.

The remainder of this section examines young people's exit routes in greater detail and discusses a number of important features of their 'journeys' out of homelessness. We first examine the early stages of young people's transitions out of homelessness in order to more fully explore the processes and experiences associated with this transition. We also examine evidence of discontinuity of

\footnotetext{
10 Two young people were not interviewed at Phase 2, but it was possible to identify their living situations at that time during the follow-up interview conducted at Phase 3.
} 
housing stability, including reports of temporary returns to homelessness and/or periods of 'hidden' homelessness, following young people's initial exits from homelessness. These experiences are important since they point to challenges that can potentially have a destabilising effect on young people's housing transitions.

\section{Initial transitions out of homelessness}

Just as becoming homeless was not a one-off or isolated event (Mayock and 0'Sullivan, 2007), the process of exiting homelessness was an incremental one, with a number of transitions and negotiations attached. For example, those who moved to transitional housing had to engage with personnel in these facilities ahead of the move and most described an application and interview process associated with the transition. For example, Jacinta had applied to a number of housing projects prior to her acceptance to transitional accommodation where she was a resident at Phase 2 of the study. This period of seeking accommodation had been difficult because of successive refusals from a number of transitional housing projects:

'There is just some people that just don't know how to do interviews. Like I didn't know how to do interviews so it's good to get people to help you with that ... the worst thing was like, you see, it pissed me off as such because everyone else, all the girls [in the hostel] that were moving out, they got places and no one was accepting me so that was kind of a bad thing.' [Jacinta, age 18, Phase 2]

Similarly, the process of moving back to the family home was challenging, often because of the need to address and resolve prior tensions. Like others, Anna talked about the importance of re-building a trusting relationship with her parents:

'I'm not a moody little teenager any more [laugh]. I suppose I have a relationship back with me family. We get on brilliant now and everything's kind of, we can communicate, we can talk to each other.' [Anna, age 19, Phase 2]

Others who moved home talked about the restrictiveness of household rules (e.g. restricted socialising time, curfews and so on) and, for a number, parental expectations sometimes led to tensions as well as efforts on the part of young people to re-negotiate agreements of various kinds. Similarly, those who moved to transitional housing or to State care had to abide by new rules and expectations, and most talked about a period of 'settling in'. At Phase 3, Lisa, who was by then living in a private rented apartment, reflected on the difficulties she experienced when placed in residential care 3 years earlier following a period of movement between emergency under-18s hostels:

'When I went there first I was 17 and they were basically laying out all these rules for me, "You can't do this and you can't do that" ... and I basically turned around and said, "Listen, I'm 17, I've basically been fending for myself for the last feckin' years so I'm not going to have two people come into me and tell me what I can and can't do"'. [Lisa, age 20, Phase 3]

Thus, the physical move to more stable housing was accompanied by emotional upheaval linked to transition and change across other dimensions of personal and social life. Prominent in accounts of the transition from hostel accommodation to stable housing was the sense of isolation young people experienced following the move. This loneliness was often linked to their having grown accustomed to communal living arrangements.

'After living in the likes of [lists a number of short- and medium-term hostels], I got used to living in a group and then I'm on my own. It's kind of like, "Where is everybody?"'. [Neil, age 26, Phase 3]

'When I went in for the interview and I saw the house [transitional housing], I thought it was gorgeous and I says, "I'll give it a try". And then [after moving], I started to hate it because it's real isolated and all. And I wasn't used to me own company so ... It was real different and, em, then ... I kind of got used to it after like a few months or something.' [Jacinta, age 21, Phase 3] 
Young people who moved to apartment-style transitional living situations over the course of the study often found that they lacked basic household management skills and a number were simply unaccustomed to taking responsibility for everyday chores and duties.

'Well, the shopping at the start was a bit difficult because, em, I suppose I seemed to always go for an easy option and, em, there's a Spar across the road which costs a lot more than going to the big supermarkets ... But, em, I sort of copped on to that like when at the end of the week there was no money left. I said, "Well, next week I'll go down to Lidl".'

[Seán, age 26, Phase 3]

Linked to the problem of not feeling adequately equipped to complete basic domestic tasks were problems with maintaining a healthy diet. Many skipped meals and/or opted for convenience food to avoid the task of cooking.

'I hate cooking ... I had visitors over there the other night, I had to cook for them, but it was more like they kind of cooked 'cos I didn't know how to do it. Most days in the school now they do lunch. It could be sausages and chips, or something. But if I had a weekend by meself, I'd be on the cereals.' [Jacinta, age 18, Phase 2]

Several also reported financial stress, as well as problems with money management and budgeting. Seán described the challenge of surviving on social welfare payments:

'I would like to socialise, but at the moment it's hard because, like I said, with the social welfare and the bills I have to pay, it's hard to have any money left over, you know that sort of way. I need to look out for a job and a training course. I can't really afford to go out.' [Seán, age 22, Phase 2]

Coming to terms with managing household bills and a weekly budget was something that young people learned only gradually.

'I've learned. I have tried to budget and tried to space my money out, but on such little money it is hard, do you know that type of way.' [Caroline, age 17, Phase 2]

There was a strong sense from the narratives that young people had to (re)learn ways of dealing with being housed. This is perhaps not surprising given that many had spent a considerable period of time 'out of home' prior to embarking on their exiting 'journeys'. The sense of safety and security often assumed to be automatically conferred by housing was perceived as threatening by some, particularly during the early stages of the transition out of homelessness. This finding points to the need for appropriate supports as young people exit homelessness and attempt to re-build their lives.

\section{Temporary returns to homelessness and periods of 'hidden' homelessness}

Five of the young people who had exited homelessness by Phase 3 of the study reported a temporary return to homelessness following an initial period of living either independently or semi-independently. Thus, their exits from homelessness were interrupted for a period, although all subsequently returned to a stable living situation. For some, a return to homelessness was precipitated by the sudden loss of accommodation, while for others, a combination of circumstances and events triggered a further homeless episode. The individual stories of three young people who returned to homelessness are documented below. These accounts help to demonstrate the highly differentiated nature of the process of exiting homelessness, as well as the vulnerability of some to a return to homelessness following an initial exit.

Caroline, who experienced homelessness for the first time at the age of 14, was living in Out-ofHours Service accommodation when she was first interviewed in 2004. By Phase 2 of the study, she had moved to transitional housing and was categorised as having made a dependent exit from homelessness. She subsequently moved to private rented accommodation, but was forced to move from that flat because the landlord sold the property. At that juncture, she moved into a two-bedroom house with her partner and child, where she lived for 7 months until the expense of maintaining rental payments became unsustainable. She then moved back to the home of her 
mother, but left within a number of weeks and moved to a women-only hostel with her child, explaining that living at home became increasingly stressful: 'I actually left me Mam's and went to [adult hostel] just because it was too hard to handle in me Mam's ... and then when I got to [hostel] with me daughter, the restrictions on me life that I hadn't had in so long were hard to deal with.' With the help and support of staff at the hostel, Caroline managed to again secure private rented accommodation, where she was living at the time of her Phase 3 interview. Her comments on her movements since the time of her previous interview draw attention to a perceived need and desire for a longer-term tenancy and a stable home:

'Three houses in three years and that's not what I want. I want to settle in a place where we [referring to daughter] can live, do you know. And this home, this apartment I decorated all myself. I've everything all the way I want it to be, all me own furniture, everything. This is where I want my home to be. I don't want to have to move again.' [Caroline, age 21, Phase 3]

Like Caroline, Rachel also lived at home and in transitional housing over the course of the study, although the sequence of her movements were very different. When first interviewed in 2004, Rachel was living in Out-of-Hours Service hostel accommodation and, when tracked at Phase 2 approximately one year later, she had recently moved home. During this interview, Rachel had in fact stated clearly that she was unhappy with the move home and was pessimistic about the sustainability of the arrangement. Perhaps significantly, she did not consider her mother's house to be 'home': 'I know I shouldn't be there, do you know that way like. It's not, it's not my home ... it's just like the place where I sleep and eat and wash myself' [age 15, Phase 2]. Home became more and more stressful for Rachel and, at the age of 17, she reluctantly returned to Out-of-Hours Service emergency accommodation, where she remained for a period before moving to transitional accommodation. From there, she moved to a private rented apartment in the city centre, which she shared with a friend for a short time before moving again: 'That was very hard, that was, I remember like, because the apartment wasn't really that nice ... we moved out of there because the place was damp and it was horrible, it was real bad.' A short time after moving to another apartment, her friend became pregnant and returned to the family home. Unable to sustain rental payments, Rachel again set about seeking an affordable rental dwelling, but found it extremely difficult to find accommodation of an acceptable standard. At the time of her Phase 3 interview, she had recently moved to an apartment where she was living alone. Rachel described the journey as challenging, but also felt that she had gained valuable experience of the private rental sector and was more aware of 'what to look out for' when seeking accommodation:

'Like, it has been hard, but it's good as well that, like, I'm getting the experience and that, do you know. I am learning because then at least I know, if I move next year, I'm going to know what to look for and ... I'll learn the things to watch out for and what way to be.' [Rachel, age 19, Phase 3]

Sarah's story of returning to homelessness was quite different to that of Caroline and Rachel, but like them she had spent time living at home as well as in the private rental sector over the course of the study. When we first met Sarah in 2004, she was living in a step-down facility for women leaving prison, following a chaotic number of years spent moving between hostels, squats and friends' homes. At the time of her Phase 2 interview, she had moved back to the family home, settled into a routine and was attending a drug treatment programme (a condition set down by her parents prior to moving home). However, she subsequently relapsed, resumed the cycle of movement between hostels and also lived in private rental accommodation with her partner for a period before being evicted.

'I was in hostels for a while because of like using [heroin] and stuff like that. So eventually, me and him [partner] got a rented place, you know, up on [city centre street] and it was just, the drugs, you know, just spiralled out of control really ... We ended up getting thrown out of that place for using.' [Sarah, age 26, Phase 3]

This loss of accommodation led to further crises and, by this time, Sarah was heavily involved in acquisitive crime to fund her drug use: 'I was going off robbing every day.' Before long, she was incarcerated for a second time, an outcome she claimed to have opted for at that juncture: 
'I eventually then got locked up. I knew I was going to get locked up. I wanted to get locked up. I handed myself into the Court and asked to be sentenced. I just, I couldn't cope with it anymore like. It was just chaotic, you know.' [Sarah, age 26, Phase 3]

Sarah became pregnant following her release from prison and lived with her partner in private rented accommodation and also with a friend during her pregnancy. She moved home for a time following the birth of her child and from there to a private rented apartment, where she was living with her child at Phase 3 of the study: 'I'm over the moon here. It's amazing, it really is, it's great like ... The way things are at the moment, I'm happy the way things are.'

Caroline, Rachel and Sarah were among 5 young people who sought accommodation in hostels following a return to homelessness. Two of the 5 also reported periods spent staying temporarily with family members or friends (accommodation places commonly described as constituting 'hidden' homelessness) and an additional 2 young people described a period of hidden homelessness but did not re-establish contact with homeless services. Episodes of hidden homelessness tended to extend for a period of weeks rather than months and typically involved staying with friends, although one young woman had spent a period living with a teacher from a training programme she previously attended. Young people most often stated that they opted to stay with friends to avoid a return to hostels: 'I sent a text around to all my friends for accommodation ... and I was just in and out of friends' houses and all' [Jacinta, age 21, Phase 3]. One young woman had slept rough with her partner at times because she felt it was preferable to accessing hostel accommodation: 'They're [hostels] not very nice and there's a lot of bullying' [Emma, age 19, Phase 2].

To a considerable extent, the stories above reveal the precariousness of some homeless exits and the vulnerability of at least some young people to a return to homelessness; they also demonstrate that housing can be hard to maintain in cases where young people are struggling with financial difficulties, trying to care for a child and/or recovering from a substance use problem. Young people demonstrated enormous determination in their attempts to sustain housing and took specific steps to avert a return to homelessness. It is significant that their strategies and actions included efforts to avoid homeless hostels, settings which most perceived as undesirable and stigmatising.

\section{The process of exiting homelessness}

The data presented so far have focused heavily on the housing transitions associated with the move out of homelessness. However, exiting homelessness was a multidimensional process that involved transitions across a range of domains, including family and peer relationships, as well as behavioural transitions most often associated with drug and/or alcohol consumption. These transitions, discussed in greater detail below, had personal and symbolic significance for young people and played an important role in their exiting 'journeys'. This section also focuses on the move from dependent to independent living situations, a common route out of homelessness and one with a number of distinctive features. It also draws attention to a number of challenges and risks faced by young people in their attempts to sustain independent living situations.

\section{Non-housing transitions and the process of exiting homelessness}

Young people invariably drew attention to ways in which their relationships with peers and family members changed over time and these relationship transitions were often depicted as enablers to 'getting out' and 'staying out' of homelessness. For many, particularly those who spent time living in hostels targeting the under-18s, creating new social connections outside of homeless 'scenes' was important. Sarah is one of several who had tried to make a break from past routines by reconnecting with former peers following her move back to the family home:

'All the friends I had before I was ever on drugs have been great ... Since I have moved home, all me friends have been great like. I mean my friends that have never been on drugs that I grew up with. Like, it has been good having that support like, you know, having your friends back.' [Sarah, age 23, Phase 2] 
Most who exited homelessness appeared to share a belief about the need to establish connections and relationships with peers not associated with hostel life and young people demonstrated considerable agency in this regard. At Phase 3, Lisa told how she had long since 'washed her hands of that scene', referring to her peer connections in Out-of-Hours Service accommodation, and went on to explain her reasons for this decision:

'... a lot of people seen it as "The Out of Hours, right this is my life", whereas I saw it as "0kay, I have to get away as quick as possible like" ... It just wasn't the life for me.' [Lisa, age 20, Phase 3]

The process of leaving street life behind (Mayock et al, 2011a) was often linked to young people's efforts to curb or quit drug use. At Phase 2 of the study, Seán explained the risks associated with continuing to associate with his former homeless peers: 'I couldn't hang around with people using drugs now. It's too much ... you can't be around people who are using drugs without using them yourself. You have to get away from that situation.' For a considerable number, the issue of substance use and how best to manage and address excessive or problematic drug or alcohol consumption featured strongly in their accounts of exiting and sustaining an exit from homelessness. Most who reported problem drug use had decreased or desisted from drug or alcohol consumption over the course of the study and all who reported problematic or dependent drug use had, or were currently, attending a drug treatment programme. Significantly, their engagement with drug treatment services coincided with, rather than preceded, the transition out of homelessness in all cases (Mayock and Corr, 2012). Whether young people exited homelessness independently (by moving home or to the private rental sector) or in a dependent sense (to transitional housing or State care), these housing transitions facilitated their efforts to reduce substance use and/or maintain a regime of abstinence.

Emma, who had a lengthy history of drug use, explained the positive impact of moving to a stable living situation. She was attending a methadone maintenance programme at the time of her Phase 3 interview and living with her partner in a private residence.

[What would be the biggest sort of change [since last interview] would you say?]

‘Oh, just having your own like, just having me own responsibilities and ... not having someone telling me what time to be in at and, you know, you can close the door like. Not having to stay rough, you know. When we got the house like, we kind of changed it around and kinda said, "We have a house now like, we could kind of do something with our life".' [Emma, age 22, Phase 3]

Consistent with the findings of other research, young people often engaged in 'distancing' strategies in their efforts to accomplish the goal of leaving street life behind (Snow and Anderson, 1993; Zlotnick et al, 1999). For example, young people stopped 'hanging out' in certain city-centre locations and many severed contact with their homeless peers: 'Yeah, like, I totally disconnected from all the old people I used to hang around with. All of the mates I have now are all in recovery, they're all clean, and, yeah they're all good' [Anna, age 19, Phase 2]. These strategies, as well as the views and perspectives underpinning them, contrast strongly with their interactions with family members, particularly their mothers, with whom many had established a closer relationship. Indeed, the support of family members appeared to have a strong positive influence on young people, with improved relationships, as well as increased contact with parents and other family members, commonly reported among those who exited homelessness. Practically all expressed a desire for a parent to remain involved in their lives and most reported efforts to re-engage with family life. Young people often depicted the renewal of family relationships as a gradual process (Mayock et al, 2011b), which hinged to a large extent on improved communication and trust.

'She's [mum] learned to trust me and that's the biggest thing. There's a bit more trust in the family. Nobody trusted me before and now they do trust me, which is great.' [Anna, age 19, Phase 2]

'There's a lot more trust. I can see the trust after building up a bit more. Em, like there was one stage where there was never money left around the house, although I never robbed off my parents or off my own.' [Seán, age 26, Phase 3] 
As well as regaining the trust of family members, Wayne, who had a lengthy history of homelessness, explained that he too had to learn to trust others:

'You see, on the streets you don't trust no one because nobody trusts you. That's the way it was ... But in the house now, now yeah, I trust my brothers and sisters. And I trust my Ma, you know what I mean. But on the streets, no, no, no one would, you know what I mean. But I mean in my Ma's house now and they trust me with everything now. But back then they didn't. They had no right to, like, you know what I mean, but they trust me with everything now. [Wayne, age 26, Phase 3]

The process of re-establishing positive family relationships was demanding for all young people, irrespective of their exit routes from homelessness. As highlighted earlier, living with a parent was not a realistic option for some young people and, for others, a period spent living at home taught them that this arrangement did not serve their best interests or aspirations. Nonetheless, most who moved to either semi-independent or independent accommodation maintained regular contact with their parent(s) and/or other family members. Indeed, a number who had moved within the private rental sector did so in order to be in closer proximity to a parent(s) or other family members. Lisa's first private tenancy was in a location close to her friends, but she subsequently moved to an area not far from her family home:

'I only moved there [first tenancy] because me friends were there at the time ... do you know, you think you're making the right choice ... and it was just like I'm too far away from my family and all. You just get isolated like, so I moved again!' [Lisa, age 20, Phase 3]

There were exceptions to the general pattern of improved family relationships and not all young people had re-established meaningful connections with family members. At Phase 3, Neil described his father as 'about as communicative as a stone wall' and his relationship with his mother also remained tenuous. Similarly, Jacinta expressed strong ambivalence about her relationship with her adoptive mother, stating that she 'didn't care' about this relationship since she could not rely on her mother for support. At the time of her Phase 3 interview, she was attending counselling and trying to gain a better understanding of her feelings about her family members.

Four of the young people, all young women, had become parents over the course of the study. Becoming a parent and parenthood itself was depicted in a very positive light and their children were a main source of joy and happiness in these young women's lives. By their own assessment, having a child had helped them to mature, often led them to re-assess personal priorities and also helped them to develop better life skills.

'My life revolves around me and me daughter now. And it doesn't matter what anybody or any of me friends are doing so long as me and [child] are happy. Maybe that's just because I'm a mother now, maybe it's not just because it's a couple of years difference, maybe it's just the fact that I'm, I have [baby] now, but I do feel different.' [Caroline, age 21, Phase 3]

All described parenthood as having a transformative impact on their lives. When asked what she felt had changed in her life since 2006, the year of her Phase 2 interview, Siobhán replied 'having my own place, getting clean, and then having the baby'. She went on to depict parenthood as a significant 'turning point' experience:

[What's life like for you now?]

'It's great ... since I had the baby. She changed me life like. Getting clean and having the baby are the biggest things. Mostly having the baby. She's made me life, she made me life better like, you know. It's the thing to keep me away from drugs.' [Siobhán, age 27, Phase 3]

Sarah, too, talked at some length about the impact of becoming a parent on her life in general and also on her personal priorities and future aspirations:

'I don't know why I just couldn't get my shit together before, but now ever since I've had him [baby], he's just [pause] ... everything's changed like. I have no desire to even go out. I just want to be with him all the time. I genuinely feel like I won't go back on drugs [pause] ... because of [baby]. Because I just want to be in his life. I want to be there for his first day of school, for his first words, for everything, you know.' [Sarah, age 26, Phase 3] 
All of these young women were living in private rented accommodation at the time of interview and none lived with the father of their child. They were in regular contact with family members and relied to a considerable extent on their parents (and, in one case, a former foster parent) for material and emotional support.

Exiting homelessness is clearly a complex and multidimensional process. Young people's exiting journeys were strongly influenced by the housing options available to them and by their individual needs and experiences, and their different ways of managing the process of exiting. All of this highlights the need to view homeless and unstably housed young people as a heterogeneous group; it also reminds us that their diverse situations, homeless histories and life experiences must be acknowledged in all attempts to support them in exiting homelessness.

\section{From dependent to independent exits}

Six of the young people transitioned from a dependent to an independent exit over the course of the study, making this a distinctive pathway out of homelessness. Of these, four had embarked on a path out of homelessness which saw them initially move to transitional housing and, some time later, to independent accommodation in the private rental sector. Two others entered a State care setting and subsequently transitioned to independent living. Although the path from a dependent to an independent exit differed for each young person, it did nonetheless have a number of distinctive features. First, young people most often moved to transitional housing or a State care setting between the ages of 16 and 18 years, at a time when their chronological age would have made the prospect of securing independent accommodation in the private rental sector difficult. Second, many in this age range strongly resisted any suggestion of entering a State care setting, sometimes because they had no prior history of care and, in other cases, because their care experiences had been negative or challenging. Finally, most felt that they were not sufficiently prepared or ready for independent living.

The following Phase 2 accounts suggest that young people perceived a need for both the time and space to prepare for the 'step' of living away from the supports that accompanied the move to transitional housing:

'When I first moved in here [transitional housing] I hadn't got a clue. I barely knew how to peel a potato, for God's sake. Me head's wrecked. Now I just feel like I'd be able to do it, you know. It's gave me the confidence to say, yeah I'd be able to live on me own with the baby. I'd be able to bath it and I won't be worrying too much, you know that kind of way.' [Caroline, age 17, Phase 2]

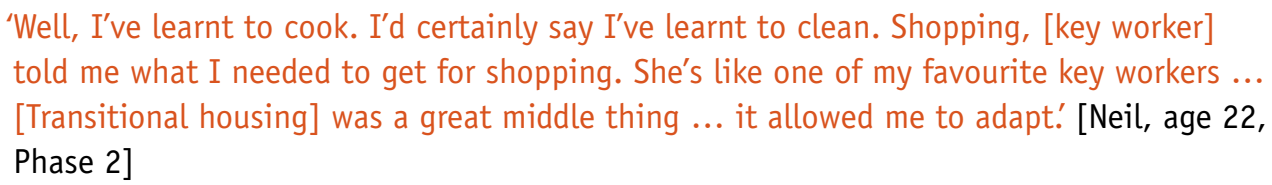

During his Phase 3 interview, Seán reflected positively on his time in transitional housing, depicting it as a 'stage' between dependence and independence:
'It [transitional housing] was good in as far as it gave you a bit more, a bit more responsibility than [hostel] ... You had to pay your own rent, look after yourself a lot more ... you had to do your own shopping and look after yourself so it gave you a bit more latitude and it gave me a bit more confidence because I felt that I was actually contributing, I suppose, to society a bit more ... I wasn't dependent. I didn't feel as if I was dependent on other people to get me by in life, you know.' [Seán, age 26, Phase 3]

The move out of homelessness to State care - a path embarked on by two young people - was challenging. Lisa talked openly during her Phase 2 interviews about the sense of resentment she felt on entering a care setting at the age of 17 . She found it difficult to establish relationships with staff and young people in the care setting and attributed these difficulties to her constant 
movement through unstable living situations: 'I don't really talk to any of the staff in here or anything like that ... I have moved too many times and I have left so many people that it is real hurtful like' [Lisa, age 17, Phase 2]. However, as time passed her perspectives changed and, by

Phase 3, Lisa spoke about the care setting in very positive terms:

'I didn't trust on anybody or nothing and I didn't, I wouldn't let anybody in for ages ... They came down hard on me, cracked me [laughs briefly] ... And I started to connect with a lot of the staff ... there was a few staff there that basically treated me like an adult on the QT [quiet].' [Lisa, age 20, Phase 3]

All of these young people subsequently moved to private rental accommodation, a transition they anticipated with great enthusiasm ahead of the move. Several looked forward to not being 'told what to do', explaining that they wanted to take on more responsibility. All had received some level of preparation ahead of the move and felt they had reached a point of readiness for independent living. Rachel, who had lived in semi-independent transitional housing between the age of 17 and 18, was clear that she wanted to live independently:

'I knew straight away when I went to [semi-independent flat] that I wasn't going to go somewhere like [names a transitional housing unit] after that. Like, I knew I wanted to go straight to renting because I already spent time in semi-independent. What's the point in going to another semi-independent? That's not growing, like; that's just staying the same. I didn't want to do that, like.' [Rachel, age 19, Phase 3]

Nonetheless, for most, the transition to independent living posed a number of specific challenges. According to Lisa, 'It was the quickest process... And what I did was I started looking for places. Now I'd been doing aftercare for weeks'. Like others, Lisa had the help of an aftercare or key worker as she set about finding private rented accommodation and this support did smooth the transition to a considerable extent. Yet, the reality of independent living came as a shock to many who felt quite vulnerable and alone following the move to private rented accommodation:

'It just kind of hit me one day - I was on me own, like ... just waking up and not hearing a sound. Like, after living in a house with about 12 people, you're just kind of, "Oh my God". Like, I was going through a stage where I had me telly on all day and all night, me radio on, do you know, constantly so there was noise. But then I kind of got more and more used to it as time went on, like.' [Lisa, age 20, Phase 3]

'Don't get me wrong. I was delighted that I got my own place, but where it is [remote suburb], the closest bus to town or [area where mother lives] is about a 20-minute walk, you know. The transport isn't great at all. That was the only thing ... I sort of felt that in a way I was sort of on me own a bit... It's a good trek down into town, you know that sort of way.' [Seán, age 26, Phase 3]

Having access to support and advice at the point of transitioning to independent living was important. For Lisa [age 20, Phase 3], aftercare support meant that she had someone to talk to if she had a problem: 'It's [aftercare support] been a great thing for me because you're not alone. You may feel alone, but if you have a problem, there's someone there to help you solve it.' Kemi [age 21, Phase 3] also drew attention to the importance of ongoing support following the move to independent living: 'She [social worker] knows everything ... they are always happy when I call them as well so they say if I have any problems, always get in touch.'

Young people who initially exited homelessness to living situations where they continued to have direct access to financial assistance as well as material and emotional support appeared to benefit from their stay in these settings. Those who initially exited homelessness in a dependent sense and later progressed to independent living had acquired skills that helped them to access and sustain housing, and they also appeared to have regained confidence and self-belief with the help of professionals in these settings. However, despite the supports offered to young people in State care or transitional settings, many found the transition to independent living challenging, highlighting the importance of 'housing support' (Jones and Pleace, 2010) following the move to self-contained, independent accommodation. 


\section{Financial challenges, instabilities and risks}

Irrespective of the route taken by young people out of homelessness, practically all found themselves dealing with some level of financial stress. By Phase 2 of the study, most had returned to education or training in the belief that this would bolster their chances of entering the labour market. Attending school or a training course also conferred feelings of achievement and self-worth. The accounts below demonstrate the value placed by young people on education.

'Once you have a goal, like, once you're doing something with yourself, like you're in school or college or work or whatever, then you're sorted like.' [Lisa, age 20, Phase 3]

'College has helped a lot in that, like, you know. If I hadn't of gone to college, I don't know where I'd be now. I don't think I'd be here sitting, talking to you anyway.' [Seán, age 26, Phase 3]

The challenges associated with entering the labour market particularly came to the fore at Phase 3 of the study, at which time 9 of the 15 who exited homelessness were not currently engaged in further education or training. Although practically all had completed an educational or training course at some point, only one was currently employed and the vast majority depended on social welfare payments. Apart from the challenges associated with surviving on a low income, young people often felt that, as recipients of social welfare payments, they were in the 'double bind'. Caroline explained that when she moved to private rental accommodation, following a temporary return to homelessness, she was forced to give up her job or otherwise face the prospect of losing her rent allowance and her home:

'I ended up giving up my job [after moving from homeless hostel to private rented accommodation] then because obviously having a home was more important than me working. But it is frustrating that I can't work; otherwise I lose me home, you know. There's no job I can work that will allow me to earn enough money to rent privately and there's no job that I can do that will allow me to earn without it affecting rent allowance.' [Caroline, age 21, Phase 3]

Lisa was one of only 5 young people participating in education or training at the time Phase 3 interviews were conducted. Like Caroline, she was critical of a system which she felt worked against young people who were trying to make their way:

'I really don't want to get into the system of social welfare because if you do that, you're stuck in a rut, you can't work. You can only work 20 hours a week and that's just brutal. That's the thing about this country. You either work or you don't. There's no other way about it, like. If you work, you don't get rent allowance, but if you don't work, you do. It's stupid ... And if you're in education, they give you nothing.' [Lisa, age 20, Phase 3]

Most of the young people had few economic opportunities and a considerable number were pessimistic about their short- or medium-term labour market prospects. Although all tried to budget as best they could, there were several examples of young people struggling to stay afloat:

'Like so I just spare it [money] out ... I'm able to manage like, I just spare out as I says. And I just get what I need and I don't go over-board. Once I have [baby's] food and nappies, then I'm happy like. I'll get [baby's] things in first and then ... whatever I have left, I get me own, I'll get me own stuff then, like, you know.' [Siobhan, age 27, Phase 3]

The experience of homelessness was fresh in the minds of a considerable number and several worried about being able to sustain their tenancies:

'I worry about not staying clean. Even though, like, I have no intentions. I suppose the homeless one would be a thing, as well. Because, like, I think sometimes, "Is something going to happen to fuck up getting your money and your allowance?", you know.

[Sarah, age 26, Phase 3]

'[I worry] ... just of ending up back on the streets again. That's all because of, now that you're on your own, it's not like before, it's not like you have anyone to help you, especially when you turn 21, like ... And if the social welfare basically deny ya [refuse application or payment], that means you have to go back into the hostels in town because you have to prove that you're homeless. And I don't think I'd be able to go through that again.' [Lisa, age 20, Phase 3] 
Economic marginality and unemployment make young people extremely vulnerable in the housing market (Rugg, 2010). Many of these young people had left compulsory education poorly qualified and, although most had returned to education or training over the course of the study, their accounts carried little sense of forward movement toward secure, rewarding employment. All hoped to gain employment in the future and saw employment as a means of stabilising their lives, in particular their accommodation. However, they were also acutely aware of the barriers they were likely to face in achieving this goal.

\section{The meaning of home}

As documented above, many who exited homelessness continued to struggle with longstanding issues in their lives and most were dealing with ongoing financial instabilities. Nonetheless, the move to stable housing - whether to the family home, transitional housing, State care or the private rental sector - emerged as a significant 'turning point' experience for all and one that also supported other positive life transitions. Perhaps more than anything, housing conferred a sense of security and safety. Being housed located young people physically and symbolically in the mainstream and was important in helping them to establish a routine. This was evident as young people began to turn their attention to schooling, work and reconnecting with former social networks. Young people also talked about embracing new responsibilities on accessing stable housing. For example, Emma had spent years alternating between sleeping rough, staying in hostels, living with family members or friends, and other tenuous living situations. She had moved into a house inherited by her partner a number of months prior to her Phase 3 interview. This was not her first exit from homelessness, but was the most stable housing situation she had accessed since we had first contact with her 6 years previously. The emphasis placed in her account on the sense of independence and responsibility that accompanied housing is significant:

"When we got the house to ourselves, we kind of changed it around and kinda said, "We have a house now, we could kind of do something with our life" ... And just kind of maturity like, you know. Kind of independent ... But just having the house there helped a lot ... We said, "Okay, we have to kind of cop on [be responsible] now"... Like, we're living in a house now and ... we have to kind of think of the house.' [Emma, age 22, Phase 3]

Later in the interview, Emma talked about her changed circumstances since the time of her Phase 2 interview. Her narrative particularly illuminates the transformative effects of housing, not simply on her drug use but also on the meanings she attached to 'home':

[And do you feel things have changed, say, since the last time I interviewed you?]

'Yeah, yeah. Probably back then, I probably wouldn't have thought twice about using heroin, you know. And a lot of things, I worry now like, you know, I make sure [pause] ... I don't ever want to see myself back homeless. When I look back at that it's like, it was an awful way of living, you know, compared to the way I'm living now ... I wouldn't like to be back in that situation. I want to keep me home, like keep it well, you know.' [Emma, age 22, Phase 3]

Stable housing conferred meanings that acted as significant enablers across a whole spectrum of daily life experiences. Melissa identified 'getting a flat' and 'getting clean' as the two most important developments since the time of her last interview. For Seán, having his own home was an important 'confidence booster':

'I've come a long way from where I was the last time I was talking to you so. I done up the apartment and then that was another sort of confidence booster that I was actually, I had somewhere I could call my own home like, you know.' [Seán, age 26, Phase 3]

Caroline similarly talked about the confidence she gained from her ability to 'run a home' and, like others, expressed pride in how she maintained her apartment and her tenancy. She also talked about not needing to rely on services and interventions, which she perceived as an additional significant marker of a 'new life': 
'I think I felt more confident, more confident in myself that I was able to do this, that I was able to run a home, that I was able to keep it clean, pay me bills, look after me daughter and not need that support [from service providers] ... that I didn't need people linking in all the time.' [Caroline, age 21, Phase 3]

It has been argued that, on becoming homeless, individuals experience the loss not simply of a place to live, but also of 'their self-identity, self-worth and self-efficacy' (Boydell et al, 2000, p. 26). In the present study, for those young people who exited homelessness, a stable place to live allowed them to reclaim ownership and control of matters far beyond the physical ramifications of having a home. Young people often talked about the sense of security, comfort and privacy that accompanied stable housing. Several also specifically mentioned the achievement of independence from services, institutions and agencies of the State.

[What would you say is the best thing that's going on for you at the moment?]

'Having this place, having me own independence and, eh, finally being out of care.' [Lisa, age 20, Phase 3]

Young people sometimes explained the importance of housing stability by contrasting their current living situations with their past experience of homelessness:

'Oh, I remember that [Out-of-Hours Service] very well. I hated that. Just going from one place to another, different people, ah no, I hated that. Oh, I thank God today I have my own home, my own family, like no, no. And I don't ever want to see somebody go through that. It's not nice, never, no.' [Kemi, age 21, Phase 3]

Support, security and emotional attachments are central to the meanings ascribed to the notion of 'home' (White, 2002). For many of the young people in this study, stable accommodation was also seen as 'a vehicle for gaining independence and an escape from negative pasts' (Brueckner et al, 2010, p. 8). Perhaps more than anything, the transition to more permanent accommodation was seen as moving into a place of their own and as a space where they could attempt to create a positive experience of 'home'.

\section{Summary}

The findings presented in this chapter demonstrate the highly differentiated nature of the exiting experience. Young people embarked on different routes out of homelessness and even those who followed the same broad housing trajectories related very different stories and experiences. Their journeys out of homelessness took different amounts of time and involved a range of housing and non-housing experiences. The findings also indicate that young people actively negotiated the route out of homelessness, albeit in different ways and with different results.

Access to affordable housing clearly plays a crucial role in young people's ability to exit homelessness and sustain housing. Speedy exits from homelessness are also critical. In general, those young people who had exited homelessness at Phase 2 of the study maintained this exit even if a number returned to homelessness temporarily during the intervening period. There were only 4 new exits from homelessness between Phases 2 and 3 of the study. All of these young people had lengthy homeless histories and it is significant that, despite having spent years alternating between emergency accommodation places, this smaller group of young people had achieved housing stability by Phase 3 of the study. Thus, even those young people with more protracted homeless histories can escape homelessness.

Gender is a striking feature of the exiting process: young women were far more likely than young men to have exited homelessness by Phases 2 and 3 of the study. The 'journeys' of a large number of young men who remained homeless are documented in detail in Chapter 5 . What seems clear, however, is that early dependent exit routes, via transitional accommodation or State care, were 
less available to young men. The reasons for this are undoubtedly complex, but the consequences were far-reaching in that many young men became entrapped within homeless and criminal justice systems and services, which ultimately served to diminish their capacity to secure and maintain stable housing (see Chapter 5).

The move from dependent to independent exits from homelessness emerged as a distinctive pathway out of homelessness. Transitional accommodation provided young people with an opportunity to strengthen their skills and to make a stepped transition to greater independence. Similarly, a stable care setting, accompanied by aftercare supports, appeared to enable young people to make a smoother transition to independent living. These findings point to a need to conceptualise supports or facilitators for homeless exits 'along a continuum, ranging from the provision of rentsubsidised accommodation at one end of the spectrum to intensive support services in transitional accommodation or State care at the other' (Mayock et al, 2011a, p. 823).

While young people can and do exit homelessness, the findings also confirm that homelessness does not necessarily end 'as soon as any type of dwelling is obtained' (Sosin et al, 1990, p. 171). A considerable number of young people experienced a return to homelessness following their initial exits and others reported periods of 'hidden' homelessness. The loss of housing was associated with a range of issues and events, but was usually the outcome of a combination of economic, social and personal circumstances. Young people's perspectives on their housing situations also influenced the course of their exit journeys; for example, a number expressed dissatisfaction with living situations which they felt were unsustainable (sometimes in the context of having returned to the family home) or substandard (primarily in the context of a move to private rented accommodation). Thus, returns to homelessness were often a consequence of their attempts 'to find improved living conditions' (May, 2000, p. 626).

At the level of structure, these problems draw attention to the impact on young people of the limited supply of, and access to, affordable housing. These problems suggest that unless there are changes to the supply of affordable housing, young people at the margins of the housing market will be frequently forced to accept substandard or inappropriate accommodation, a situation that makes them vulnerable to further episodes of homelessness. Young people's highly constrained opportunities for labour market participation also places them in a position of vulnerability, both in the short and medium term, and means that many are likely to face economic challenges in the future. Their opportunities for educational engagement appeared to diminish with the passing of time and, perhaps ironically, to an even greater extent from the point of securing stable housing. This finding signals a deficit in the supports offered to young people after the point of securing (more) stable housing, as well as strong barriers to young people's ability to move beyond the margins of the labour and housing markets.

The impact of the experience of homelessness on young people's well-being cannot be overstated and many found themselves struggling to escape vulnerability even after they exited homelessness. It certainly appeared that the memory and experience of homelessness loomed large in the minds of a considerable number, highlighting young people's need for ongoing support after they make the transition to stable accommodation. 


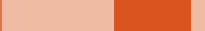




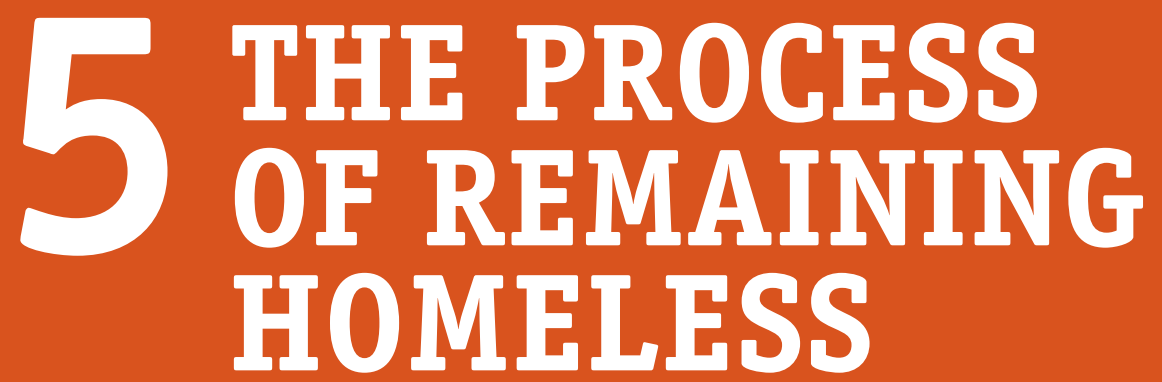


This chapter examines the experiences of the 13 young people who remained homeless at Phase 3 of the study. By this stage, this subgroup of participants had homeless histories of well in excess of 10 years, although some had exited temporarily for short periods. Here, a discussion of the transition from youth to adult homelessness is followed by an examination of a number of prominent features of their biographical accounts over the 3 phases of the study. The chapter concludes by questioning the extent to which the experiences of those who remained homeless amount to a process of 'acculturation' to street life, a commonly rehearsed explanation for longer term homelessness among both youth and adults. We rather suggest that their prolonged homelessness is better explained by a process of 'institutionalisation' which was set in motion relatively early in the lives of young men in particular. The 'institutional circuit' they embarked upon exacerbated their homelessness and simultaneously diminished their ability to secure and sustain housing.

\section{From youth to adult homelessness}

Of the 28 young people re-interviewed at Phase 3, just under half, or 13 young people (12 of them young men) remained homeless. In contrast to young people who had exited homelessness, their experiences signal strong barriers to housing stability, particularly as the duration of their homelessness progressed. At Phase 1, 8 of these young people had been living in an emergency/ short-term under-18s or adult hostel, 3 were in prison and 2 were sleeping rough. They continued to access the most unstable living situations by Phase 3 of the study: 5 young men were in prison, 4 young men were living on the streets, 2 (one male and one female) were living in B\&B accommodation and 2 young men were staying in adult hostels. Twelve had been homeless at the time of their last contact with the study, suggesting that the longer young people remained homeless, the less likely they were to achieve greater stability of housing. Perhaps significantly, 10 of the 13 who remained homeless had exited temporarily - usually only for short periods - over the course of the study. These patterns of exiting and returning to homelessness are discussed in greater detail below (see 'The process of remaining homeless'). The remainder of this section is concerned with documenting young people's 'journeys' from youth to adult homelessness.

In contrast to young people who had exited homelessness, those who remained homeless at Phase 3 of the study did not move to stable accommodation at an early juncture; instead, they embarked on a cycle of repeated entry to emergency or short-term hostels targeting the under-18s. A majority had accessed accommodation through the Out-of-Hours Service, typically between the ages of 13 and 17, and all reported constant movement between several emergency hostels based in the city centre. Adjusting to hostel life had been initially challenging as they tried to integrate and establish friendships in social spaces that fostered feelings of isolation and made them extremely vulnerable to victimisation. Several who were well acquainted with city-centre hostels claimed that bullying was pervasive in these contexts:

'The little kids who can't defend themselves, they're the ones that get bullied the most into doing things.' [Ronan, age 19, Phase 1]

'There's a lot of bullying, yeah, with little kids. Yeah, there is. Big people bullying little kids, there's a lot of it.' [Declan, age 19, Phase 1]

Some reflected on their early homeless experiences during later phases of the study, claiming that if they had not come to the city centre to access emergency under-18s accommodation, their lives would in all likelihood have taken a different course. Indeed, the move from their home neighbourhoods to the city centre to access emergency accommodation was depicted as a 'turning point' experience by a considerable number. Exacerbated by having to vacate hostels in the early morning, these young people were forced to spend their long days of unstructured time in very public settings where their risk of involvement in criminal activity and alcohol/drug use was high. Indeed, several linked their involvement in criminal activity to their exposure to street life. At Phase 2 of the study, Paul and Ronan described a daily routine that involved criminal activity and drug use: 
'In the hostels ... when you're going through the Out of Hours, you're out at 10 o'clock in the morning and you're not back in 'til 8, 9, 10 at night. So during the day, like, you just go into a shop and just rob the shop, you know. Rob the shop and then just, that'd be your food.' [Paul, age 21, Phase 2]

'It's, it's just the whole idea of being on the streets, like. I was going through it and was fucking robbin' everyone. Like, I was never strung out on gear [heroin] or anything like that, but I just robbed people, you know ... so you just end up robbing and getting yourself a charge sheet, locked up.' [Ronan, age 19, Phase 2]

The cycle of repeatedly accessing emergency hostel accommodation targeting the under-18s extended to the statutory age of adulthood for most who remained homeless: 'They took me out of an environment [hostel] that was ... unsafe and they ... put me into an environment [hostel] that was unsafe' [Christian, age 22, Phase 3]. Several noted the sudden withdrawal of support on reaching the age of 18 , at which point they faced the challenge of moving to adult services. Luke's account suggests a belief among young people that they had been abandoned at the age of 18:

'When you're living in placement when you're under 18, you should be shown a few things: what to cook, budgeting skills and shit like that. That's what I struggle with at the most, keeping me money ... They wash their hands of us when we're 18.' [Luke, age 19, Phase 2]

This feeling of abandonment is also evident in Fergal's reflections of having been 'dropped' by services at the age of 18 , with no option but to return 'to the street':

'Find out what the young person wants and what he needs and give him that. Don't just fuck him out to the street. Say, "There's nothing we can do for you" and close the door in your face, and it's up to you then to raise yourself.' [Fergal, age 23, Phase 3]

Emergency hostel accommodation, the services most frequently accessed by those who remained homeless, may well have provided young people with access to basic resources, but did not enable or empower them to move off the streets. On reaching the official age of adulthood (18 years), young people typically embarked on a cycle of movement through adult hostels, B\&B accommodation and other emergency or short-term sleeping places. Most also reported periods spent sleeping rough and squatting. By Phase 3 of the study, 11 had slept rough on many occasions (2 on a long-term basis) and 11 had accessed adult hostels or B\&B accommodation. Entry to adult hostels was a point of particular vulnerability for young people due in large part to the sense of despair many experienced at this juncture and the transition to adult homeless services was most often depicted as a crisis point.

'The Out-of-Hours has banned me. They said they didn't want me using the services so I had to go out to [adult hostel] and that's, that's like another leap. It's like the over-18 hostels, you know. It's a bit much fucking [pause] ... more like everybody is like a zombie in it, you know what I mean. They're there out of their heads asleep, you know.' [Brendan, age 18, Phase 2]

The move to adult hostels brought young people into daily contact with other drug users, cultivating an acceptance of 'hard' drug use and, for a number, marked the point of initiation to heroin use:

'That's when it all goes wrong. That's when it starts - smoking heroin, injecting it, taking coke, tablets, you know.' [Declan, age 26, Phase 3]

Declan described the experience of living in the hostels as 'getting [him] down' and, like others, he had opted at times to sleep on the streets or in squats in order to avoid these settings.

However, such strategies often exposed young people to further vulnerability and several recounted experiences of repeat victimisation in street-based settings. James (age 23, Phase 3 ) told that, on more than one occasion, individuals not known to him had tried to set fire to him and his brother while they slept on city-centre streets. Such experiences of victimisation led a number to draw on strategies of personal protection: 
'Trust me ... it'll get to you mentally. Like, I never slept out without a blade at night or a steel bar, a chain, a glass bottle, some form of weapon ... underneath me head, down me trousers, somewhere. Because you get people coming up, kicking you, hitting you, standing on you, eh, taking your cup off you and your bag, trying to set you on fire, trying to piss on you.' [Fergal, age 23, Phase 3]

All who remained homeless had transitioned to adult homelessness at the age of 18 years and most had spent the previous years commuting between hostels targeting the under-18s. By the time they entered adult homeless hostels, their journeys through homelessness were characterised by high levels of instability, with few having lived in one setting for more than a number of consecutive weeks or months. Compared to young people who exited homelessness, they were more socially isolated, had fewer protective resources and most also faced additional challenges related to their drug use and criminal activity.

\section{The process of remaining homeless}

The experiences of those who remained homeless signal strong obstacles to them accessing and sustaining housing and these barriers intensified as the duration of homelessness progressed. While young people's experiences of commuting between temporary living situations varied, as did the chronology of their movements, they nonetheless recounted a number of similar experiences. For example, a considerable number had exited homelessness temporarily over the course of the study, but failed to sustain these exits. All reported problematic or dependent drug use and a large number described a cycle of incarceration followed by another episode or prolonged period of homelessness. These dimensions of the process of remaining homeless are discussed in greater detail below.

\section{Temporary exits from homelessness}

As highlighted earlier, the experiences of young people who remained homeless at Phase 3 were defined by a cycle of movement between the most unstable of accommodation settings. However, 10 had attempted to exit homelessness, some on more than one occasion, over the course of the study. These young people moved temporarily to private rented accommodation, the family home or to semi-independent living situations and, in some cases, to a combination of these living situations. For a range of reasons, these moves out of homelessness proved unsustainable.

The stories of a number of young people who exited homelessness temporarily are presented below. These accounts help to illuminate the challenges faced by young people (young men in particular) with lengthy homeless histories in their efforts to access and maintain housing, particularly in the absence of reliable informal or formal support systems.

At Phase 2, Colm was living in private rented accommodation with his girlfriend and was categorised as having made an independent exit at that time. His was one of the more successful attempts at exiting homelessness among those who had remained homeless since he maintained this exit for a period of over one year. Nonetheless, at Phase 2 his account did suggest a number of potential threats to housing stability since he was dealing with a number of challenges, including the poor state of his accommodation, conflict with his landlord, low social support, financial instability and continued drug use. Things did initially improve for Colm after his Phase 2 interview and he and his girlfriend moved to new private rented accommodation that was in far better condition than their first flat. They also regained partial custody of their son. Colm's situation, however, was to change quickly when, failing to fulfil the requirements of the Drugs Court programme, he was detained in custody for one week. During that time, his relationship with his girlfriend broke down and he was unable to return to his private rented flat on release. He stayed with his brother for 2 weeks, but subsequently returned to adult hostels. Having secured a long-term residential hostel for 8 or 9 months, he lost this placement because of having to attend to a sick relative in England. On his return to Ireland, Colm had no option but to access emergency hostels. At the time of his Phase 3 interview, he was moving between adult hostels and the home of a friend, and using heroin on a daily basis. 
A number of other young men reported unsuccessful attempts at exiting homelessness in the company of a romantic partner. On release from prison, Luke had moved in with his girlfriend who was living in local authority housing with her two children. He explained that he 'wasn't ready' for this level of commitment following his release from prison and that his alcohol and drug use led to conflict with his girlfriend. He left this accommodation after a 6-month period and returned to adult hostels in the city centre before being re-incarcerated. At Phase 3, Luke was in prison and due for release within a number of months. He was uncertain about what the future held:

'Yeah, I wouldn't mind getting another chance. If I got another chance, and like I know what to watch out for this time ... And to try and make a bit of space, get me head ready for it.' [Luke, age 23, Phase 3]

Ronan had been incarcerated for most of the 3-year period spanning Phases 2 and 3 of the study. During one period of release, he initially moved into his sister's home, but left a short time later and moved to his 'own flat':

'I'd be just fighting with them [sister and partner], you know. They'd be trying to tell me to come home at a certain time and all and I'd be just clearing out, then eventually I just left, just left that house and stayed in my own flat.' [Ronan, age 23, Phase 3]

Ronan's 'own flat' was, in fact, his girlfriend's private rented accommodation. Within a matter of weeks, he returned to custody on serious assault and robbery charges and had been sentenced to 7 years in prison at the time of his Phase 3 interview.

Like Ronan, Brendan struggled to maintain stable accommodation following his release from prison and had been re-incarcerated by Phase 3. On his previous release from prison, he spent a brief period in adult hostels and rented a flat with his girlfriend some weeks later. Before long, however, they were struggling financially:

'She [landlady] never said anything about bills or anything like that. We thought that was all included and after being there a while, she was sticking electricity bills on a month or NTL bills like that. It was too dear for us. The two of us were on the dole like at the time. So it was too dear.' [Brendan, age 22, Phase 3]

Brendan and his girlfriend left this apartment and stayed temporarily with family members before he returned to homeless hostels in the city centre. His account describes his feelings of hopelessness at this juncture and also highlights his disillusionment with what had become a cycle of movement through unstable living situations:

'I didn't feel too good. It felt like the same shit, different day all over again, sick of it. Didn't feel good at all. It's a hopeless feeling in them hostels, the dirt of them, smell of them. It felt not good. Too young for all that.' [Brendan, age 22, Phase 3]

While these young men had attempted to exit homelessness in the company of a romantic partner, others moved to semi-independent accommodation or to the family home over the course of the study. The break-down of these living arrangements was often linked to young people's continued involvement in drug use or criminal activity. Both Christian and Fergal had secured a placement in semi-independent accommodation between their Phase 1 and Phase 2 interviews, but lost this accommodation because of breaches of rules related to the consumption of drugs on the premises. Both subsequently alternated between prison, the streets and homeless hostels.

Finally, Aoife, the only young woman who remained homeless by Phase 3 of the study, was living in a hostel when she first engaged with the study at Phase 1 (aged 19). A short time after this interview, an outreach worker had helped her to secure a bedsit, where she lived for a period of approximately 6 months. She left this accommodation and returned to her mother's home until she became pregnant and moved to a halting site with her partner, whom she said 'used to give me a hard time, used to beat me up'. Aoife's son was taken into care when he was 10 days old and she again returned to her mother's home, having separated from her boyfriend. She subsequently left home and moved into B\&B accommodation with her current partner. She was 3 months' pregnant 
at the time of her Phase 3 interview and had been released from prison, having served a 2-week sentence just one week earlier. Aged 24 years, she was anxious for 'someone to help [her] get more private accommodation'.

Those who had attempted to exit homelessness over the course of the study did so in the context of continued instability in their lives. This instability in many cases was linked to their continued drug use and involvement in criminal activity, but was also strongly associated with the time of release from prison. A number had tried to make a home with a romantic partner, but struggled with a range of personal and financial challenges. It is significant that these young people had few or no formal or informal supports to enable them to sustain an exit from homelessness. Their accounts further suggest that they were attempting to access and sustain housing in ways that made them vulnerable to further episodes of homelessness and incarceration.

\section{Drug and housing careers}

All who remained homeless by Phase 3 of the study had a history of 'heavy end' or dependent drug use. Although many had initiated drug use prior to becoming homeless, their drug consumption levels typically escalated during the period subsequent to leaving home, a development that was strongly related to their increased exposure to drug use on entering the official network of homeless youth. Drug use and drug transitions were implicated in their homeless 'careers' in two significant and interconnected ways: increased drug use was depicted by a majority as closely linked to their remaining in the most unstable accommodation types (e.g. hostels, sleeping rough, squatting) and, in turn, remaining in such accommodation acted as a strong barrier to successfully addressing their drug use. Moving between temporary living places brought these young people into contact with other drug users, creating contexts for easy access to drugs. The transition from under-18s to adult homeless hostels was a point of particular vulnerability, due largely to the sense of despair they experienced at this juncture.

Over time, the homeless experience altered young people's perceptions of the role and function of alcohol and drugs, paving the way for a greater acceptance of 'hard' drug use for some. Christian is one of a number who initiated heroin use between Phases 1 and 2 of the study, although he had expressed strong anti-heroin sentiments at the time of his baseline interview: 'I wouldn't do gear [heroin]. People have to have standards' [Christian, age 17, Phase 1]. He acknowledged his earlier anti-heroin sentiments during his Phase 2 interview and went on to explain that he 'got into a different scene' and 'became one of them' following his transition to adult homeless services:

'It's because I got into a different scene ... I moved into town to that place [adult hostel] and you start fuckin' seeing all the tablet heads [individuals taking prescription drugs], all the junkies all over the place ... I just became one of them ... and it was only a matter of months. But just before that, I wasn't into it. I hated it ... I thought it was all right to smoke hash, drink, take coke or whatever. But I just went into that [heroin] scene then.' [Christian, age 19, Phase 2]

Close proximity to other drug users within street and hostel settings often reinforced young people's commitment to drug scenes and this, coupled with easy access to drugs, allowed fledgling habits to become entrenched. Escalating drug consumption affected a range of areas of young people's lives, including their physical and mental health, and also negatively impacted their ability to maintain meaningful ties to society. Many living in these situations described their dependency on drugs and some, like Fergal (who had also initiated heroin use between Phases 1 and 2 of the study), had come to view drug use as necessary for survival:

'It's [heroin] a fuckin' horrible drug. I need it now to survive every day. I wouldn't be able to do other things. I need gear [heroin] to actually do what I have to do during the day.' [Fergal, age 19, Phase 2] 
Many had attempted to address the matter of their drug consumption and several had sought treatment at some time. However, their efforts to address drug abuse and/or dependence were constantly hampered by the absence of a stable place to live, rendering abstinence a constant struggle. Colm, for example, had engaged with drug treatment in an attempt to address his heroin use on a number of occasions, something he felt had been going 'really well' during a temporary exit from homelessness when he lived in private rented accommodation. On his return to adult hostels, however, he had resumed heroin use, albeit not to previous levels:

'They put people that were strung out to bits, using needles with the virus, and then they put like clean people in that's trying to get [clean] and then these people start, people that are on drugs or whatever, they start selling drugs and you're only after coming off them and the temptation is too much 'cos it's right there where you're living, like. It's in your sitting room literally, where you're getting your dinner and all, so it's hard, like.' [Colm, age 25, Phase 3]

Declan had also been trying to 'get sorted' and address his drug use, but his attempts had been severely hampered by living in adult hostels. He subsequently decided that leaving hostels and returning to the streets would better assist him in his attempts to remain drug-free:

'The reason I sort of left there [hostel] was I was trying to get myself sorted out and in the likes of them hostels, as you know like, there's people coming in, they're drinking, there's heroin there, there's tablets, everything all around you and I couldn't stay in them places because, like, it was getting me down, you know, really, really down.' [Declan, age 26, Phase 3]

Consistent with other research, a link between prolonged homelessness and drug use is apparent (Allgood and Warren, 2003; Tyler and Johnson, 2006). Nonetheless, the relationship between homelessness and drug use is extremely complex (Doherty and Stuttaford, 2007; Neale, 2001). The findings documented here strongly suggest that prolonged homelessness placed young people in contexts where drugs were easily available and in constant use (Mayock and Corr, 2012). Furthermore, all who remained homeless reported increased levels of consumption as their 'careers' in homelessness progressed. The 'double jeopardy' (Neale, 2001) of homelessness and drug use was strongly apparent in their attempts to curb or abstain from use, an endeavour that was significantly hampered by the absence of a stable home.

\section{Crime and incarceration}

In general, young people who were homeless at Phase 3 reported far more persistent criminal involvement and sustained criminal justice contact than those who had exited homelessness. All 13 of those who remained homeless at Phase 3 had a criminal history, 11 had engaged in significant levels of offending throughout their homeless 'careers' and most had been convicted of one or a number of the following crimes: criminal damage, trespassing, shoplifting, theft, dealing and possession of drugs, or assault. Twelve (11 males and 1 female) of the 13 had been incarcerated at some stage and 5 (all male) were in prison at the time of their Phase 3 interviews. Two with a history of incarceration had been detained for relatively short periods, but most had been in prison on multiple occasions. As their criminal careers progressed, many had also received longer sentences, with 8 having served sentences of 2 years or more. Repeat periods of incarceration, followed by returns to homelessness, were a strong feature of this cycle, a pattern which started at a young age for a number.

Christian, who had spent time in a children's detention school during his early teenage years, explained the frequency with which he was arrested and 'locked up':

'I fuckin' couldn't stay out of there [prison]. Every time I got out of there, in a couple of days I'd get arrested on the street, fuck sake, and back inside. Every time I walk down the street ... I was getting fuckin' locked up ... I was getting locked up for everything. They just wanted to get me off the street for as long as possible.' [Christian, age 19, Phase 2] 
By his Phase 3 interview, Christian summed up the period since his previous interview as years spent

'in and out, you know ... just prison' and recounted a cycle of homelessness and incarceration:

'I ended up starting to slip [after period in drug treatment], went into full relapse after about 4 months and, eh, then I was homeless. Then I was locked up ... Yeah, I was in prison and, eh, that was really it. Now it's back to square one.' [Christian, age 22, Phase 3]

Fergal, too, reported several periods of incarceration since his previous interview 3 years earlier: 'I just, I've been locked up an awful lot since then [Phase 2 interview]. About 16 times since I last seen you. You know, Cloverhill, St. Pat's, Mountjoy, Wheatfield. Yeah, that's it. And the Midlands one ...' [Fergal, age 23, Phase 3]

Some who had spent several periods in prison appeared to have grown accustomed to this cycle and had come to view prison as an alternative place to stay. Indeed, time spent in prison was sometimes depicted in a positive light, perhaps reflecting the harsh reality of life 'outside':

'Just like, I was going through and I was floating in and out of hostels and I hadn't really got a proper place to stay. There was a telly in there [prison] in the bedroom, meals and the people that were in the cell were fuckin' bang on, sound ... Like, don't get me wrong now, I wasn't having the time of me life in there, but it's not as bad as I thought it would have been.' [Luke, age 19, Phase 2]

A number of young people linked the cycle of incarceration directly to their homelessness, explaining that their criminal activity was motivated by a need 'to survive'. Paul felt strongly that his move into the city centre to access homeless services marked his initiation into more serious criminal activity:

'If I didn't come into town, I wouldn't be here [prison]. I know I wouldn't ... Out there [home neighbourhood], like, I'd probably could have a robbed car charge ... instead, but I wouldn't, I wouldn't be having, you know, the serious bad assault and all. I wouldn't say so in any way. Just in town, it's much different, it's totally different than the suburbs and then you come into the city like, it's much different.' [Paul, age 21, Phase 2]

While young people sometimes claimed that their continued homelessness at least partly explained their involvement in criminal activity, their accounts equally suggest that incarceration served to maintain and exacerbate their homelessness. When incarceration was repeated and/or interrupted young people's attempts to exit homelessness, the challenge of resettlement was particularly acute. As documented earlier, young people did make temporary exits from homelessness and, for some, periods of incarceration were strongly implicated in the failure of these attempts, often leading to the loss of accommodation. Over time, and particularly for those who moved in and out of prison repeatedly, family and other social supports dwindled. The absence of support from within the criminal justice system, both prior and subsequent to release, also exacerbated the challenge of resettlement and young people often felt that they were 'getting out' only to repeat the same cycle.

'When you get out, you're after having a bad life and then you're in there. Go in, do a sentence, you come out, off the drugs and all. You have your weight on. You're getting out to the streets again ... You're not getting out to anything. They're not like letting me out into a flat, letting me out in a different area. They're letting you stray back out of the gate and fuck off after that ... Come back to the streets and drugs.' [Fergal, age 23, Phase 3].

Brendan highlighted the practical difficulties of leaving prison and had found support in a local drop-in homeless service with which he had established a relationship over the years:

'When I got out, I had to go to [adult homeless services]. They [service provider] were holding the money. I hadn't got a bank account, so they would hold my money for me.' [Brendan, age 22, Phase 3].

Although an important support for Brendan, this connection with a trusted service provider only enabled him to access hostel accommodation in the city centre: 'I stayed in one of their places ... big hostel, just a big building really ... for a couple of weeks'. This return to hostel life did not lead 
to stable housing and merely served as a reminder of the years he had spent in precarious living situations: 'I don't like anywhere in town anymore. I hate the place with a passion. It's done no good for me over the years' [Brendan, age 22, Phase 3]. Brendan's continued search for a place to stay quickly led to trespassing charges, which reactivated his otherwise suspended sentence; he was back in prison at the time of his Phase 3 interview.

Paul, who was serving a long sentence, also highlighted the lack of support on leaving prison: 'The longer sentence you're doing, yeah, the less they give you. Like, the less they help you, it seems'. Aware that he would be unable to return to his mother's home at the time of his expected release date, he worried about how he would secure a place to live at that juncture:

'Yeah, well, I know I have a bit long left, but ... I'll be getting out like. I won't be using, you know, my ma's address ... I'm going to have to get my own flat when I get out and all so. Like the worse thing they can do is just fuck me out onto the streets when my release date starts ... That worries me more than anything else about getting fucked out.' [Paul, age 24, Phase 3]

There was a strong sense that many of the young men had entered into a cycle that was increasingly difficult to break. The relationship between homelessness and experiences of offending or criminal justice involvement is well established in Europe (Dyb, 2009; Hickey, 2002), North America (Metraux and Culhane, 2004; Shlay and Rossi, 1992) and Australia (Baldry et al, 2006). It is also well documented in studies of homeless populations of adults (Shlay and Rossi, 1992) and youth (Hagan and McCarthy, 1997; Baron, 2003 and 2006). Indeed, incarceration has been described as a 'major gateway' to homelessness (Dyb, 2009), although the direction of the relationship between homelessness and incarceration is far from a settled question. The findings of the present study suggest a complex pattern of interaction between homelessness, offending and incarceration, although there is strong evidence to suggest that criminal justice contact - and incarceration in particular - served to maintain young people's 'careers' in homelessness. Rather like the homeless men in Gowan's (2002, p. 525) ethnographic study, 'once they were trapped within the cycle, causality moved both ways with equal strength, as men shuffled backwards and forwards between the prison and the street, between punishment and abandonment by the wider society'.

\section{Acculturation or institutionalisation?}

The vast majority of young people who remained homeless had left school early, they had only sporadic contact with family members and their social connections outside of hostel and streetbased settings were tenuous at best. The instability of daily life made job-seeking challenging and, in general, the notion of labour market participation was perceived as out of reach. This was increasingly the case with the passing of time and as drug use and related activity came to dominate a routine of 'getting by'. The experiences and transitions documented above may well be suggestive of young people's growing involvement in street life and it could be posited that many were immersed in a homeless and drugs lifestyle based on an assessment of their daily routines and perceived needs. However, being homeless was not something that young people accepted and practically all expressed a desire for their lives to take a different direction.

'Being homeless is shit. Walking around the streets, having nothing to do all day is shit. You should be up doing a course or something. Something. Sit out of the cold, you know what I mean ... Just life at the moment for me is shit.' [Tony, age 28, Phase 3]

The acculturation thesis suggests that individuals develop a growing sense of 'belonging' to a homeless subculture as their 'careers' in homelessness progress. Central to the acculturation thesis also referred to as the cultural identification thesis (Westerfelt, 1990; Piliavin et al, 1996) - is the notion that a longer duration of homelessness supports individuals' adaptation to and acceptance of homelessness as a 'way of life'. Research has highlighted the increasingly complex needs of young people who remain homeless, with the chronically homeless presenting the most challenging needs due to their participation in, and attachment to, a 'homeless subculture'. Chronic homelessness, 
according to Chamberlain and MacKenzie (1994, p. 8), 'denotes the adaption of young people into a subculture where homelessness has become a "way of life" '.

In the present study, while most who remained homeless had lost contact with friends in their home neighbourhoods, they had not, on the whole, established meaningful ties with other homeless youth. Indeed, they most often described those with whom they socialised as 'associates' rather than friends and were generally distrustful of other residents of the hostels they frequented: ' $I$ wouldn't call them mates' [Brendan, age 17, Phase 1]. Many, like Ronan and Fergal, were sceptical about trusting others and their social networks rarely conferred a sense of loyalty, trust or security: 'You've no one to trust. I don't trust anyone. They'd rob you blind they would... Take the clothes off your back, they would.' [Ronan, age 19, Phase 2]

'I wouldn't really hang around ... they're just associates.' [Fergal, age 19, Phase 2]

Young people's narratives also point to a longing to resolve their homelessness and drug use problems rather than to an acceptance of their situations: 'I'd just love to get off the streets, that's being honest. That's all I want is to get off the streets' [Gavin, age 20, Phase 3]. All who remained homeless, in fact, expressed a desire to exit street life and they frequently articulated ways in which they hoped this might be achieved in the future. For example, Fergal, who had a lengthy homeless history and was living in $B \& B$ accommodation at the time of his Phase 3 interview, told of having a number of criminal charges, which he expected to be 'dealt with' by the Courts in the not-so-distant future. He expected to be able to avail of a detoxification programme following his incarceration, an outcome he viewed as somewhat inevitable. This, he hoped, would help to break what he described as a 'cycle' of accessing homeless hostel accommodation:

'I'll end up getting me [criminal] charges dealt with; get me 16-day detox; then when I'm in there [prison], get off the drugs and then head down to me brother's [home] ... instead of being locked up for the rest of me life like everyone fucking else in here [in the B\&B].' [Fergal, age 23, Phase 3]

Although consecutive years without stable housing, as well as failed attempts at exiting homelessness, have seriously compromised these young people's futures, they continued to aspire to changing their lives and to the achievement of quite conventional goals, including stable housing. Aspirations to 'settle down' [Ronan, age 19, Phase 2], have 'my kids, job, my own place' [Declan, age 26, Phase 3] and 'have a normal life' [Christian, age 19, Phase 3] were commonly expressed and point to a rejection, rather than an acceptance, of membership of a homeless subculture. James [age 23, Phase 3], who had not accessed stable housing since he first experienced homelessness at the age of 15 , aspired to a life off the streets, including marriage, children and 'a proper' place to stay. A similar desire to make a break from what had become a continuous cycle of accessing emergency accommodation was expressed by Colm, who had returned to homelessness from private rented accommodation by Phase 3. Living between hostels at that time, and having re-engaged with a drug treatment programme, Colm was focused on trying to resolve his difficulties by decreasing his methadone intake and accessing independent accommodation:

'Just getting myself sorted out. I want to get off the methadone ... and get off it altogether and just get, hopefully get, a private rented gaff [flat or house]. Or if I could get a corporation gaff [local authority housing], that would be even better, and get me kid back eventually. I know it will take a couple of years, but I believe I'll get there - I'll do what it takes.' [Colm, age 25, Phase 3]

Those who remained homeless had spent up to or exceeding a decade, in many cases, without a stable place to live and some had embarked on this circuit at a young age, with histories of State care and/or detention as children. Ronan explained that he was 'locked up' for most of his teenage years:

'Me ma got cancer and she died from it, so we all got put into foster families... This is my family, other people are different ... But that was it and I went through voluntary care homes, about 12 foster homes I went through ... that was 8 years ago ... Yeah, about 12 different houses, yeah. Then I was put in [remand \& assessment unit] for 6 months when I was only 12 or something. I was locked up for most of ... me teenage years.' [Ronan, age 17, Phase 1] 
Five of the 13 who remained homeless had histories of State care and 4 reported a period spent in a children detention school. Six in total, all young men, had spent a period as children in either State care or detention. From such early experiences, they entered into multiple systems of intervention, thus 'extending the institutional apparatus that had largely defined their life to date' (Hopper et al, 1997, p. 662). Paul's account below illustrates the frequency with which he moved between under-18s and adult hostels over a period of just one year between his Phase 1 and 2 interviews:

'[Hostel 1] was the first hostel I was in. I was in there again [later] you know, but in between the hostels, I was in the Out-of-Hours. 'Cos, like, you get fucked out and then you have to go through the Out-of-Hours again. So [Hostel 1] for 5 months and then back through the Out-of-Hours for a few months and then I got back into [Hostel 1] again. And I was only in there for 2 months that time and back through the Out-of-Hours again. Then after that to [Hostel 2]. I was in there 3 times. I lived there 3 times and then, em, going through [Hostel 3] as well. That's it, that's about it. And then I turned 18 and started using [adult hostel].' [Paul, age 21, Phase 2]

For some, this constant movement between services marked a 'life cycle' that became increasingly difficult to break.

'Why is this a life cycle for me? Why is it the life cycle for all of us? I'm going to have to do different things to break that life cycle, no one else. I know it's a life cycle.'

[Fergal, age 23, Phase 3]

Rather than a process of 'acculturation' to a homeless lifestyle, the experiences of those who remained homeless are better characterised as an 'institutional circuit', defined by 'sequential stints in a series of institutions in place of a stable living situation' (Metraux and Culhane, 2006, p. 505). From an early age, they had constantly moved between unstable living situations, punctuated by only short periods in more stable environments. They transitioned from youth to adult homeless services and, as time progressed, periods of incarceration were the only 'interruption' to their stays in homeless hostels. A process of acculturation, where evidence of this pattern of habituation did emerge, can be primarily attributed to the failure of services to meet young people's housing needs at an early juncture (Mayock et al, 2013).

\section{Summary}

Young people who remained homeless at Phase 3 were primarily young men who had long histories of homelessness, marked by an absence of sustainable exit routes. In contrast to those who had exited homelessness, they did not move to stable accommodation at an early juncture and their ability to exit and sustain tenancies became more challenging as time progressed. Their early homeless 'careers' were characterised by a cycle of constant movement between the most unstable types of accommodation, a pattern which extended beyond the age of 18 years when they transitioned to adult homeless services. As the duration of their homelessness progressed, most became further entrenched in drug use and criminal activity, and practically all had spent one or more periods in prison. Their marginal economic and social status, as well as the very public nature of their daily lives, made them susceptible to arrest and (re)incarceration (Snow et al, 1989). Several had attempted to exit homelessness, often to private rented accommodation, but were unable to sustain these tenancies. They had often attempted to access housing at a critical juncture - on release from prison or at the point of completing a residential drug treatment programme - in the context of very limited material and social support. It is significant that these young people did not accept homelessness as 'a way of life', as acculturation accounts of prolonged or chronic homelessness suggest; rather, they aspired to conventional goals - a job, a relationship, children and stable housing. 


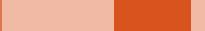


6 KEY MESSAGES 
As outlined in Chapter 2, this longitudinal study set out to examine the experiences of homeless young people over time. A core aim was to examine temporal change in young people's living situations and to identify their pathways into, through and out of homelessness. The generalisibility of the findings is clearly constrained by the small sample size. However, this research was primarily concerned with uncovering processes, contexts and meanings associated with the homeless and housing trajectories of young people. The study has enabled a perspective that foregrounds transition and change, thus circumventing the weaknesses associated with point-in-time analyses and offering a relatively rare insight into the dynamic nature of homeless experiences among the young.

The findings documented in this report have focused primarily on the processes associated with young people exiting and remaining homeless. As a consequence, it does not claim to provide a full account of the lives and experiences of the study's young people; rather, the emphasis has been on seeking to unravel the complexities of young people's homeless and housing pathways over the 6 -year period of the study. This final chapter discusses five issues that are central to understanding the dynamics of the homeless and housing pathways of young people:

- the importance of speedy exits from homelessness;

- the transition from the child welfare system to adult services;

- exiting homelessness: an incremental process;

- the 'institutional circuit' and the process of remaining homeless;

- facilitators and barriers to housing stability.

The report concludes by outlining several key messages for policy arising from the study's findings.

\section{The importance of speedy exits from homelessness}

The processes associated with exiting or remaining homeless were set in motion early in young people's homeless 'careers'. A large number of those who had exited at Phase 3 of the study had already done so by Phase 2. Those, on the other hand, who remained homeless embarked on a cycle of movement between emergency hostels targeting the under-18s and, on reaching the age of 18, most transitioned to adult homeless services. While some of the latter group did exit temporarily over the course of the study, they all subsequently returned to homelessness. These patterns point to the importance of speedy exits from homelessness: the earlier young people 'get out' of homelessness, the more likely they are to 'stay out'. What certainly seems clear is that those young people who commuted between emergency Out-of-Hours Service hostel accommodation were far more likely to remain homeless than those who attained relative housing stability at an earlier juncture. They were also more likely to enter adult hostels, a transition which further diminished their stake in society as well as the likelihood of their exiting homelessness.

Those young people whose homelessness extended beyond the age of 18 years invariably talked about the transience of their lives, as well as the difficulties they experienced in maintaining meaningful ties with family and community. Indeed, the relationships they forged in hostel settings pushed them towards activities that served to further alienate them from mainstream society as they became further entrenched in drug use and criminal activity. In contrast, young people who moved out of hostel settings to more stable living situations at an early juncture began to re-engage with education and reconnect with family members and former social networks. Several who reported a drug problem also enrolled in a drug treatment programme and a stable place to live greatly assisted their efforts to reduce their drug consumption or remain abstinent. Young people's engagement with drug treatment coincided with, rather than preceded, their move to stable housing so that abstinence was not a prerequisite to housing stability.

These findings strongly suggest that the duration of young people's homelessness significantly impacts the transition to stable housing. In keeping with research on homeless adults, the provision of affordable accommodation and/or financial assistance towards housing costs emerged as a significant determinant of the duration of young people's homelessness and the likelihood of their 
exiting (Piliavin et al, 1993). It is widely acknowledged that people should spend the shortest time possible in temporary or emergency accommodation before accessing more permanent housing (Quilgars et al, 2008). This study's findings highlight significant barriers to housing stability, particularly for young men who had spent years navigating a system of emergency provision.

\section{The transition from the child welfare system to adult services}

In keeping with the findings of previous research, the transition from youth to adult homeless services emerged as a point of entry to the adult homeless population (MacKenzie and Chamberlain, 2003). Indeed, this study's findings point strongly to the transition from child welfare to adult homeless services as one of the most significant contributors to ongoing or prolonged homelessness among young people. A large number of young people depicted this transition as a 'turning point' experience in the negative sense of it constituting a crisis. Disillusionment and despair were the emotions most frequently articulated by those young people who 'graduated' from under-18s to adult hostel settings. On entering the adult system of intervention, young people's situations generally deteriorated as daily life became even more unpredictable and they perceived their housing options as progressively narrowing.

It is perhaps important to reiterate some of the observations made in Chapter 1 concerning the definition of youth homelessness in the Irish context. The Youth Homelessness Strategy (Department of Health and Children, 2001) did not provide a clear definition of 'youth' and, in the main, speaks of children and young people under the age of 18 years in terms of the policy and service responses and actions it outlines. This situation implicitly suggests that those over the age of 18 years are 'adult' homeless, a distinction which does not reflect the reality of the lives and experiences of homeless young people and the fact that housing instability is likely to be an ongoing challenge for many who experience homelessness as teenagers. The barriers to housing stability faced by young people who transitioned to adult homeless services are well documented in this report, as are the harmful consequences of their entry to the adult system of intervention. As noted in previous publications arising from Phases 1 and 2 of this research (Mayock et al, 2008 and 2013), the point of transition between child and adult homeless services requires urgent attention and far more fluid systems of intervention are needed to accommodate homeless young people up to their mid-20s. Such a system must include sustainable housing solutions aimed at supporting young people to make the transition from emergency hostels to stable accommodation at the earliest possible juncture. A priority must be 'to minimise the length of time spent homeless to an absolute minimum and ensure rapid and appropriate move-on' (Quilgars et al, 2011, p. 34).

\section{Exiting homelessness: An incremental process}

Young people's exit routes from homelessness were diverse; they varied in duration, involved a range of housing and non-housing transitions, and were patterned in complex ways. The housing transitions associated with young people's 'journeys' out of homelessness also differed. For example, some had exited independently (most often to the family home) at Phase 2 and sustained this exit by Phase 3, while others initially exited to transitional housing or State care and subsequently moved to an independent living situation, most often in the private rental sector. A smaller number had exited more recently, following a more lengthy period of movement between under-18s and adult homeless hostels.

Irrespective of the route taken by young people out of homelessness, a large number reported movement between living situations - and sometimes a return to homelessness - over the course of their exiting journeys. Some experienced setbacks of various kinds, whether related to losing accommodation or having to move because of unforeseen developments or events. Thus, the exiting process was an incremental one, characterised by transition and change as young people adjusted to being housed and attempted to make a 'new life'. Nonetheless, a large number had sustained 
an exit from homelessness between Phases 2 and 3 of the study and they demonstrated enormous determination to maintain their living situations. The transition to stable housing was facilitated by a number of developments, all of which accompanied, rather than preceded, the move to stable housing. For example, the vast majority returned to education or a training course and all talked about the need to distance themselves from street 'scenes'. Family support was a significant enabler to their exiting homelessness (Mayock et al, 2011b and 2012). Most had re-established connections with family members and were in regular contact with a parent(s) and siblings by Phase 3 of the study. Contact with family was an important source of material and emotional support, irrespective of the housing situations of young people at various junctures. Those who moved home clearly benefited from the support of family members. Equally, however, young people who initially exited homelessness in a dependent sense (to transitional housing or State care) valued contact with a parent(s) and their siblings, and most had attempted to rebuild family relationships, even if they recognised that living at home was not a realistic or desirable option. Finally, for a number, engagement with a drug treatment programme was an important facilitator to exiting homelessness and sustaining housing. Importantly, these young people were not required to be drug- or alcoholfree in order to access housing; rather, housing enabled them to engage with drug/alcohol treatment and maintain a regime of abstinence (Mayock and Corr, 2012).

The incremental nature of exiting homelessness was perhaps most apparent among those who moved from a dependent to an independent exit over the course of the study. These young people initially moved to transitional housing or a State care setting and, subsequently, to private rental accommodation. Young people appeared to benefit from this sequence of movement in that it helped them to access the resources and skills to bridge the gap between street and settled accommodation (Kresky-Wolff et al, 2010). It also provided them with a secure setting from which to connect with other services and re-engage with education or training. At the time young people moved to transitional housing or State care, all were at an age (16-20 years) when the move to private rental accommodation may not have been a realistic option given their far more restricted access to welfare and housing support and their complex needs. It is recognised that young people in this age range are highly susceptible to 'hidden' homelessness and to 'drift' within the emergency hostel system, patterns of movement that make them vulnerable to prolonged homelessness (FEANTSA, 2010; Mayock et al, 2008 and 2013).

While 'stepped' or staircase approaches to housing homeless people ${ }^{11}$ have been subjected to strong and, in some cases, severe criticism in recent years (e.g. Sahlin, 2005; Hansen Lofstrand, 2010), there is general consensus in the UK that transitional models are often appropriate for young people (Quilgars et al, 2008). This, according to Quilgars et al (2008, p. 113) is 'particularly the case for 16-18-year old (and sometimes older) young people who often need a supportive environment for a significant period of time before moving to independent living'. Since many homeless young people may lack the knowledge and experience required to manage a tenancy, they can benefit from training and support that helps them to re-establish the skills they need to live independently, sustain a tenancy, and settle into their community (Jones et al, 2001). It appears that transitional or linear models remain important for young people, a finding which also has implications for how the parameters of youth homelessness is understood and defined. According to Quilgars et al (2011, p. 32):

'... as youth is a transitional mobile stage in most people's lives, transitional or linear models remain important for this group, and an emphasis on immediate access to independent, permanent housing is not as relevant as it is with older homeless people. This

\footnotetext{
${ }^{11}$ Continuum of care or staircase models of housing homeless people, which involve progressing them through a series of residential services (typically, from emergency hostels to transitional/supportive housing and then towards independent living), have been subject to strong criticism in recent years due in large part to emerging evidence of far better housing outcomes associated with 'Housing First' models (Atherton and McNaughton-Nicholls, 2008; Stefancic and Tsemberis, 2007; Tsemberis et al, 2004; Culhane and Metraux, 2008). Housing First models essentially 'bypass' the transitional phases of staircase models and place the most vulnerable homeless people directly into permanent, independent tenancies with support. The Housing First approach 'does not attempt to "fix" clients to make them "housing ready", but rather is premised on the assumption that the best place to prepare for independent living is in independent accommodation' (Johnsen and Teixeira, 2010, p. 6).
} 
may then impact on the types of accommodation one would view as constituting "homeless accommodation" for young people, possibly implying a distinction between older and younger people with respect to definitions of homelessness.'

While the 'strategic "tiering" of support makes sense theoretically' (Quilgars et al, 2008, p. 78), it is nonetheless important that stays in transitional accommodation do not become overly prolonged. A number of young people in this study who moved from transitional to independent accommodation experienced difficulty in adjusting to life in private rented accommodation, often because they had become accustomed to living in communal settings and/or because they found it difficult to cope with the responsibility of living alone without formal support. This finding highlights the need for appropriate 'move-out' supports for young people both during and after the transition to independent housing. The transition to independent living is recognised as a juncture at which people are vulnerable to homelessness. As noted by FEANTSA (2010, p. 14), '[n]o young person should be made homeless because of a lack of first-time housing options, services or entitlement to benefits during the transition to independent living'.

There is a strong likelihood that young people will experience movement, instability and, possibly, the loss of accommodation following the initial move out of homelessness (Johnson, 2006). Furthermore, when young people first exit homelessness, they may go through a number of temporary and unstable moves and it is this feature of their housing pathways that makes them susceptible to a return to homelessness. As documented in Chapter 4, a considerable number of young people experienced a return to 'official' or 'hidden' homelessness following their initial exit. Although all subsequently returned to stable housing, these experiences nonetheless highlight their vulnerability in the housing market and the susceptibility of at least some to further episodes of homelessness. Young people with a history of homelessness are likely to experience difficulties sustaining their tenancies (Clapham et al, 2012). Abilities to sustain tenancies were affected by high costs and expenses, too little support, loneliness and a lack of independent living skills. There was also evidence that young people's lack of experience in the private rental sector led them to encounter difficulties in accessing and choosing accommodation that was appropriate for them. For many, affordable housing options were highly constrained.

Most who exited homelessness reported financial strain and a considerable number struggled to make ends meet. The vast majority who had moved to stable housing by Phase 3 were dependent on social welfare payments and their employment prospects were highly restricted, although most had returned to education or training over the course of the study. Insisting that they did not want to remain reliant on social welfare payments, a number expressed frustration about their situations and the fact that they could 'not afford' to work because of the risk of losing welfare allowances and, possibly, their homes. The risk of a poverty trap and/or long-term benefit dependency, therefore, seems high for a considerable number who had exited homelessness. Several studies have highlighted the problems single homeless people face in securing employment (Communities Scotland, 2004; Jones and Pleace, 2010; St. Mungo's, 2010). Without the sense of purpose and the clear structure and goals that accompany paid work, young people may continue to experience social isolation and low self-worth, a situation referred to elsewhere as 'day time homelessness' (Jones and Pleace, 2010) to describe circumstances in which people continue to experience many of the effects associated with their previous homelessness, despite being housed. It is critical that young people are supported to continue to develop skills, attain qualifications and remain involved in activities that can lead to employment, both before and after they make the transition to independent living situations.

Despite the challenges faced by many who exited homelessness, the importance of stable housing cannot be overstated. Housing conferred a sense of safety and security; it located young people physically and symbolically in the mainstream of society and was critical in enabling them to establish a routine. A stable place to live also enabled young people to address long-standing issues and problems, including heavy or dependent drug use in some cases, in a safe and secure setting. In summary, more permanent accommodation enabled young people to shift from their categorisation as 'other' and 'homeless', make sense of traumatic pasts, begin to make connections, become at-home and make decisions about the future (Manzo, 2003; Robinson, 2002; Stephen, 2000). 


\section{The "institutional circuit' and the process of remaining homeless}

Those young people who remained homeless by Phase 3 of the study were primarily young men who had first experienced homelessness during their early or mid-teenage years. Young men were far less likely than their female counterparts to exit homelessness at an early juncture and, by Phase 3 , most had spent in excess of 10 years commuting between unstable living situations punctuated only by short periods in more stable accommodation. A majority reported that their drug/alcohol use had long since escalated to problematic levels, most had served more than one prison sentence and all had low education attainment with little prospect of entering the labour market. To a considerable extent, the findings documented in Chapter 5 confirm those of earlier studies, which have identified a link between sustained homelessness and substance misuse (Tyler and Johnson, 2006), histories of incarceration (Caton et al, 2005; Dyb, 2009) and poor educational achievement (Shelton et al, 2009). However, this study's longitudinal design has permitted an exploration of the processes associated with prolonged or chronic homelessness among young people. Time, duration and the ability to identify the chronology of housing and non-housing events associated with continued housing instability has produced a complex and multifaceted account of some young people's unresolved homelessness, particularly young men.

Perhaps most importantly, these young people's homelessness was not resolved at an early juncture; indeed, they typically embarked on a process of 'drift', initially through services targeting the under$18 \mathrm{~s}$ and later within adult systems of intervention. Their homelessness was interrupted by periods of more stable accommodation, but these exits from homelessness were usually maintained for only relatively short periods of time. The vast majority had left school early and, as time progressed, many had only sporadic contact with family members. Thus, those supportive mechanisms demonstrated to facilitate an exit from homelessness - including family support and participation in education - were largely absent. It is also significant that their contact with services was primarily linked to their need for shelter, food and clothing. In other words, their service engagement was crisis-driven and service responses appeared to be directed at resolving their immediate needs, rather than those of the medium or longer term. While these emergency responses provided young people with access to basic resources, they did not enable or empower them to move off the streets. Young people had a strong awareness of the chronology of events and experiences associated with their current situations; many claimed to have been 'dropped' by the system at the age of 18, while others emphasized the damaging consequences of the cycle of hostel use, a path which had pushed them towards more entrenched drug use and criminal involvement. Like the long-term homeless in the study by May (2000, p. 623), practically all 'had serious and sometimes multiple vulnerabilities', including problematic or dependent drug or alcohol use. Nonetheless, it is noteworthy that the private rental sector was an important feature of these young people's homeless 'careers', perhaps complicating our understanding of long-term homelessness. Young people entered into private rental accommodation at different junctures, some on more than one occasion, but were unable to sustain these exits from homelessness. It was at these points in an already highly irregular accommodation biography that they fell back into homelessness. Thus, the accommodation options available to young men in particular at a number of critical junctures appeared to 'place them at considerable, and repeated, risk of becoming homeless' (ibid, p. 626).

Constant movement between temporary accommodation places and incarceration were two experiences shared by a large number of those who remained homeless. On release from prison or detention, many returned to the streets where they were susceptible to re-arrest and reincarceration. This cycle of movement, through homelessness and prison, has been documented previously (Gowan, 2002; Hagan and McCarthy, 1997) and is noteworthy since arrest history and incarceration are strong predictors of a longer duration of homelessness (Caton et al, 2005). Indeed, for some who remained homeless, the criminal justice system functioned as a provider of services, including housing and drug treatment, which are ordinarily received from other systems. Thus, young men in particular 'disappeared' temporarily into places of detention only to resurface some time later in the system, typically in emergency hostel settings. 
Such movement through an 'institutional circuit' has been previously identified by Hopper et al (1997), who examined the residential histories of homeless individuals, aged 17 and over, which included time spent in prisons, jails, psychiatric hospitals and care. For over half of their respondents, shelter stays formed part of a more durable pattern of a life on this institutional circuit', which was interrupted only by occasional breaks of temporary housing. Thus, according to Hopper et al (1997), homeless service systems acted as independent agents shaping the course of homelessness, with these and allied systems of intervention having the institutional effect of perpetuating, rather than arresting, the 'residential instability' of those experiencing homelessness. Similar patterns of institutional engagement have been documented by Metraux and Culhane (2006) in a study of the incarceration histories and shelter use patterns of individuals in New York City public shelters. Similar to that 2006 study, the present study's findings point to the role that carceral institutions play in subsequent patterns of homelessness, as well as their potential role as intervention points.

One of the most striking features of the accounts of young people whose homelessness remained unresolved was their continued attempts to find a stable place to live. Far from accepting homelessness as 'a way of life', they continually endeavoured, albeit with limited success in many cases, to negotiate the constraints shaping their access to housing. Strongly aware of their biographical pasts and of their marginal status, they nonetheless aspired to a 'better life' and a stable place to live.

\section{Facilitators and barriers to housing stability}

As highlighted in Chapter 1, homelessness is increasingly understood as a fluid and changeable status and one that does not necessarily descend into chronic homeless states. Thus, from an almost exclusive focus on factors and experiences associated with young people becoming homeless, research has increasingly sought to unravel the mechanisms associated with the move out of homelessness to stable housing. Simultaneously, researchers are increasingly drawing on longitudinal approaches that enable a perspective on those events, circumstances, services and interventions that facilitate exits from homelessness. These approaches equally have the analytic potential to uncover the mechanics of prolonged or chronic homelessness.

Access to stable, affordable accommodation emerged as the single most important determinant of successful and sustained exits from homelessness: those young people who moved to secure accommodation at an early juncture were likely to maintain this exit, even if a number returned to homelessness temporarily. Family support, disaffiliation from former 'street' peers, engagement in drug treatment, participation in education or training, and ongoing professional supports also emerged as important facilitators to the exiting process. Continued family and professional supports - particularly aftercare and 'move on' support - were critical enablers to young people's ability to sustain housing in the private rental sector. Young people who exited homelessness did face a number of potential instabilities and risks, associated primarily with their weak economic positions and their restricted access to the labour market, and most were welfare-dependent at the time of our last contact with them.

Barriers to stable housing were numerous and diverse, and appeared to intensify as the duration of young people's homelessness progressed. Those who remained homeless had not accessed stable, sustainable housing over the course of the study. That they did not do so at an early juncture is significant given risks associated with 'drift' within the hostel system. The transition from youthoriented services to the adult system of intervention at the age of 18 served to alienate young people further from mainstream society and also produced strong feelings of hopelessness and despair. Other problems associated with this transition - and the stark absence of sustainable housing options at this juncture - included young people's greater exposure to drug use and criminal activity. By Phase 3 of the study, most had embarked on an 'institutional circuit', defined by their movement between prison and transitory accommodation types. 
Figure 2 summarises the key facilitators and barriers to housing stability to emerge from the study's findings.

Figure 2: Facilitators and barriers to housing stability - Phases 1, 2 and 3

\begin{tabular}{|c|c|}
\hline \multicolumn{2}{|c|}{ PHASE 1} \\
\hline \multicolumn{2}{|c|}{ HOMELESS $=40$} \\
\hline$y$ & 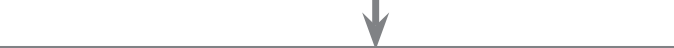 \\
\hline $\begin{array}{l}\text { FACILITATORS TO EXITING HOMELESSNESS } \\
\text { - Speedy access to housing } \\
\text { - Family support } \\
\text { - Limited movement between temporary forms } \\
\text { of accommodation } \\
\text { - Disaffiliation from former peer networks } \\
\text { - Establishment of positive and enabling social } \\
\text { - } \text { relationships } \\
\text { - Professional support } \\
\text { - Participation in education/training } \\
\text { Drug treatment in conjunction with access to } \\
\text { appropriate housing }\end{array}$ & $\begin{array}{l}\text { BARRIERS TO EXITING HOMELESSNESS } \\
\text { - Lack of access to housing } \\
\text { - Constant movement between multiple unstable } \\
\text { - } \text { accommodation types } \\
\text { - } \text { Incaps in accommodation and service provisions } \\
\text { - Time spent homeless } \\
\text { - Lack of employment/training opportunities } \\
\text { - Problems with alcohol, drugs and/or mental } \\
\text { health }\end{array}$ \\
\hline \\
\hline EXIT HOMELESSNESS = 17 & \multirow{2}{*}{ CONTINUED HOMELESS = 13} \\
\hline Independent exit $=7 \quad$ Dependent exit $=10$ & \\
\hline$y$ & $\downarrow$ \\
\hline $\begin{array}{l}\text { FACILITATORS TO SUSTAINING HOUSING } \\
\text { - } \quad \text { Family support } \\
\text { - Professional supports (in transitional housing } \\
\text { - } \text { and in care settings) } \\
\text { - } \text { Contercare support } \\
\text { - Continued participation in education/training } \\
\text { - }\end{array}$ & $\begin{array}{l}\text { BARRIERS TO EXITING HOMELESSNESS } \\
\text { - Continuous cycle of movement between } \\
\text { homeless hostels and places of detention } \\
\text { - an 'institutional circuit' } \\
\text { - Incarceration - returning to homelessness } \\
\text { - on release from prison } \\
\text { - Limited access to stable housing } \\
\text { - } \text { Dinancial constraints }\end{array}$ \\
\hline \multicolumn{2}{|c|}{ PHASE 3} \\
\hline EXIT HOMELESSNESS = 15 & \\
\hline Independent exit = 12 & \\
\hline
\end{tabular}




\section{Key messages for policy}

\section{Pathways 'into' homelessness}

- Histories of State care and breakdown of family relationships emerged as the two dominant experiences associated with young people becoming homeless.

- Most young people with a history of State care had moved in and out of numerous care settings. More structured approaches are required to cater for the needs of young people whose placements break down and every effort must be made to ensure that they do not enter the 'official' network of homeless youth.

- Working proactively with young people at risk of homelessness and their families, whether through family mediation or the provision of respite arrangements, is essential. Such work can enable young people to remain at home or to return home in cases where this is a safe and appropriate option.

- Continued investment in homeless prevention is required to ensure that all possible measures are taken to avert homelessness. Similarly, early intervention efforts are critical to ensuring that the 'newly' homeless do not join the ranks of the longer term homeless. Particular efforts need to be invested in identifying young people who are living in 'hidden' homeless situations and at risk of entering homeless systems and services.

\section{The importance of early exits from homelessness}

- One of the clearest messages arising from this research is the importance of speedy exits from homelessness. Those young people who 'got out' early were likely to 'stay out', even if a number did return to homelessness temporarily for a period. On the other hand, young people who commuted between Out-of-Hours Service hostel accommodation for long periods were far more likely to remain homeless than those who attained relative housing stability at an earlier juncture. Furthermore, the longer the duration of homelessness, the less likely young people were to make successful exits from homelessness.

- These findings signal a need for timely, planned access to stable housing for young people who experience homelessness.

\section{From youth to adult homelessness}

- The transfer from childen (under-18) to adult homeless services presents a major risk and emerged as a significant 'crisis point' for young people who made this transition. Currently, a young person may lose most, if not all, of their prior supports on reaching the age of 18 and are then required to seek assistance from adult services.

- It is critical that young homeless people do not experience an abrupt end to formal support services at the age of 18 . This sudden removal of support clearly diminishes the prospect of young people negotiating a successful exit from homelessness.

- More fluid systems of intervention, designed to meet the needs of young people aged 18-25 who are homeless or at risk of homelessness, are required in order to prevent young people from entering the world of adult homelessness.

- The role of the criminal justice system in maintaining homelessness, particularly among young men, is a significant finding to emerge from this study. Patterns of repeat incarceration became more commonplace after young people moved beyond the age of 18 and as their 'careers' in homelessness progressed. Furthermore, the experience of prison was strongly implicated as a factor in young men's continued homelessness. Diverting young people from custody, where appropriate, through the use of community-based sanctions must be a core objective.

- Where custody is required, there is a need to focus on the discharge policies for offenders and to give particular attention to those young people who are most vulnerable to homelessness. Strategies need to be put in place well in advance of an individual's release date to ensure that they are not discharged to precarious living places or to situations of 'hidden' homelessness. A priority must be to ensure that no young person enters hostel accommodation at the point of leaving prison. 


\section{Housing and support options for young people}

- Young people who experience homelessness are a heterogeneous group. Their paths to homelessness vary and they enter homeless services having encountered a wide variety of disruptions and difficulties, accompanied in most cases by traumatic life experiences. Young people who experience homelessness have diverse needs and there is consequently no single or 'one size fits all' solution to their situations. Returning home may be an option for some, but not for all. For those young people who cannot move home - either in the short or long term - the provision of age-appropriate and 'stage'-appropriate housing options is essential.

- Transitional or supported housing is likely to be an appropriate option for many who cannot return home, particularly for those young people in the 16-21 age range who have complex needs and lack the confidence and skills to live independently. ${ }^{12}$ Equally, clear and attainable goals are required for those young people who enter transitional accommodation to ensure that they do not become 'stuck' in this provision. In other words, move-on options need to be planned early in consultation with young people and in conjunction with a comprehensive needs assessment. Neither should it be presumed that all young people are unable to live independently.

- Affordable housing options for young people on benefits or low incomes are currently extremely limited. This situation means that homeless accommodation may be the only viable option for young people who are unable to access affordable housing.

- Irrespective of the route taken by young people out of homelessness - whether they return home, move to transitional accommodation or exit directly to an independent living situation support whilst in housing is required to ensure that young people have the requisite assistance to bolster their chances of sustaining housing.

\section{Supporting the transition to independent living}

- A clear finding arising from this research is that the process of exiting homelessness is an incremental one. In other words, young people are very likely to experience challenges and setbacks following the initial move out of homelessness.

- The move to independent living situations is often a difficult transition for young people and one which can lead to significant emotional upheaval. Deficits in life skills, as well as loneliness, can pose a significant risk as young people attempt to negotiate this transition. Young people are also likely to experience some measure of financial stress following the move to an independent living situation.

- The provision of appropriate support services following the transition to independent living is essential if returns to homelessness are to be avoided. Housing assistance and support should aim to help young people to identify appropriate housing options, negotiate with landlords and intervene if problems develop. It should also help young people to identify educational and training options that increase their future employment prospects.

- The provision of specialist health and care services, including mental health and drug treatment services, will be essential for some in preventing returns to homelessness.

- For those young people with a history of State care, aftercare support is critical. Leaving care is a major life event and one that involves making the transition from dependence on State accommodation to so-called self-sufficiency. Despite recent improvements in aftercare provision, many young people currently leaving care in Ireland do not receive the ongoing supports required to make a successful transition to independent living.

- Rather than generic and time-limited, the range of supports offered to young people following the move to independent living should be responsive to each individual's needs. In other words, planned supports ought to vary in nature, intensity and duration depending on the needs of individual young people.

\footnotetext{
12 The terms 'transitional', 'supported' and 'semi-independent' are often used interchangeably to describe housing that is aimed at individuals who need time and assistance to prepare for independent living. In general, these provisions are understood to offer medium-term housing, with support to help residents to develop the skills and capacity to establish themselves in their own home.
} 


\section{Sustaining housing}

- Young people with a history of homelessness are likely to face particular difficulties in accessing educational, employment and other developmental and transitional opportunities. Many may also have experienced, and are still recovering from, traumatic life experiences and life events. Sustained exits from homelessness require access to stable and secure housing as an essential first step. However, additional supports are needed if young people are to have a realistic chance of successfully maintaining housing.

- Family support emerged as an important enabler to young people in exiting homelessness and in sustaining housing, irrespective of the route taken by them out of homelessness. This finding highlights the importance of working in collaborative ways with homeless young people and their families in order to rebuild and maintain relationships, which can in turn bolster their prospects of sustaining housing.

- Specialist support services, particularly mental health and alcohol/drug services, are required to ensure that young people have a realistic prospect of sustaining housing.

- The risk of a poverty trap is clearly high for those young people who are unemployed and dependent on social welfare payments. Young people's accounts point strongly to their awareness of their economic marginality and to their rejection of 'a life' of welfare dependency. Many were also experiencing financial difficulties and were highly disadvantaged in terms of both their labour market and educational opportunities. The welfare safety net for young people is currently weak and their access to affordable housing is highly constrained. Young people are therefore at risk of becoming 'trapped' in emergency hostel accommodation and those who access housing also remain vulnerable to further episodes of homelessness.

\section{Gender and the homeless pathways of young people}

- The findings of this research strongly suggest that young women were far more likely to exit homelessness than their male counterparts. Compared to young men, women exited homelessness at an earlier juncture and they also tended to sustain housing, even if some returned to homelessness temporarily.

- Housing options, including returns to the family home, placement in residential or foster care, and moves to transitional or supported housing, were more readily available to young women at an early juncture. In place of stable housing, young men often embarked on an 'institutional circuit' of commuting between under-18s hostels initially and, subsequently, between adult homeless services. Incarceration emerged as a key component of this cyclical pattern of movement through various unstable accommodation types as alternatives to stable housing.

\section{Monitoring youth homelessness}

- Historically, the lack of reliable data clearly thwarted any attempt to accurately measure the scale of the problem of homelessness among children and young people in Ireland and to trace changes over time.

- The problems and limitations associated with current measures of homelessness among children and young people (see Chapter 1 ) highlight the need to develop a more comprehensive information system on child and youth homelessness.

- Targeted research is needed to improve knowledge and understanding of 'hidden' homelessness among children and young people.

\section{Concluding remarks}

Young people who experience homelessness are not an homogeneous group and the paths they follow after becoming homeless are clearly diverse. To a considerable extent, the findings documented in this report challenge us to reconsider how we understand and conceptualise the problem we call 'youth homelessness', the definitions we deploy to delineate the problem, as well as the 'shape' and ultimate aim and effectiveness of the policies and service structures designed to meet the needs of those who experience homelessness and housing instability at an early stage in their lives. 


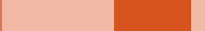


REFERENCES 
Allgood, S. and Warren, R.S. (2003) 'The duration of homelessness: Evidence from a national survey', Journal of Housing Economics, Vol. 12, pp. 273-90.

Anderson, I. (2001) Pathways through Homelessness: Towards a Dynamic Analysis. Paper presented at Research Seminar, 27 March 2001. Scotland: Housing Policy and Practice Unit, University of Stirling.

Anderson, I. and Christian, J. (2003) 'Causes of homelessness in the UK: A dynamic analysis', Journal of Community and Applied Social Psychology, Vol. 13, No. 2, pp. 105-18.

Anderson, I. and Tulloch, D. (2000) Pathways through Homelessness: A Review of the Research Evidence. Edinburgh: Scottish Homes.

Arnett, J.J. (2004) Emerging Adulthood: The Winding Road from the Late Teens through the Twenties. New York: Oxford University Press.

Atherton, I. and McNaughton-Nicholls, C. (2008) 'Housing First as a means of addressing multiple needs and homelessness', European Journal of Homelessness, Vol. 2, pp. 289-303.

Avramov, D. (2002) 'Figures on the extent of homelessness in the European Union revisited', Homelessness in Europe, FEANTSA's Magazine, Spring, pp. 5-6.

Baldry, E., McDonnell, D., Maplestone, P. and Peeters, M. (2006) 'Ex-prisoners, homelessness and the state in Australia', The Australian and New Zealand Journal of Criminology, Vol. 3, No. 1, pp. 20-33.

Baron, S.W. (2003) 'Self-control, social consequences, and criminal behavior: Street youth and the general theory of crime', Journal of Research in Crime and Delinquency, Vol. 40, No. 4, pp. 403-25.

Baron, S.W. (2006) 'Street youth, strain theory, and crime', Journal of Criminal Justice, Vol. 34, pp. 209-23.

Boydell, K.M., Goering, P. and Morrell-Bellai, T.L. (2000) 'Narratives of identity: Re-presentation of self in people who are homeless', Qualitative Health Research, Vol. 10, No. 1, pp. 26-38.

Brueckner, M., Green, M. and Saggers, S. (2010) 'The trappings of home: Young homeless people's transitions towards independent living', Housing Studies, Vol. 26, No. 1, pp. 1-16.

Busch-Geerstema, V. (2010) 'Defining and measuring homelessness'. In: E. O'Sullivan, V. BuschGeertsema, D. Quilgars and N. Pleace (eds.), Homelessness Research in Europe. Brussels: FEANTSA, pp. 19-39.

Bynner, J., Elias, P., McKnight, A., Pan, H. and Pierre, G. (2002) Young People's Changing Routes to Independence. York: Joseph Rowntree Foundation.

Carlson, H. (1990) 'Women and homelessness in Ireland', Irish Journal of Psychology, Vol. 11, No. 1, pp. 69-76.

Caton, C.L.M., Dominguez, B., Schanzer, B., Hasin, D.S., Shrout, P.E., Felix, A., McQuistion, H., Opler, L.A. and Hsu, E. (2005) 'Risk factors for long-term homelessness: Findings from a longitudinal study of first-time homeless single adults', American Journal of Public Health, Vol. 95, No. 10, pp. 1753-59.

CSO (2012) Homeless Persons in Ireland: A Special Census Report. Dublin: Central Statistics Office.

Chaitin, J. (2004) 'My story, my life, my identity', International Journal of Qualitative Methods, Vol. 3, No. 4, pp. 1-17.

Chamberlain, C. and MacKenzie, D. (1994) 'Temporal dimensions of youth homelessness', Australian Journal of Social Issues, Vol. 29, No. 1, pp. 1-25.

Charmaz, C. (2006) Constructing Grounded Theory: A Practical Guide through Qualitative Analysis. London: Sage.

Clapham, D. (2002) 'Housing pathways: A post modern analytic framework', Housing, Theory and Society, Vol. 19, No. 2, pp. 57-68.

Clapham, D. (2003) 'Pathways approaches to homeless research', Journal of Community and Applied Social Psychology, Vol. 13, No. 2, pp. 119-27.

Clapham, D., Mackie, P., Orford, S., Buckley, K., Thomas, I., Atherton, I. and McAnulty, U. (2012) Housing Options and Solutions for Young People in 2020. York: Joseph Rowntree Foundation.

Communities Scotland (2004) Routes into Employment for Homeless People. Edinburgh: Communities Scotland.

Conover, S., Berkman, A., Gheith, A., Jahiel, R., Stanley, D., Geller, P.A., Valencia, E. and Susser, E. (1997) 'Methods of successful follow-up of elusive urban populations: An ethnographic approach with homeless men', Bulletin of the New York Academy of Medicine, Vol. 74, No. 1, pp. 90-108. 
Corden, A. and Millar, J. (2007) ‘Qualitative longitudinal research for social policy - Introduction to a themed section', Social Policy \& Society, Vol. 6, No. 4, pp. 529-32.

Cotter, R.B., Burke, J.D., Stouthamer-Loeber, M. and Loeber, R. (2005) 'Contacting participants for follow-up: How much effort is required to retain participant in longitudinal studies', Evaluation Program Planning, Vol. 28, pp. 15-21.

Craig, T., Hodson, S., Woodward, S. and Richardson, S. (1996) Off to a Bad Start: A Longitudinal Study of Homeless Young People in London. London: The Mental Health Foundation.

Culhane, D. and Hornburg, S. (eds.) (1997) Understanding Homelessness: New Policy and Research Perspectives. Washington, DC: Fannie Mae Foundation.

Culhane, D. and Metraux, S. (2008) 'Rearranging the deck chairs or the lifeboats? Homelessness assistance and its alternatives', Journal of the American Planning Association, Vol. 74, No. 1, pp. 111-21.

Denyer, S., Sheehan, A. and Bowser, A. (2013) Every Child a Home: A Review of the Implementation of the Youth Homelessness Strategy, Department of Children and Youth Affairs. Dublin: Government Publications. Available at: www.dcya.ie

Denzin, N.K. (1970) The Research Act: A Theoretical Introduction to Sociological Methods (2nd edition). New York: McGraw-Hill.

Denzin, N.K. (1982) 'Contributions of anthropology and sociology to qualitative research methods', New directions for institutional research: Qualitative methods for institutional research, Vol. 34, No. 2, pp. 17-26.

Department of the Environment and Local Government (2002) Homeless Preventative Strategy: A Strategy to prevent Homelessness. Patients leaving Hospital and Mental Health Care, Adult Prisoners and Young Offenders leaving Custody and Young People leaving Care. Dublin: Government Publications.

Department of Health and Children (2000) Our Children - Their Lives: National Children's Strategy. Dublin: Government Publications.

Department of Health and Children (2001) Youth Homelessness Strategy. Dublin: Government Publications.

Doherty, J. and Stuttaford, M. (2007) 'Preventing homelessness among substance users in Europe', Journal of Primary Prevention, Vol. 28, pp. 245-63.

Doyle, A., Mayock, P. and Burns, K. (2012) 'Aftercare not afterthought: Supporting the transition to adulthood for children in care'. In: D. Lynch and K. Burns (eds.), Children's Rights and Child Protection: Critical Times, Critical Issues in Ireland. Manchester: Open University Press, pp. 202-21.

DRHE and Housing and Sustainable Communities Agency (2012) Homelessness and the Housing Needs Assessment 2011: The Revised Report for Dublin. Dublin: Dublin Region Homeless Executive and Housing and Sustainable Communities Agency.

Dyb, E. (2009) 'Imprisonment: A major gateway to homelessness', Housing Studies, Vol. 24, No. 6, pp. 809-24.

Edgar, B. (2009) European Review of Statistics on Homelessness. Brussels: FEANTSA (European Federation of National Associations Working with the Homeless).

Edgar, B., Harrison, M., Watson, P. and Busch-Geertsema, V. (2007) Measurement of Homelessness at European Union Level. Brussels: European Commission.

Farrall, S. (2006) What is Qualitative Longitudinal Research? Papers in Social Research Methods, Qualitative Series No.11. London: London School of Economics and Political Science Methodology Series.

FEANTSA (2007) Child Homelessness in Europe - An Overview of Emerging Trends. Brussels: FEANTSA (European Federation of National Associations Working with the Homeless).

FEANTSA (2010) Ending Homelessness: A Handbook for Policy Makers. Brussels: FEANTSA (European Federation of National Associations Working with the Homeless). Available at: http://www.epha.org/IMG/pdf/HANDBOOK_TO_END_HOMELESSESS.pdf

Fitzpatrick and Associates (2006) Review of the Implementation of the Government's Integrated and Preventative Homeless Strategies. Dublin: Government Publications.

Fitzpatrick, S. (1999) Pathways to Independence: The Experience of Young Homeless People. Edinburgh: Scottish Homes. 
Fitzpatrick, S. (2000) Young Homeless People. Basingstoke: Macmillan.

Fitzpatrick, S. (2005) 'Explaining homelessness: A critical realist perspective', Housing, Theory and Society, Vol. 22, No. 1, pp. 1-17.

Fitzpatrick, S., Kemp, P. and Klinger, S. (2000) Single Homelessness: An overview of research in Britain. Bristol: Policy Press.

Fitzpatrick, S., Quilgars, D. and Pleace, N. (eds.) (2009) Homelessness in the UK: Problems and Solutions. Trowbridge: Chartered Institute of Housing.

Furlong, A. and Cartmel, F. (1996) Young People and Social Change. Milton Keynes: Open University Press.

Gowan, G. (2002) 'The Nexus: Homelessness and incarceration in two American cities', Ethnography, Vol. 3, No. 4, pp. 500-34.

Hagan, J. and McCarthy, B. (1997) Mean Streets: Youth Crime and Homelessness. Cambridge: Cambridge University Press.

Haglund, K. (2004) 'Conducting life history research with adolescents', Qualitative Health Research, Vol. 14, No. 9, pp. 1309-19.

Hansen Lofstrand, C. (2010) 'Reforming the work to combat long-term homelessness in Sweden', Acta Sociologica, Vol. 53, pp. 19-34.

Harvey, B. and Menton, M. (1989) 'Ireland's young homeless', Children and Youth Services Review, Vol. 11, No. 1, pp. 31-43.

Hickey, C. (2002) Crime and Homelessness. Dublin: Focus Ireland and PACE.

Hobden, K., Curtis Forney, J., Wyszaki Durham, K. and Toro, P. (2011) 'Limiting attrition in longitudinal research on homeless adolescents: What works best', Journal of Community Psychology, Vol. 39, pp. 443-51.

Holland, J. (2011) 'Timescapes: Living a qualitative longitudinal study', Forum: Qualitative Social Research, Vol. 12, No. 3, Art. 9.

Holland, J., Thompson, R. and Henderson, S. (2004) Feasibility Study for a Possible Qualitative Longitudinal Study: Discussion Paper. London: Economic and Social Research Council.

HOPE (1979) Out in the Cold: A Report of Unattached Youth in Dublin in the Winter of 1978/79. Dublin: Hands On Peer Education.

Homeless Agency (2005) Counted In 2005. Dublin: Homeless Agency.

Homeless Agency (2008) Counted In 2008. Dublin: Homeless Agency.

Hopper, K., Jost, J., Hay, T., Welber, S. and Haglund, G. (1997) 'Homelessness, severe mental illness, and the institutional circuit', Psychiatric Services, Vol. 48, No. 5, pp. 659-64.

Houghton, F.T., Kelleher, P. and Kelleher, C. (2001) 'Children out-of-home in Ireland'. In: A. Cleary, M. Nic Ghiolla Phadraig and S. Quin (eds.), Understanding Children. Volume 1: State, Education and Economy. Cork: Oak Tree Press, pp. 79-98.

Housing Agency (2011) Housing Needs Assessment 2011. Dublin: Housing Agency.

HSE (2012) Leaving and Aftercare Services: National Policy and Procedure. Naas: Health Service Executive.

Hutson, M. and Liddiard, M. (1994) Youth Homelessness: The Construction of a Social Issue. London: Macmillan.

Jacobs, K., Kemeny, J. and Manzi, T. (1999) 'The struggle to define homelessness: A constructivist approach'. In: S. Hutson and D. Clapham (eds.), Homelessness: Public Policies and Private Troubles. London: Cassell, pp.11-28.

Johnsen, S. and Teixeira, L. (2010) Staircases, Elevators and Cycles of Change: 'Housing First' and Other Housing Models for Homeless People with Complex Support Needs. London: Crisis.

Johnson, G. (2006) On the Move: A Longitudinal Study of Pathways in and out of Homelessness. Thesis submitted in the School of Global Studies, Social Science and Planning, RMIT University, in fulfilment of the requirements for the Degree of Doctor of Philosophy.

Jones, G. (2002) The Youth Divide: Diverging Paths to Adulthood. York: Joseph Rowntree Foundation.

Jones, A. and Pleace, N. (2010) A Review of Single Homelessness in the UK 2000-2010. London: Crisis.

Kelleher, P., Kelleher, C. and Corbett, M. (2000) Left Out on Their Own: Young people leaving care in Ireland. Dublin: Focus Ireland/0ak Tree Press.

Kennedy, S. (1985) But Where Can I Go? Homeless Women in Dublin. Dublin: Arlene House. 
Kleschinsky, J.H., Bosworth, L.B., Nelson, S.E., Walsh, E.K. and Shaffer, H.J. (2009) 'Persistence pays off: Follow-up methods for difficult-to-track longitudinal samples', Journal of Studies on Alcohol and Drugs, Vol. 70, pp. 751-61.

Klockars, C.B. (1974) The Professional Fence. London: Tavistock Publications.

Kresky-Wolff, M., Larson, M.J., O'Brien, R.W. and McGraw, S.A. (2010) 'Supportive housing approaches in the Collaborative Initiative to help end Chronic Homelessness (CICH)', Journal of Behavioral Services \& Research, Vol. 37, No. 2, pp. 213-25.

Kurtz, D.P., Lindsey, E.W., Jarvis, S. and Nackerud, L. (2000) 'How runaway and homeless youth navigate troubled waters: The role of formal and informal helpers', Child and Adolescent Social Work Journal, Vol. 17, pp. 381-402.

MacDonald, R., Shildrick, T., Webster, C. and Simpson, D. (2005) 'Growing up in poor neighbourhoods: The significance of class and place in the extended transitions of "socially excluded" young adults', Sociology, Vol. 39, pp. 873-91.

MacKenzie, D. and Chamberlain, C. (2003) Homeless Careers: Pathways In and Out of Homelessness. Melbourne: Swinburne and RMIT Universities.

MacKnee, C.M. and Mervyn, J. (2002) 'Critical incidents that facilitate homeless people's transition off the streets', Journal of Social Distress and the Homeless, Vol. 11, No. 4, pp. 293-306.

Mallet, S., Rosenthal, D., Keys, D. and Averill, R. (2010) Moving On, Moving Out: Young People's Pathways In and Through Homelessness. London: Routledge.

Manzo, L.C. (2003) 'Beyond house and haven: Toward a revisioning of emotional relationships with places', Journal of Environmental Psychology, Vol. 23, pp. 47-61.

May, J. (2000) 'Housing histories and homeless careers: A biographical approach', Housing Studies, Vol. 15, pp. 613-38.

Mayock, P. and Corr, M.L. (2012) 'The meaning of drug use among homeless young people: A longitudinal pathways analysis'. In: M. Wouters, J. Fountain and D.J. Korf (eds.), The Meaning of High: Variations according to Drug, Set, Setting and Time. Lengerich: Pabst Science Publishers, pp. 132-48.

Mayock, P., Corr, M.L. and O'Sullivan, E. (2008) Young People's Homeless Pathways. Dublin: Homeless Agency.

Mayock, P., Corr, M.L. and O'Sullivan, E. (2011b) ‘Homeless young people, families and change: Family support as a facilitator to exiting homelessness', Child \& Family Social Work, Vol. 16, pp. 391-401.

Mayock, P., Corr, M.L. and O'Sullivan, E. (2012) 'Young people exiting homelessness: The role of family support'. In: D. Lynch and K. Burns (eds.), Children's Rights and Child Protection: Critical Times, Critical Issues in Ireland. Manchester: Open University Press, pp. 184-201.

Mayock, P., Corr, M.L. and O'Sullivan, E. (2013) 'Moving on, not out: When young people remain homeless', Journal of Youth Studies (in press).

Mayock, P. and O'Sullivan, E. (2007) Lives in Crisis: Homeless Young People in Dublin City. Dublin: Liffey Press.

Mayock, P., O'Sullivan, E. and Corr, M.L. (2011a) 'Young people exiting homelessness: An exploration of process, meaning and definition', Housing Studies, Vol. 26, No. 6, pp. 803-26.

Mayock, P. and Sheridan, S. (2012) Women's 'Journeys' to Homelessness: Key Findings from a Biographical Study of Homeless Women in Ireland. Women and Homelessness in Ireland, Research Paper 1. Dublin: School of Social Work and Social Policy and Children's Research Centre, Trinity College, Dublin.

Mayock, P. and Vekić, K. (2006) Understanding Youth Homelessness in Dublin City: Key findings from the First Phase of a Longitudinal Cohort Study, Office of the Minister for Children. Dublin: Government Publications.

Metraux, S. and Culhane, D. (2004) 'Homeless shelter use and reincarceration following prison release', Criminology and Public Policy, Vol. 3, No. 2, pp. 139-60.

Metraux, S. and Culhane, D.P. (2006) 'Recent incarceration history among a sheltered homeless population', Crime \& Delinquency, Vol. 52, No. 3, pp. 504-17.

Miles, M.B. and Huberman, A.M. (1994) Qualitative Data Analysis: An Expanded Sourcebook (2nd edition). Thousand Oaks, CA: Sage.

Miller, J. and Glassner, B. (1997) 'The "inside" and the "outside": Finding realities in interviews'. In: D. Silverman (ed.), Qualitative Research: Theory, Method and Practice. London: Sage, pp. 99-112. 
Molloy, D., Woodfield, K. and Bacon, J. (2002) Longitudinal Qualitative Research Approaches in Evaluation Studies, Working Paper Number 7. London: Stationery Office.

National Campaign for the Homeless (1985) Ireland's Young Homeless, 1985: Report of the First Survey on Homelessness among Young People in Ireland, with Analysis and Recommendations. Dublin: National Campaign for the Homeless.

National Youth Policy Committee (1984) Final Report. Dublin: Stationery Office.

Neale, J. (1997) 'Homelessness and theory reconsidered', Housing Studies, Vol. 12, No. 1, pp. 47-61.

Neale, J. (2001) 'Homelessness amongst drug users: A double jeopardy explored', International Journal of Drug Policy, Vol. 12, pp. 353-69.

Neale, B. and Flowerdew, J. (2003) 'Time, texture and childhood: The contours of longitudinal qualitative research', International Journal of Social Research Methodology, Vol. 6, No. 3, pp. 189-99.

Nebbit, V., House, L., Thompson, S.J., and Pollio, D.E. (2007) 'Successful transitions of runaway/ homeless youth from shelter care', Journal of Child and Family Studies, Vol. 16, No. 4, pp. 545-55.

0'Sullivan, E. (2008a) 'Sustainable solutions to homelessness: The Irish case', European Journal of Homelessness, Vol. 3, pp. 205-33.

0'Sullivan, E. (2008b) 'Researching homelessness in Ireland: Explanations, themes and approaches'. In: D. Downey (ed.), Perspectives on Irish Homelessness: Past, Present and Future. Dublin: Homeless Agency, pp. 16-23.

0'Sullivan, E. (2012) Ending Homelessness - A Housing-led Approach. Dublin: Department of the Environment, Community and Local Government.

O'Sullivan, E. and Mayock, P. (2008) 'Youth homelessness in Ireland: The construction of a social problem', Youth Studies Ireland, Vol. 3, pp. 15-29.

Perris, A. (1999) Youth Homelessness in Clondalkin: A Community Perspective. Dublin: Clondalkin Area Partnership.

Pickering, K., Fitzpatrick, S., Hinds, K., Lynn, P. and Tipping, S. (2003) Tracking Homelessness: A Feasibility Study. Edinburgh: Stationery Office.

Piliavin, I., Entner-Wright, B., Mare, R. and Westerfelt, A. (1996) 'Exits from and returns to homelessness', Social Service Review, Vol. 70, No. 1, pp. 33-57.

Pleace, N. (2011) 'Homelessness and inequality'. In: I. Andersen and D. Sim (eds.), Housing and Inequality. Coventry: Chartered Institute of Housing, pp. 187-204.

Pleace, N., Fitzpatrick, S., Johnsen, S., Quilgars, D. and Sanderson, D. (2008) Statutory Homelessness in England: The Experience of Families and 16-17 year-olds. London: Communities and Local Government.

Pleace, N. and Quilgars, D. (1999) 'Youth homelessness'. In: J. Rugg (ed.), Young People, Housing and Social Policy. London: Routledge.

Quilgars, D. (2010) 'Youth homelessness'. In: B. Edgar and J. Doherty (eds.), Homelessness Research in Europe. Brussels: FEANTSA (European Federation of National Associations Working with the Homeless), pp. 187-210.

Quilgars, D., Fitzpatrick, S. and Pleace, N. (2011) Ending Youth Homelessness: Possibilities, Challenges and Practical Solutions. York: Centre for Housing Policy, University of York and School of the Built Environment, Heriot-Watt University.

Quilgars, D., Johnsen, S. and Pleace, N. (2008) Youth Homelessness in the UK: A Decade of Progress? York: Joseph Rowntree Foundation.

Raleigh-DuRoff, C. (2004) 'Factors that influence homeless adolescents to leave or stay living on the street', Child and Adolescent Social Work Journal, Vol. 21, No. 6, pp. 561-72.

Reeve, K. and Batty, E. (2011) The Hidden Truth about Homelessness: Experiences of Single Homelessness in England. London: Crisis.

Roberts, B. (2002) Biographical Research. Buckingham: Open University Press.

Robertson, M.J. and Toro, P.A. (1999) 'Homeless Youth: Research, intervention and policy'. In: L.B. Fosburg and D.L. Dennis (eds.), Practical Lessons: The 1998 National Symposium on Homelessness Research. Washington, DC: US Department of Housing and Urban Development and US Department of Health and Human Services. 
Robinson, C. (2002) " "I think home is more than a building": Young home(less) people on the cusp of home, self and something else', Urban Policy and Research, Vol. 20, No. 1, pp. 27-38.

Robinson, C. (2003) Understanding Iterative Homelessness: The Case of People with Mental Disorders. Melbourne: Australian Housing and Research Institute.

Rugg, J. (2010) Young People and Housing: The Need for a New Policy Agenda. York: Joseph Rowntree Foundation.

Sahlin, I. (2005) 'The staircase of transition: Survival through failure', Innovation, Vol. 18, pp. 115-35.

Saldana, J. (2003) Longitudinal Qualitative Research: Analyzing Change through Time. Walnut Creek, Lanham, New York, Oxford: AltaMira Press.

Shelton, K.H., Taylor, P.J., Bonner, A. and Van den Bree, M. (2009) 'Risk factors for homelessness: Evidence from a population-based study', Psychiatric Services, Vol. 60, No. 4, pp. 465-72.

Shlay, A.B., and Rossi, P.H. (1992) 'Social science research and contemporary studies of homelessness', Annual Review of Sociology, Vol. 18, pp. 129-60.

Snow, D. and Anderson, L. (1993) Down on Their Luck: A Study of Homeless Street People. Berkeley, CA: University of California Press.

Snow, D.A., Baker, S.G. and Anderson, L. (1989) 'Criminality and homeless men: An empirical assessment', Social Problems, Vol. 36, No. 5, pp. 532-49.

Sosin, M., Piliavin, I. and Westerfelt, H. (1990) 'Toward a longitudinal analysis of homelessness', Journal of Social Issues, Vol. 46, No. 4, pp. 157-74.

St. Mungo's (2010) Work Matters. London: St. Mungo's.

Stefancic, A. and Tsemberis, S. (2007) 'Housing First for long-term shelter dwellers with psychiatric disabilities in a suburban county: A four-year study of housing access and retention', Journal of Primary Prevention, Vol. 28, pp. 265-79.

Stephen, D.E. (2000) 'Young women construct themselves: Social identity, self-concept and psychosocial well-being in homeless facilities', Journal of Youth Studies, Vol. 3, No. 4, pp. 445-60.

Stockley, D., Canter, D. and Bishopp, D. (1993) Young People on the Move. Guildford: Psychology Department, University of Surrey.

Taplin, S. (2005) Methodological Design Issues in Longitudinal Studies of Children and Young people in Out-of-home Care. Ashfield: Department of Community Services, New South Wales Government.

Thomson, R., Holland, J., McGrellis, S., Bell, R., Henderson, S. and Sharpe, S. (2004) 'Inventing adulthoods: A biographical approach to understanding youth citizenship', The Sociological Review, Vol. 52, No. 2, pp. 218-39.

Third, H. (2000) 'Researching homelessness and rough sleeping in the Scottish context', Social, Policy and Administration, Vol. 34, No. 4, pp. 448-64.

Tomas, A. and Dittmar, H. (1995) 'The experience of homeless women: An exploration of housing histories and the meaning of home', Housing Studies, Vol. 10, pp. 493-515.

Tsemberis, S., Gulcur, L. and Nakae, M. (2004) 'Housing First, consumer choice, and harm reduction for homeless individuals with dual diagnosis', American Journal of Public Health, Vol. 94, pp. 651-56.

Tyler, K.A. and Johnson, K.A. (2006) 'Pathways in and out of substance use among homelessemerging adults', Journal of Adolescent Research, Vol. 21, No. 2, pp. 133-57.

Watson, S. and Austerberry, H. (1986) Housing and Homelessness: A Feminist Perspective. London: Routledge and Kegan Paul.

Westerfelt, H. (1990) The ins and outs of homelessness: Exit patterns and predictions, Unpublished PhD thesis. Madison, WI: University of Wisconsin-Madison.

White, N.R. (2002) ' “Not under my roof!” Young people's experience of home', Youth \& Society, Vol. 34, No. 2, pp. 214-31.

Zlotnick, C., Robertson, M.J. and Lahiff, M. (1999) 'Getting off the streets: Economic resources and residential exits from homelessness', Journal of Community Psychology, Vol. 27, No. 2, pp. 209-24. 


\section{Appendix: ETHOS Typology on Homelessness and Housing Exclusion}

\begin{tabular}{|c|c|c|c|}
\hline Concept & \multicolumn{2}{|c|}{ Operational category } & Living situation \\
\hline \multirow[t]{2}{*}{ Rooflessness } & 1 & People living rough & $\begin{array}{l}\text { Where people are living without shelter } \\
\text { (e.g. on the streets or in public spaces) }\end{array}$ \\
\hline & 2 & $\begin{array}{l}\text { People staying in } \\
\text { emergency accommodation } \\
\text { (i.e. night shelters) }\end{array}$ & $\begin{array}{l}\text { Where people with no usual place of } \\
\text { residence are using emergency shelters on a } \\
\text { night-by-night basis }\end{array}$ \\
\hline \multirow[t]{5}{*}{ Houselessness } & 3 & $\begin{array}{l}\text { People in homeless } \\
\text { accommodation }\end{array}$ & $\begin{array}{l}\text { Where people are temporarily living in } \\
\text { homeless hostels, temporary accommodation } \\
\text { or transitional supported accommodation }\end{array}$ \\
\hline & 4 & $\begin{array}{l}\text { People in women's shelters } \\
\text { (i.e. refuges) }\end{array}$ & $\begin{array}{l}\text { Where women are temporarily accommodated } \\
\text { due to experiences of domestic violence }\end{array}$ \\
\hline & 5 & $\begin{array}{l}\text { People in accommodation } \\
\text { for migrants }\end{array}$ & $\begin{array}{l}\text { Where migrants are living in reception centres } \\
\text { or migrant workers' accommodation due to } \\
\text { their immigrant status }\end{array}$ \\
\hline & 6 & $\begin{array}{l}\text { People due to be released } \\
\text { from institutions (i.e. prisons, } \\
\text { residential drug/alcohol } \\
\text { treatment, hospitals and } \\
\text { children's homes) }\end{array}$ & $\begin{array}{l}\text { Where people are at risk of homelessness } \\
\text { due to support needs and a lack of suitable } \\
\text { move on housing following their stay in an } \\
\text { institutional setting }\end{array}$ \\
\hline & 7 & $\begin{array}{l}\text { People receiving longer-term } \\
\text { support due to homelessness }\end{array}$ & $\begin{array}{l}\text { Where people are living in long-term supported } \\
\text { accommodation, or are unable to move on } \\
\text { from supported accommodation, due to a lack } \\
\text { of suitable housing }\end{array}$ \\
\hline \multirow[t]{3}{*}{ Insecure } & 8 & $\begin{array}{l}\text { People living in insecure } \\
\text { accommodation }\end{array}$ & $\begin{array}{l}\text { Where people are residing in insecure living } \\
\text { situations with no legal rights or (sub) } \\
\text { tenancies (e.g. squatting, illegal camping, } \\
\text { sofa surfing, sleeping on floors, staying with } \\
\text { friends or relatives) }\end{array}$ \\
\hline & 9 & $\begin{array}{l}\text { People living under } \\
\text { threat of eviction }\end{array}$ & $\begin{array}{l}\text { Where legal orders for eviction from } \\
\text { accommodation or repossession of property are } \\
\text { operative }\end{array}$ \\
\hline & 10 & $\begin{array}{l}\text { People living under } \\
\text { threat of violence }\end{array}$ & $\begin{array}{l}\text { Where police action is taken to ensure a place } \\
\text { of safety for people experiencing violence }\end{array}$ \\
\hline \multirow[t]{3}{*}{ Inadequate } & 11 & $\begin{array}{l}\text { People living in temporary/ } \\
\text { non-standard structures }\end{array}$ & $\begin{array}{l}\text { Where people are residing in temporary or } \\
\text { semi-permanent structures (e.g. mobile homes, } \\
\text { make-shift shelters, huts, cabins) }\end{array}$ \\
\hline & 12 & People living in unfit housing & $\begin{array}{l}\text { Where people are living in accommodation } \\
\text { that is considered unfit for habitation by } \\
\text { national legislation or building regulations }\end{array}$ \\
\hline & 13 & $\begin{array}{l}\text { People living in } \\
\text { extreme overcrowding }\end{array}$ & $\begin{array}{l}\text { Where people are living in accommodation } \\
\text { that exceeds the national density standard for } \\
\text { floor-space or useable rooms }\end{array}$ \\
\hline
\end{tabular}

Source: Adapted from http://www.feantsa.org/spip.php?article120 



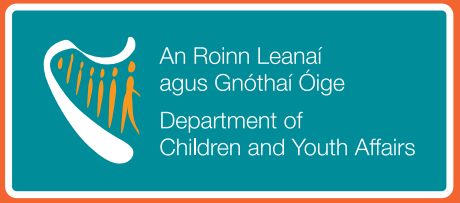

PUBLISHED BY THE STATIONERY OFFICE DUBLIN

To be purchased from GOVERNMENT PUBLICATIONS,

52 ST. STEPHEN'S GREEN, DUBLIN 2

[Tel: 016476834 or 1890 213434; Fax: 01647 6843] or through any bookseller

Price: $€ 5.00$

Department of Children and Youth Affairs 43-49 Mespil Road

Dublin 4

Tel: $+353(0) 16473000$

Fax: +353(0)1 6670826

E-mail: dcyaresearch@dcya.gov.ie

Web: www.dcya.ie 